\title{
Health benefits of (-)-epicatechin and other flavonoids
}

Citation for published version (APA):

Ruijters, E. J. B. (2014). Health benefits of (-)-epicatechin and other flavonoids. [Doctoral Thesis, Maastricht University]. Uitgeverij BOXPress. https://doi.org/10.26481/dis.20141209er

Document status and date:

Published: 01/01/2014

DOI:

10.26481/dis.20141209er

Document Version:

Publisher's PDF, also known as Version of record

\section{Please check the document version of this publication:}

- A submitted manuscript is the version of the article upon submission and before peer-review. There can be important differences between the submitted version and the official published version of record.

People interested in the research are advised to contact the author for the final version of the publication, or visit the DOI to the publisher's website.

- The final author version and the galley proof are versions of the publication after peer review.

- The final published version features the final layout of the paper including the volume, issue and page numbers.

Link to publication

\footnotetext{
General rights rights.

- You may freely distribute the URL identifying the publication in the public portal. please follow below link for the End User Agreement:

www.umlib.nl/taverne-license

Take down policy

If you believe that this document breaches copyright please contact us at:

repository@maastrichtuniversity.nl

providing details and we will investigate your claim.
}

Copyright and moral rights for the publications made accessible in the public portal are retained by the authors and/or other copyright owners and it is a condition of accessing publications that users recognise and abide by the legal requirements associated with these

- Users may download and print one copy of any publication from the public portal for the purpose of private study or research.

- You may not further distribute the material or use it for any profit-making activity or commercial gain

If the publication is distributed under the terms of Article $25 \mathrm{fa}$ of the Dutch Copyright Act, indicated by the "Taverne" license above, 


\title{
HEALTH BENEFITS OF (-)-EPICATECHIN AND OTHER FLAVONOIDS
}

\author{
Erik J.B. Ruijters
}


(C) 2014 Erik J.B. Ruijters

ISBN: 978-94-6295-015-3

Design and layout: Erik Ruijters

Printed by: Proefschriftmaken.nl || Uitgeverij BOXPress

The research presented in this dissertation was conducted at NUTRIM School for Nutrition, Toxicology and Metabolism of Maastricht University which participates in the Graduate School VLAG (Food Technology, Agrobiotechnology, Nutrition and Health Sciences), accredited by the Royal Netherlands Academy of Arts and Sciences
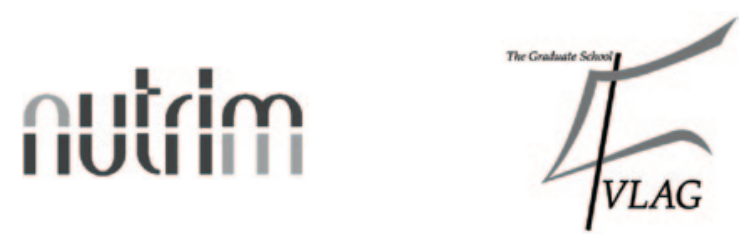

Financial support by D\&R data (Maastricht) for the printing of this thesis is gratefully acknowledged.

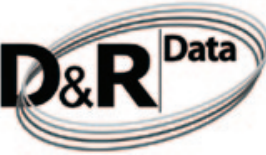




\title{
Health benefits of (-)-epicatechin and other flavonoids
}

\author{
PROEFSCHRIFT
}

ter verkrijging van de graad van doctor aan de Universiteit Maastricht, op gezag van de Rector Magnificus, Prof.dr. L.L.G. Soete

volgens het besluit van het College van Decanen,

in het openbaar te verdedigen

op dinsdag 9 december 2014 om 14:00 uur

door

\section{Erik Johannes Bernardus Ruijters}

Geboren te Maastricht op 11 April 1984 


\section{Promotor}

Prof. dr. A. Bast

\section{Co-promotores}

Dr. G.R.M.M. Haenen

Dr. A.R. Weseler

\section{Beoordelingscommissie}

Prof. dr. C. Neef (voorzitter)

Prof. dr. B.J. Blaauboer (Universiteit Utrecht)

Prof. dr. G. Haegeman (Universiteit Gent, België)

Prof. dr. P.W. de Leeuw

Prof. dr. E.F.M. Wouters

The research described in this thesis was funded by the European Union grant 226588, entitled Flaviola, within the 7th Framework program. 




\section{Contents}

Abbreviations

8

Chapter 1 General introduction

Chapter 2 The flavanol (-)-epicatechin and its metabolites protect against oxidative stress in primary endothelial cells via a direct antioxidant effect

Chapter 3 The cocoa flavanol (-)-epicatechin protects the cortisol response

Chapter 4 The anti-inflammatory efficacy of dexamethasone is protected by (-)-epicatechin

Chapter 5 Food-derived bioactives can protect the anti-inflammatory activity of cortisol by antioxidant-dependent and-independent mechanisms

Chapter 6 Pleiotropic benefit of monomeric and oligomeric flavanols on vascular health - A randomized controlled clinical pilot study

Chapter 7 General discussion

Chapter 8 Summary

Samenvatting

Valorisatie 141

Dankwoord 147

Curriculum vitae 153

List of publications 157 


\section{Abbreviations}

\begin{tabular}{|c|c|}
\hline 3'ME & 3'-O-methyl-EC \\
\hline $4^{\prime} \mathrm{ME}$ & 4'-O-methyl-EC \\
\hline 4'ME7G & 4'-O-methyl-EC-7- $\beta$-D-glucuronide \\
\hline 8-iso-PGF $2 a$ & 8-isoprostaglandine $\mathrm{F}_{2 a}$ \\
\hline $11 \beta-H B S D$ & $11 \beta$-hydroxysteroid dehydrogenase \\
\hline $\mathrm{ACh}$ & acetylcholine \\
\hline ADP & adenosine diphosphate \\
\hline AP1 & activator protein-1 \\
\hline APA & induced percentage aggregation \\
\hline APAR & induced percentage aggregation rate \\
\hline BMI & body mass index \\
\hline Cat & catechin \\
\hline CAT & catalase \\
\hline $\mathrm{CHD}$ & coronary heart disease \\
\hline COPD & chronic obstructive pulmonary disease \\
\hline $\operatorname{cox} 2$ & cyclooxygenase-2 \\
\hline CPA & collagen induced platelet aggregation \\
\hline CPAR & collagen induced platelet aggregation rate \\
\hline CRP & Creactive protein \\
\hline CVD & cardiovascular disease \\
\hline DBP & diastolic blood pressure \\
\hline DCFH-DA & $2^{\prime}, 7^{\prime}$-dichlorofluorescein-diacetate \\
\hline DNPH & 2,4-dinitrophenylhydrazine \\
\hline EC & (-)-epicatechin \\
\hline E4'S & EC-4'-sulfate \\
\hline E7G & EC-7- $\beta$-D-glucuronide \\
\hline eNOS & endothelial nitric oxide synthase \\
\hline ET1 & endothelin-1 \\
\hline FMD & flow-mediated vasodilation \\
\hline FEV1 & forced expiratory volume in 1 second \\
\hline Fib & Fibrinogen \\
\hline FMD & flow-mediated dilation \\
\hline GAPDH & glyceraldehyde-3-phosphate dehydrogenase \\
\hline GC & glucocorticoid \\
\hline GCR & glucocorticoid receptor \\
\hline GPX1 & glutathione peroxidase- 1 \\
\hline GPX4 & glutathione peroxidase-4 \\
\hline GRE & glucocorticoid responsive elements \\
\hline GSR & glutathione reductase \\
\hline GSH & glutathione \\
\hline GSSG & glutathione disulphide \\
\hline HAT & histone acetyltransferases \\
\hline HDAC2 & histone deacetylase 2 \\
\hline HDL & high density lipoprotein cholesterol \\
\hline
\end{tabular}




\begin{tabular}{|c|c|}
\hline $\mathrm{HO}-1$ & heme oxygenase 1 \\
\hline IBD & inflammatory bowel disease \\
\hline ICAM & intercellular adhesion molecule 1 \\
\hline IKK & IkB-kinases \\
\hline IL & interleukin \\
\hline IL-8 & interleukin-8 \\
\hline LDF & Laser-Doppler-flowmetry \\
\hline $\mathrm{LDH}$ & lactate dehydrogenase \\
\hline LDL & low-density lipoprotein \\
\hline L-NMMA & L-NG-monomethyl-arginine \\
\hline LPS & lipopolysaccharides \\
\hline MAPK & mitogen activated protein kinases \\
\hline $\mathrm{MH}$ & monoHER, 7-mono-O-( $\beta$-hydroxyethyl)-rutoside \\
\hline MOF & monomeric and oligomeric flavanols \\
\hline MR & mineralocorticoid receptor \\
\hline NADPH & nicotinamide-adenine dinucleotide phosphate \\
\hline NBT & nitro blue tetrazolium \\
\hline $\mathrm{NF}-\mathrm{kB}$ & nuclear factor kappa-light-chain-enhancer of activated B cells \\
\hline NOX & NADPH oxidase \\
\hline NOx & nitrate and nitrite \\
\hline Nrf2 & nuclear factor-erythroid 2-related factor 2 \\
\hline PI3K & phosphoinositide 3-kinase \\
\hline PKA & protein kinase $A$ \\
\hline PMA & phorbol 12-myristate 13-acetate \\
\hline RA & rheumatoid arthritis \\
\hline ROS & reactive oxygen species; \\
\hline SRB & sulforhodamine B \\
\hline RT-PCR & real-time polymerase chain reaction \\
\hline SBP & systolic blood pressure \\
\hline SIN-1 & 3-morpholinosydnonimine hydrochloride \\
\hline SNP & sodium nitroprusside \\
\hline SOD & superoxide dismutase \\
\hline SP & DL-sulforaphane \\
\hline SRB & sulforhodamine B \\
\hline tChol & total cholesterol \\
\hline TEAC & trolox equivalent antioxidant capacity \\
\hline TG & triglycerides \\
\hline TNF & tumor necrosis factor \\
\hline VCAM & vascular adhesion molecule 1 \\
\hline $\mathrm{VHI}$ & vascular health index \\
\hline Q & quercetin \\
\hline Q3G & quercetin-3-O-glucuronide \\
\hline Q3M & 3-O-methyl quercetin \\
\hline XO & xanthine oxidase \\
\hline
\end{tabular}





\section{Chapter 1}

General Introduction 


\section{Flavonoids: classification, molecular structure and dietary sources}

Flavonoids are a group of polyphenols which are widely distributed in the plant kingdom. Consequently, they are found in plant derived foods and beverages such as wine, tea, apples, plums and cocoa beans [1]. These polyphenols contribute to the color and taste properties of plants and consist of more than one aromatic ring, each substituted with at least one hydroxyl group [2]. Flavonoids are a subclass of polyphenols that have a C6C3-C6 backbone structure consisting of phenolic and pyrane rings. These flavonoids are subdivided in several classes, based on the arrangements of hydroxyl- and methoxygroups and the conjugation between the A- and B- rings. The main subclasses of flavonoids are flavonols, flavanols, flavanones, flavones, isoflavones and anthocyanidins $[3,4]$. In plants, flavonoids are usually present in their glycosylated form rather than their aglycone [4]. The molecular structures, and an example of food rich in these compounds, are given in figure 1.

Soy beans are a rich source of isoflavones, like genistein, and flavonols, like quercetin, are found in various fruits and vegetables, e.g. grapes, apples and onions. Anthocyanidins can be found in fruits, like strawberries, and citrus fruits contain flavanones, like narengenin. Flavones, like luteolin and rutin, are present in relatively high quantities in peppers. Flavanols, like (-)-epicatechin (EC) and (+)-catechin (Cat), are present in most fruits and vegetables, like apples and plums, but also in beverages, like tea and red wine. Another dietary source of EC is the cocoa bean. Where plums contain on average $2.2 \mathrm{mg}$ EC per $100 \mathrm{~g}$ food weight, cocoa beans contain $158 \mathrm{mg} / 100 \mathrm{~g}$ food weight. After processing dark chocolate still contains $70 \mathrm{mg} / 100 \mathrm{~g}$ food weight of EC [5-7].

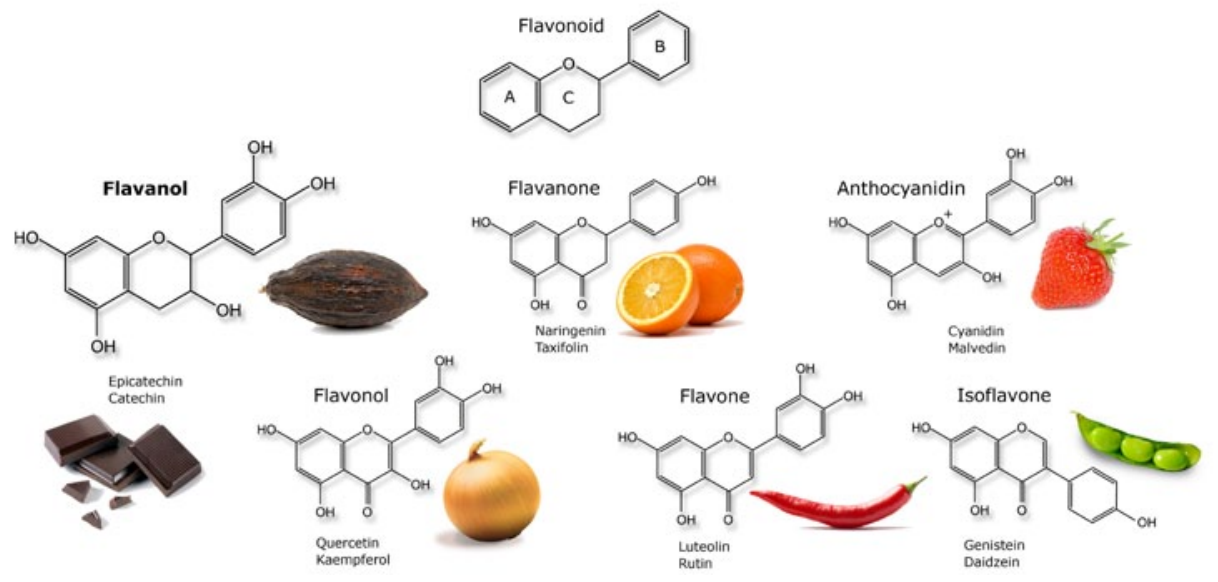

Figure 1. Classes of flavonoids and example of dietary sources. 


\section{Intake and bioavailability of flavonoids in Europe}

Quantitatively, flavanols represent a major group of flavonoids in the Western diet [8]. In the European Union, the average intake of fruits amounts to $166 \mathrm{~g} / \mathrm{capita} /$ day, being lowest in the UK (95 g/day) and highest in the central Eastern Europe (203 g/ day). Coffee, tea and cocoa intake is $633 \mathrm{~g} /$ day with the highest consumption reported in The Netherlands (887 g/day) [9]. In addition, in the Spanish "PREvención con Dleta MEDiterránea" (PREDIMED) study, mean polyphenol intake was reported to be $820 \mathrm{mg} /$ day and flavonoid intake $443 \mathrm{mg} /$ day [10].

Flavonoids are extensively metabolized before entering the blood stream. After absorption in the intestine flavanols reach the liver via the portal vein. In the liver they are metabolized by phase II metabolizing enzymes leading to methylated, glucuronidated and sulfated metabolites [11,12]. Despite this extensive first-pass effect, after a single dose of flavanol-rich cocoa drink, EC has been shown to reach a plasma peak concentration up to $6 \mu \mathrm{M}$ after $2 \mathrm{~h}$ [13]. Four hours after ingestion only small trace amounts of this flavanol are remaining and after 8 hours EC is not detectable anymore. Despite studies reporting un-metabolized EC plasma levels (see above), it is currently assumed that the majority of EC becomes bioavailable as O-methylated, sulfated and glucuronidated metabolites (table 1) [14-16].

Table 1. (-)-Epicatechin metabolites [17-19].

\begin{tabular}{|c|c|c|}
\hline Parent structure & Metabolites & Abbreviation \\
\hline \multirow{7}{*}{$\left.\right|_{\mathrm{OH}} ^{\mathrm{HO}}$} & 3'-O-methyl-(-)-epicatechin & 3'ME \\
\hline & 4'-O-methyl-(-)-epicatechin & 4'ME \\
\hline & 3'-O-methyl-(-)-epicatechin-5-sulfate & 3'ME5S \\
\hline & 3'-O-methyl-(-)-epicatechin-7-sulfate & 3'ME7S \\
\hline & $\begin{array}{l}\text { 4'-O-methyl-(-)-epicatechin-7- } \beta \text {-D- } \\
\text { glucuronide }\end{array}$ & 4'ME7G \\
\hline & (-)-epicatechin-3'- $\beta$-D-glucuronide & E3'G \\
\hline & (-)-epicatechin-3'-sulfate & E3'S \\
\hline \multirow{2}{*}{ (-)-epicatechin } & (-)-epicatechin-4'-sulfate & E4'S \\
\hline & (-)-epicatechin-7- $\beta$-D-glucuronide & E7G \\
\hline
\end{tabular}




\section{Oxidative stress}

Oxidative stress is defined as an imbalance between oxidants and antioxidants in favor of the oxidants, potentially leading to cellular and subcellular damage [20]. Reactive oxygen species (ROS) are generated during the reduction of oxygen and comprise two groups of molecules namely free radicals and other ROS. Free radicals such as hydroxyl radicals $(\cdot \mathrm{OH})$ and superoxide anion radicals $\left(\mathrm{O}_{2}{ }^{--}\right)$are chemically very reactive due to the unpaired free electron and have relatively short biological half-lives. Non-radicals, such as hydrogen peroxide $\left(\mathrm{H}_{2} \mathrm{O}_{2}\right)$ and hypochlorous acid $(\mathrm{HOCl})$, are relatively less reactive and have a longer half-life than most free radicals [21, 22]. Although $\mathrm{H}_{2} \mathrm{O}_{2}$ is less reactive, the longer half-life and because it is easily diffusible within and between cells, makes it an important mediator in oxidative stress induced cell damage [23].

ROS can be derived from endogenous and exogenous sources as mitochondria, activated inflammatory cells, drugs and cigarette smoke. Within human cells, ROS are produced by various oxidase enzymes, including nicotinamide-adenine dinucleotide phosphate (NADPH) oxidase (NOX), xanthine oxidase (XO), uncoupled endothelial NO synthase (eNOS), cyclooxygenase, glucose oxidase, lipoxygenase, and during the mitochondrial electron transport chain [24].

At low, physiological, concentration ROS are important physiological regulators of intracellular signaling pathways through the covalent modification of specific cysteine residues (i.e. thiols) found within redox-sensitive target proteins [25]. As an example, all of the mitogen-activated protein kinases (MAPK) have been shown to be activated in various cell types by ROS [26]. Other pathways where ROS are involved include cell growth, cell-cell adhesion, differentiation, senescence and apoptosis [27].

Excessive ROS production, however, has been implicated in the etiology of numerous diseases [28-31]. Oxidative stress is indicated as an important mediator in the pathophysiology of cardiovascular diseases such as endothelial dysfunction, atherosclerosis and hypertension $[32,33]$. Free radicals can also contribute to the development of diabetes mellitus by promoting the autoimmune destruction of betacells in the pancreas, leading to impaired insulin action. Next to direct DNA damage ROS also interfere with mutation repair systems, such as DNA repair enzymes, apoptotic modulators and the p53 protein leading to genetic aberrations and mutations [34].

\section{Inflammation and chronic inflammatory diseases}

During inflammation vasodilation occurs which facilitates the recruitment of immune cells to the side of injury to repair tissue or remove pathogens. Acute inflammation is usually 
a response to infections by pathogens or to tissue damage. This inflammatory response helps to remove pathogens and enables tissue repair. An inflammatory response can also be chronic, i.e. lasting months to years, in the absence of an obvious activator. Instead of repair, chronic inflammation will lead to pathological aberrations and tissue damage [34]. Chronic inflammation in the cardiovascular system can have major health implications. Activated inflammatory immune cells, for example, enhance the formation of atherosclerotic plaques inside of arterial blood vessels. The early stages of atherosclerosis involve infiltration of inflammatory cells, monocyte conversion to macrophages, oxidized low-density lipoprotein (LDL) uptake by macrophages and the subsequent release of inflammatory mediators and adhesion molecules [35]. Additionally, oxidative stress in the vascular wall plays a role in the pathogenesis of atherosclerosis and consequently the development of cardiovascular disease (CVD) [36, 37].

An over-activated inflammatory response in the body is also a key characteristic in the pathophysiology of other chronic inflammatory diseases such as inflammatory bowel disease (IBD), rheumatoid arthritis (RA), and chronic obstructive pulmonary disease (COPD). These diseases are also associated with high levels of oxidative stress $[38,39]$. For example, one of the clinical features of COPD is a high level of ROS in the exhaled air [40].

\section{Cross-talk between inflammation and oxidative stress}

The process of inflammation and oxidative stress cannot be treated separately. They are tightly intertwined and one process influences the other. Depending on the environment and circumstance, ROS can both activate and inhibit the inflammatory NF-KB signaling. These interactions also appear to be cell type-specific [41]. During inflammation, inflammatory cells like neutrophils are attracted to the inflamed region. These cells produce ROS, including $\mathrm{O}_{2}^{--}, \cdot \mathrm{OH}$ and $\mathrm{H}_{2} \mathrm{O}_{2}$ to fight off invading pathogens [42]. If the production of ROS is not sufficiently terminated, oxidative stress triggers inflammation. Oxidative stress enhances IKB-kinases (IKK) which phosphorylates inhibitory protein IKBa, an inhibitor protein bound to $\mathrm{NF}-\mathrm{KB}$, subsequently leading to a rapid ubiquination and consequently in degradation of $\mathrm{NF}-\mathrm{KB}$ to the cell nucleus where it binds to the NF-KB responsive element in the promoter region of pro-inflammatory genes, activating their transcription. This will increase the level of various interleukins like IL-6, IL-1 $\beta$ and TNFa and chemokines like IL-8 (Figure 2) [43-45]. These inflammatory cytokines have been shown to initiate the generation of ROS in non-phagocytic-cells too [34]. In this way inflammation and oxidative stress continuously reinforces each other which cumulates in a downward spiral. The key role 
of ROS in the ethiology of respiratory diseases characterized by inflammation, including asthma and COPD, is well established [46].

\section{Glucocorticoids in the treatment of inflammatory diseases}

The name glucocorticoid (GC) originates from their role in glucose metabolism. However, GCs also regulate other important physiological processes involved in development, metabolism, neural function, programmed cell death and inflammation $[47,48]$.

The endogenous GC cortisol is produced by the adrenal gland and its diverse array of activities includes: regulation of lipid, carbohydrate and protein metabolism, controlling responses to distress and disease and suppression of inflammation [49, 50]. Cortisol is also called the stress hormone since its level rises during physical or emotional stress. In response to inflammation, cortisol is produced to mitigate inflammation. First the inactive precursor cortisone is formed, which is converted into the active cortisol by $11 \beta$-hydroxysteroid dehydrogenase type 1 (11ß-HSD1) mostly in the liver, but also in other tissues including brain, adipocytes, vascular cells and osteoblasts. The reverse reaction, catalyzed by type $211 \beta$-hydroxysteroid dehydrogenase (11 $\beta$-HSD2) leads to the inactivation of cortisol [51-53]. This regulates the cortisol response at a cellular level

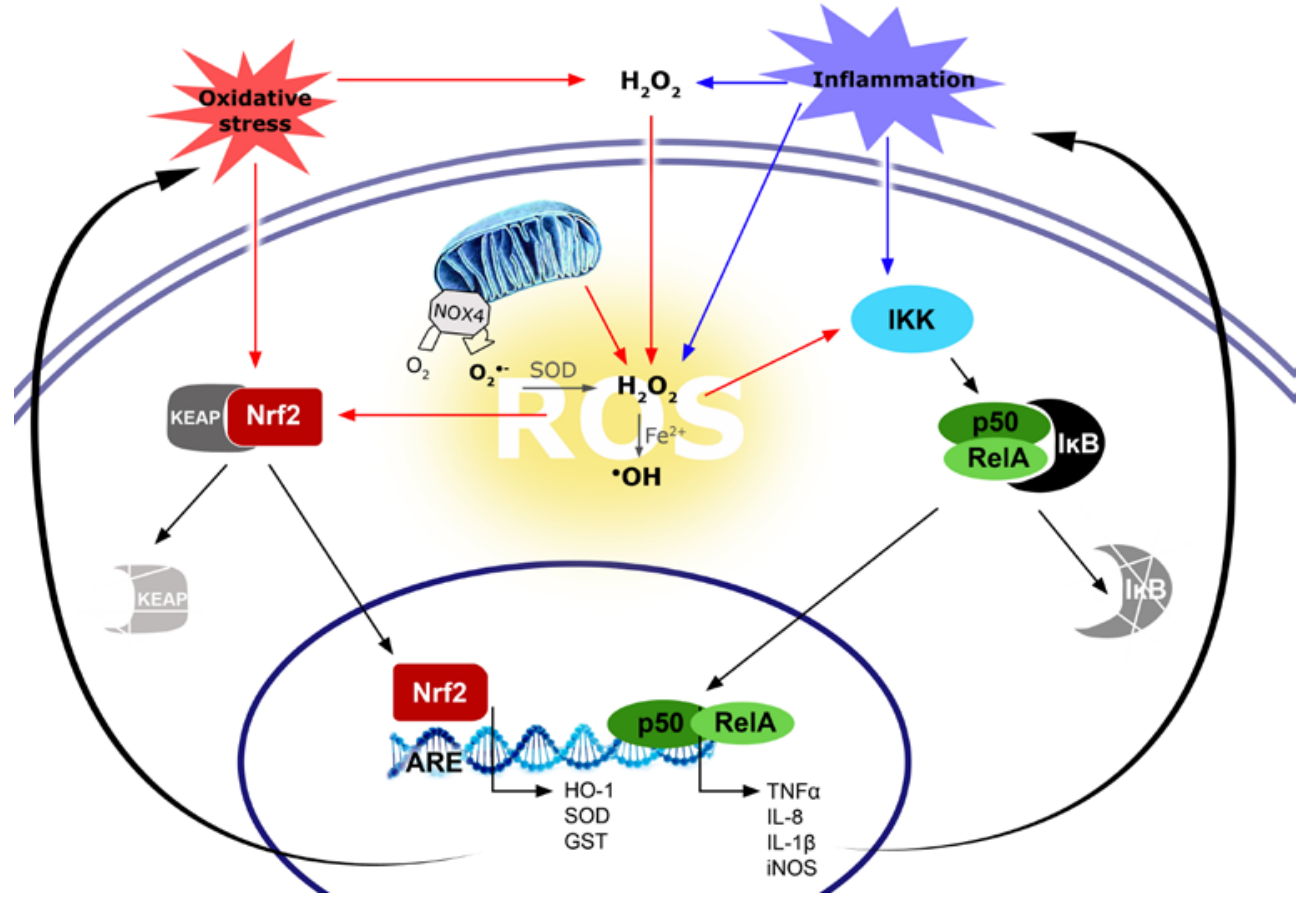

Figure 2. The crosstalk between oxidative stress and NF-kB activation. 
and prevents activation of the mineralocorticoid receptor (MR) which regulates salt and water excretion by the kidney. The receptor has a high affinity for the mineralocorticoid aldosterone, but cortisol can also activate this receptor [54].

GC receptors (GRs), both the active GRa and the inactive $G R \beta$, are present in almost all tissue cells [48]. Upon binding of GC, GRa translocates to the nucleus where it directly modulates gene transcription by binding to the glucocorticoid responsive elements (GRE) in the promoter region of multiple genes. Activated GR complex also reduces the activity of activator protein (AP)-1 and the pro-inflammatory transcription factor NF-kB and trans-activates their inhibitor proteins [55-57]. As a consequence, pro-inflammatory gene expression becomes inhibited. Additionally, the recruitment of histone deacetylase 2 (HDAC2) to the nucleus by GR-GC complex is important for the termination of the NF-kB-mediated transcription of pro-inflammatory mediators [50, 58]. In the resting cell, DNA is tightly compacted around histone proteins to prevent transcription factor accessibility. The amino-terminal ends of histones are subject to various modifications. Histone acetylation is linked to activation of gene transcription because this opens the chromatin structure, making it accessible for the transcription machinery. This chemical modification is carried out by histone acetyltransferases (HAT) and counteracted by histone deacetylases (HDACs), leading to gene repression [59,60].

To reduce inflammation and treat chronic inflammatory diseases, such as IBD, RA, and COPD, synthetic GCs like budesonide, prednisolone and dexamethasone are widely prescribed $[55,61]$. Dexamethasone is no substrate for $11 \beta-H S D 2$, which increases its local availability. When taken orally, dexamethasone is 26 times more potent than cortisol and 5 times more than prednisone. Synthetic glucocorticoids are developed to be selective for the GR and have relatively low MR activity. GCs are prescribed to approximately $2.5 \%$ of the elderly and $0.2 \%$ to $0.5 \%$ of the general population and are indispensable, highly effective anti-inflammatory therapeutics $[52,62]$.
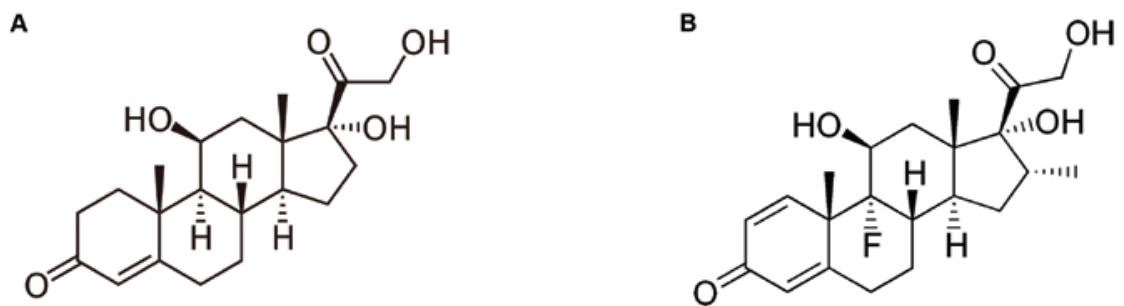

Figure 3. A) Cortisol (hydrocortisone), the primary endogenous glucocorticoid. B) Dexamethasone, a synthetic glucocorticoid. It displays anti-inflammatory and immunosuppressant activity. When taken orally, it is 26 times more potent than the naturally occurring hormone cortisol. 
Prolonged use of GCs causes various serious side effects like osteoporosis. GC receptors are present on both osteoclasts and osteoblasts. GCs shorten the lifespan of bone forming osteoblasts and prolong the lifespan of osteoclasts, cells responsible for bone resorption. The resulting osteoporosis increases the fracture risk [63-65]. Other side effects include depression of adrenal gland function, reduction of growth (in children), hyperglycemia, diabetic complications, psychosis, muscle wasting, atherosclerosis, hypertension and metabolic syndrome [61, 66-68]. As a result of long-term glucocorticoid use, patients can also develop iatrogenic Cushing's syndrome [51].

Although synthetic GCs can efficiently reduce inflammation in most cases, some patients do not respond to the GC treatment. This GC resistance is a major impediment in the treatment of inflammatory diseases $[58,69]$. GC-resistant patients often still have side effects, even though the anti-inflammatory response to GCs is reduced or absent. Moreover, in these patients GCs are often used at a higher dose, making them more susceptible to adverse events [70]. The mechanisms currently proposed for GC resistance include (1) decreased HDAC2 activity [39, 70], preventing repression of pro-inflammatory genes; (2) increased expression of the transcriptionally inactive GRß [71, 72]; (3) reduced binding affinity, translocation or stability of $G R a$, preventing the transcription of antiinflammatory proteins [73]; and (4) increased pro-inflammatory gene expression by excessive activation of the pro-inflammatory transcription factor activator protein 1 (AP1) $[50]$.

Increasing the dose is an option to reduce inflammation in GC-resistant patients, but as mentioned above this will also augment the detrimental side effects of GCs. Alternative treatments have been proposed in recent years [38, 74]. The extensive crosstalk between oxidative stress and inflammation indicates that antioxidant supplementation is a rational strategy to overcome GC resistance.

\section{Health benefits of flavonoids}

Since flavonoids are present in many foods and beverages consumed in the Western world, intake is relatively high. In the past decades many research has been performed to unravel the health effects of flavonoids in vitro and in vivo and in clinical studies. Clinical intervention studies revealed that flavonoids exert beneficial effects on the heart and vascular system [75-80]. Flavonoids have shown to improve platelet and endothelial cell function, reduce blood pressure and improve vascular function assessed as flow-mediated vasodilation (FMD) [81, 82]. Their efficacy has been attributed to their antioxidant activity, but recently also anti-inflammatory and vasodilatory properties are 
considered as important mechanisms of action [83]. Also improvement of the nervous system and brain function has been reported. A flavonoid-rich diet has been reported to improve cognitive function by increasing spatial memory performance [84]. In addition, flavonoids have been suggested to inhibit the development of Alzheimer disease [85] and numerous studies showed that a diet rich in fruits and vegetables helps to reduce the incidence of cancer [86-88].

Flavonoids are also recognized to reduce inflammation and the risk of chronic diseases like asthma, type 2 diabetes, lung and prostate cancer [89]. In a critical review by Boeing et al. [90] various health benefits of fruit and vegetable consumption are summarized. The risk of coronary heart disease (CHD) is reported to be reduced by $4-7 \%$ for each additional daily ingested portion of fruits or vegetables [91]. Increased intake of fruits is also associated with a reduced risk of COPD and asthma. For example, intake of fruits (> $180 \mathrm{~g} /$ day), vegetables and whole grains is positively associated with the forced expiratory volume in 1 second ( FEV1) and a reduced prevalence of COPD symptoms. [92].

The anti-inflammatory and antioxidant activity of flavonoids has been studied extensively. In test tubes studies, flavonoids display radical scavenging activity. Also in cellular systems, flavonoids efficiently protect cells against oxidative stress, partly by directly scavenging radicals, but also by activating cellular antioxidant defense systems (e.g. via nuclear factor-erythroid 2-related factor 2 (Nrf2)) or inhibiting cellular radicalgenerating systems (e.g. NOX4 enzyme, mitochondria). These antioxidant effects are suggested to contribute to the prevention of the development of various diseases and the improvement of cellular function by flavonoids. Likewise, in the development and progression of atherosclerosis, the oxidation of LDL by ROS and the recruitment of inflammatory cells plays a very important role. The ability of flavonoids to attenuate both ROS levels and the inflammatory response, prevents foam cell formation in arteries. Eventually, the risk to develop cardiovascular disease is considerably reduced [93].

By means of in vitro experiments, the mode of action of flavonoids has been increasingly elucidated and several mechanisms have been proposed. Various molecular signaling pathways are modulated by flavonoids and suggested to be involved in their anti-inflammatory activities. These actions include: inhibition of pro-inflammatory enzymes, such as cyclooxygenase-2 (COX2), lipoxygenase and inducible NO synthase; inhibition of NF-KB and AP-1 via interaction with upstream signalling pathways (IKK phosphorylation, MAPK phosphorylation and phosphoinositide 3-kinase (PI3K) / protein kinase $B$ (Akt) phosphorylation) and activation of phase II antioxidant detoxifying enzymes, via MAPK, protein kinase C and Nrf2 [82, 94, 95]. 


\section{The role of the flavanol (-)-epicatechin in health}

Accumulating evidence from epidemiological studies, dietary intervention trials and in vitro research suggest beneficial health effect of cocoa and cocoa-derived products like chocolate [96]. Improvement in cardiovascular health trough reduced blood pressure, improved endothelial function, improved platelet function, reduced LDL cholesterol and increased insulin sensitivity has been described in literature [77, 97-101]. (-)-Epicatechin, the major monomeric flavanol present in cocoa, has been identified as one of the active compounds, being responsible for the beneficial vascular effects observed following cocoa consumption [81]. Therefore, we focused our research on EC to better understand the mechanisms involved in the observed protective effects.

\section{Aim and outline of the thesis}

Food-derived flavanols are part of our daily diet and several health benefits have been described. Flavonoids have a beneficial effect on the cardiovascular system, help to prevent cancer and improve cognitive brain function by their anti-inflammatory and antioxidant activity. This thesis aims to further elucidate the potential health benefits resulting from the anti-inflammatory and antioxidant effects of flavonoids, with a focus on the flavanol EC. In the following chapters we investigated the following research questions:

1. What are the antioxidant properties of (-)-epicatechin and its metabolites?

2. Can (-)-epicatechin prevent oxidative stress induced endogenous glucocorticoid resistance?

3. Can (-)-epicatechin maintain the anti-inflammatory efficacy of therapeutic glucocorticoids?

4. Which other plant-derived compounds are able to restore the anti-inflammatory action of endogenous glucocorticoids?

5. Can flavanols improve (cardio)vascular health in humans?

In chapter 2 the antioxidant activity of EC was determined and compared with phase II metabolites to investigate the effect of metabolism of flavanols on their radical scavenging activity. Additionally, the toxicity of the unmetabolized and metabolized flavanols was assessed in primary human umbilical vein endothelial cells. 
Treatment of chronic inflammatory diseases is often hampered because patients develop GC resistance. Chronic inflammation is also associated with oxidative stress and there is an extensive crosstalk between inflammation an oxidative stress. In chapter $\mathbf{3}$ we investigated the ability of EC to protect the anti-inflammatory potency of the endogenous glucocorticoid cortisol induced by oxidative stress using human macrophage-like cells. In the next chapter, chapter 4, we further characterized the cellular system of human monocytes differentiated to macrophage-like cells for the investigation of GC resistance. Moreover, the potency of EC to maintain the anti-inflammatory action of the synthetic glucocorticoid dexamethasone in the presence of oxidative stress was assessed.

In chapter 5 a wide range of bioactives were screened for their antioxidant effect an potential to protect the endogenous cortisol response to further study the link between the antioxidant and anti-inflammatory effect of flavonoids.

In chapter $\mathbf{6}$ we describe the pleiotropic health effects in the vasculature of humans after an 8 weeks daily supplementation with monomeric and oligomeric flavanols. Finally, in chapter $\mathbf{7}$ the major findings of all the studies presented in the thesis will be discussed and put in perspective. Moreover, possibilities for further research will be suggested. 


\section{References}

1. Cheynier V. Polyphenols in foods are more complex than often thought. Am J Clin Nutr. 2005;81:223S-9S.

2. Corcoran MP, McKay DL, Blumberg JB. Flavonoid basics: chemistry, sources, mechanisms of action, and safety. J Nutr Gerontol Geriatr. 2012;31:176-89.

3. Heim KE, Tagliaferro AR, Bobilya DJ. Flavonoid antioxidants: chemistry, metabolism and structure-activity relationships. J Nutr Biochem. 2002;13:572-84.

4. Robbins RJ, Kwik-Uribe C, Hammerstone JF, Schmitz HH. Analysis of flavanols in foods: what methods are required to enable meaningful health recommendations? J Cardiovasc Pharmacol. 2006;47 Suppl 2:S1108; discussion S9-21.

5. Rothwell JA, Urpi-Sarda M, Boto-Ordonez M, Knox C, Llorach R, Eisner R, et al. Phenol-Explorer 2.0: a major update of the Phenol-Explorer database integrating data on polyphenol metabolism and pharmacokinetics in humans and experimental animals. Database (Oxford). 2012;2012:bas031.

6. Arts IC, van De Putte B, Hollman PC. Catechin contents of foods commonly consumed in The Netherlands. 2. Tea, wine, fruit juices, and chocolate milk. J Agric Food Chem. 2000;48:1752-7.

7. Arts IC, van de Putte B, Hollman PC. Catechin contents of foods commonly consumed in The Netherlands. 1. Fruits, vegetables, staple foods, and processed foods. J Agric Food Chem. 2000;48:1746-51.

8. Heiss C, Keen CL, Kelm M. Flavanols and cardiovascular disease prevention. Eur Heart J. 2010;31:2583-92.

9. Elmadfa I, Meyer A, Nowak V, Hasenegger V, Putz P, Verstraeten R, et al. European Nutrition and Health Report 2009. Ann Nutr Metab. 2009;55 Suppl 2:1-40.

10. Tresserra-Rimbau A, Medina-Remon A, Perez-Jimenez J, Martinez-Gonzalez MA, Covas MI, Corella D, et al. Dietary intake and major food sources of polyphenols in a Spanish population at high cardiovascular risk: the PREDIMED study. Nutr Metab Cardiovasc Dis. 2013;23:953-9.

11. Monagas M, Urpi-Sarda M, Sanchez-Patan F, Llorach R, Garrido I, Gomez-Cordoves C, et al. Insights into the metabolism and microbial biotransformation of dietary flavan-3-ols and the bioactivity of their metabolites. Food Funct. 2010;1:233-53.

12. Lotito SB, Zhang WJ, Yang CS, Crozier A, Frei B. Metabolic conversion of dietary flavonoids alters their antiinflammatory and antioxidant properties. Free Radic Biol Med. 2011;51:454-63.

13. Holt RR, Lazarus SA, Sullards MC, Zhu QY, Schramm DD, Hammerstone JF, et al. Procyanidin dimer B2 [epicatechin-(4beta-8)-epicatechin] in human plasma after the consumption of a flavanol-rich cocoa. Am J Clin Nutr. 2002;76:798-804.

14. Spencer JP, Schroeter H, Rechner AR, Rice-Evans C. Bioavailability of flavan-3-ols and procyanidins: gastrointestinal tract influences and their relevance to bioactive forms in vivo. Antioxid Redox Signal. 2001;3:1023-39.

15. Kuhnle G, Spencer JP, Schroeter H, Shenoy B, Debnam ES, Srai SK, et al. Epicatechin and catechin are O-methylated and glucuronidated in the small intestine. Biochem Biophys Res Commun. 2000;277:50712.

16. Scalbert A, Williamson G. Dietary intake and bioavailability of polyphenols. J Nutr. 2000;130:2073S-85S.

17. Natsume M, Osakabe N, Oyama M, Sasaki M, Baba S, Nakamura Y, et al. Structures of (-)-epicatechin glucuronide identified from plasma and urine after oral ingestion of (-)-epicatechin: differences between human and rat. Free Radic Biol Med. 2003;34:840-9.

18. Ottaviani Jl, Momma TY, Kuhnle GK, Keen CL, Schroeter H. Structurally related (-)-epicatechin metabolites in humans: assessment using de novo chemically synthesized authentic standards. Free Radic Biol Med. 2012;52:1403-12.

19. Rodriguez-Mateos A, Toro-Funes N, Cifuentes-Gomez T, Cortese-Krott M, Heiss C, Spencer JP. Uptake and metabolism of (-)-epicatechin in endothelial cells. Arch Biochem Biophys. 2014.

20. Mittal M, Siddiqui MR, Tran K, Reddy SP, Malik AB. Reactive Oxygen Species in Inflammation and Tissue Injury. Antioxid Redox Signal. 2014;20:1126-67.

21. Weseler AR, Bast A. Oxidative stress and vascular function: implications for pharmacologic treatments. 
Curr Hypertens Rep. 2010;12:154-61.

22. Brieger K, Schiavone S, Miller FJ, Jr., Krause KH. Reactive oxygen species: from health to disease. Swiss Med Wkly. 2012;142:w13659.

23. Paravicini TM, Touyz RM. NADPH oxidases, reactive oxygen species, and hypertension: clinical implications and therapeutic possibilities. Diabetes Care. 2008;31 Suppl 2:S170-80.

24. Valko M, Leibfritz D, Moncol J, Cronin MT, Mazur M, Telser J. Free radicals and antioxidants in normal physiological functions and human disease. Int J Biochem Cell Biol. 2007;39:44-84.

25. Forman HJ, Fukuto JM, Torres M. Redox signaling: thiol chemistry defines which reactive oxygen and nitrogen species can act as second messengers. Am J Physiol Cell Physiol. 2004;287:C246-56.

26. Son Y, Cheong YK, Kim NH, Chung HT, Kang DG, Pae HO. Mitogen-Activated Protein Kinases and Reactive Oxygen Species: How Can ROS Activate MAPK Pathways? Journal of signal transduction. 2011;2011:792639.

27. Finkel T. Signal transduction by reactive oxygen species. J Cell Biol. 2011;194:7-15.

28. Sundar IK, Yao H, Rahman I. Oxidative stress and chromatin remodeling in chronic obstructive pulmonary disease and smoking-related diseases. Antioxid Redox Signal. 2013;18:1956-71.

29. Van der Vliet A, Bast A. Effect of oxidative stress on receptors and signal transmission. Chem Biol Interact. 1992;85:95-116.

30. Haenen GR, Veerman M, Bast A. Reduction of beta-adrenoceptor function by oxidative stress in the heart. Free Radic Biol Med. 1990;9:279-88.

31. Alfadda AA, Sallam RM. Reactive oxygen species in health and disease. J Biomed Biotechnol. 2012;2012:936486.

32. Cai H. Hydrogen peroxide regulation of endothelial function: origins, mechanisms, and consequences. Cardiovasc Res. 2005;68:26-36.

33. Mikkelsen RB, Wardman P. Biological chemistry of reactive oxygen and nitrogen and radiation-induced signal transduction mechanisms. Oncogene. 2003;22:5734-54.

34. Khansari N, Shakiba Y, Mahmoudi M. Chronic inflammation and oxidative stress as a major cause of agerelated diseases and cancer. Recent patents on inflammation \& allergy drug discovery. 2009;3:73-80.

35. Auclair S, Milenkovic D, Besson C, Chauvet S, Gueux E, Morand C, et al. Catechin reduces atherosclerotic lesion development in apo E-deficient mice: a transcriptomic study. Atherosclerosis. 2009;204:e21-7.

36. Sugamura K, Keaney JF, Jr. Reactive oxygen species in cardiovascular disease. Free Radic Biol Med. 2011;51:978-92.

37. Taverne YJ, Bogers AJ, Duncker DJ, Merkus D. Reactive oxygen species and the cardiovascular system. Oxid Med Cell Longev. 2013;2013:862423.

38. Roche N, Marthan R, Berger P, Chambellan A, Chanez P, Aguilaniu B, et al. Beyond corticosteroids: future prospects in the management of inflammation in COPD. Eur Respir Rev. 2011;20:175-82.

39. Ito K, Hanazawa T, Tomita K, Barnes PJ, Adcock IM. Oxidative stress reduces histone deacetylase 2 activity and enhances IL-8 gene expression: role of tyrosine nitration. Biochem Biophys Res Commun. 2004;315:240-5.

40. Dekhuijzen PN, Aben KK, Dekker I, Aarts LP, Wielders PL, van Herwaarden CL, et al. Increased exhalation of hydrogen peroxide in patients with stable and unstable chronic obstructive pulmonary disease. Am J Respir Crit Care Med. 1996;154:813-6.

41. Morgan MJ, Liu ZG. Crosstalk of reactive oxygen species and NF-kappaB signaling. Cell Res. 2011;21:10315.

42. Yang $Y$, Bazhin AV, Werner J, Karakhanova S. Reactive oxygen species in the immune system. Int Rev Immunol. 2013;32:249-70.

43. Ivison SM, Wang C, Himmel ME, Sheridan J, Delano J, Mayer ML, et al. Oxidative stress enhances IL-8 and inhibits CCL20 production from intestinal epithelial cells in response to bacterial flagellin. Am J Physiol Gastrointest Liver Physiol. 2010;299:G733-41.

44. Moodie FM, Marwick JA, Anderson CS, Szulakowski P, Biswas SK, Bauter MR, et al. Oxidative stress and 
cigarette smoke alter chromatin remodeling but differentially regulate NF-kappaB activation and proinflammatory cytokine release in alveolar epithelial cells. FASEB J. 2004;18:1897-9.

45. van den Berg R, Haenen GR, van den Berg H, Bast A. Transcription factor NF-kappaB as a potential biomarker for oxidative stress. Br J Nutr. 2001;86 Suppl 1:S121-7.

46. Zuo L, Otenbaker NP, Rose BA, Salisbury KS. Molecular mechanisms of reactive oxygen species-related pulmonary inflammation and asthma. Mol Immunol. 2013;56:57-63.

47. Biddie SC, Conway-Campbell BL, Lightman SL. Dynamic regulation of glucocorticoid signalling in health and disease. Rheumatology (Oxford). 2011.

48. Zanchi NE, Filho MA, Felitti V, Nicastro H, Lorenzeti FM, Lancha AH, Jr. Glucocorticoids: extensive physiological actions modulated through multiple mechanisms of gene regulation. J Cell Physiol. 2010;224:311-5.

49. Whitehouse MW. Anti-inflammatory glucocorticoid drugs: reflections after 60 years. Inflammopharmacology. 2011;19:1-19.

50. Adcock IM, Barnes PJ. Molecular mechanisms of corticosteroid resistance. Chest. 2008;134:394-401.

51. Kadmiel M, Cidlowski JA. Glucocorticoid receptor signaling in health and disease. Trends Pharmacol Sci. 2013;34:518-30.

52. Edwards C. Sixty years after Hench--corticosteroids and chronic inflammatory disease. J Clin Endocrinol Metab. 2012;97:1443-51.

53. Nijm J, Jonasson L. Inflammation and cortisol response in coronary artery disease. Ann Med. 2009;41:22433.

54. Fuller PJ, Young MJ. Mechanisms of mineralocorticoid action. Hypertension. 2005;46:1227-35.

55. De ludicibus S, Franca R, Martelossi S, Ventura A, Decorti G. Molecular mechanism of glucocorticoid resistance in inflammatory bowel disease. World J Gastroenterol. 2011;17:1095-108.

56. Bougarne N, Paumelle R, Caron S, Hennuyer N, Mansouri R, Gervois P, et al. PPARalpha blocks glucocorticoid receptor alpha-mediated transactivation but cooperates with the activated glucocorticoid receptor alpha for transrepression on NF-kappaB. Proc Natl Acad Sci U S A. 2009;106:7397-402.

57. Newton R. Molecular mechanisms of glucocorticoid action: what is important? Thorax. 2000;55:603-13.

58. Yang N, Ray DW, Matthews LC. Current concepts in glucocorticoid resistance. Steroids. 2012;77:1041-9.

59. Nightingale KP, O'Neill LP, Turner BM. Histone modifications: signalling receptors and potential elements of a heritable epigenetic code. Curr Opin Genet Dev. 2006;16:125-36.

60. Schamberger AC, Mise N, Meiners S, Eickelberg O. Epigenetic mechanisms in COPD: implications for pathogenesis and drug discovery. Expert opinion on drug discovery. 2014;9:609-28.

61. Hakim A, Adcock IM, Usmani OS. Corticosteroid resistance and novel anti-inflammatory therapies in chronic obstructive pulmonary disease: current evidence and future direction. Drugs. 2012;72:1299-312.

62. Buttgereit F. A fresh look at glucocorticoids how to use an old ally more effectively. Bull NYU Hosp Jt Dis. 2012;70 Suppl 1:26-9.

63. Toth M, Grossman A. Glucocorticoid-induced osteoporosis: lessons from Cushing's syndrome. Clin Endocrinol (Oxf). 2013;79:1-11.

64. Manolagas SC. Steroids and osteoporosis: the quest for mechanisms. J Clin Invest. 2013;123:1919-21.

65. Dore RK. Long-term safety, efficacy, and patient acceptability of teriparatide in the management of glucocorticoid-induced osteoporosis. Patient preference and adherence. 2013;7:435-46.

66. Almeida M, Han L, Ambrogini E, Weinstein RS, Manolagas SC. Glucocorticoids and tumor necrosis factor alpha increase oxidative stress and suppress Wnt protein signaling in osteoblasts. J Biol Chem. 2011;286:44326-35.

67. Rickard AJ, Young MJ. Corticosteroid receptors, macrophages and cardiovascular disease. J Mol Endocrinol. 2009;42:449-59.

68. Hasselgren PO, Alamdari N, Aversa Z, Gonnella P, Smith IJ, Tizio S. Corticosteroids and muscle wasting: role of transcription factors, nuclear cofactors, and hyperacetylation. Curr Opin Clin Nutr Metab Care. 
2010;13:423-8.

69. Farrell RJ, Kelleher D. Glucocorticoid resistance in inflammatory bowel disease. J Endocrinol. 2003;178:33946.

70. Barnes PJ, Adcock IM. Glucocorticoid resistance in inflammatory diseases. Lancet. 2009;373:1905-17.

71. Li LB, Leung DY, Martin RJ, Goleva E. Inhibition of histone deacetylase 2 expression by elevated glucocorticoid receptor beta in steroid-resistant asthma. Am J Respir Crit Care Med. 2010;182:877-83.

72. Webster JC, Oakley RH, Jewell CM, Cidlowski JA. Proinflammatory cytokines regulate human glucocorticoid receptor gene expression and lead to the accumulation of the dominant negative beta isoform: a mechanism for the generation of glucocorticoid resistance. Proc Natl Acad Sci U S A. 2001;98:6865-70.

73. Barnes PJ. Corticosteroid resistance in patients with asthma and chronic obstructive pulmonary disease. J Allergy Clin Immunol. 2013;131:636-45.

74. Keenan CR, Salem S, Fietz ER, Gualano RC, Stewart AG. Glucocorticoid-resistant asthma and novel antiinflammatory drugs. Drug Discov Today. 2012;17:1031-8.

75. Arts IC, Hollman PC, Feskens EJ, Bueno de Mesquita HB, Kromhout D. Catechin intake might explain the inverse relation between tea consumption and ischemic heart disease: the Zutphen Elderly Study. Am J Clin Nutr. 2001;74:227-32.

76. Buijsse B, Feskens EJ, Kok FJ, Kromhout D. Cocoa intake, blood pressure, and cardiovascular mortality: the Zutphen Elderly Study. Arch Intern Med. 2006;166:411-7.

77. Corti R, Flammer AJ, Hollenberg NK, Luscher TF. Cocoa and cardiovascular health. Circulation. 2009;119:1433-41.

78. De Graaf J, De Sauvage Nolting PR, Van Dam M, Belsey EM, Kastelein JJ, Haydn Pritchard P, et al. Consumption of tall oil-derived phytosterols in a chocolate matrix significantly decreases plasma total and low-density lipoprotein-cholesterol levels. Br J Nutr. 2002;88:479-88.

79. de Pascual-Teresa S, Moreno DA, Garcia-Viguera C. Flavanols and anthocyanins in cardiovascular health: a review of current evidence. Int J Mol Sci. 2010;11:1679-703.

80. Galleano M, Oteiza PI, Fraga CG. Cocoa, chocolate, and cardiovascular disease. J Cardiovasc Pharmacol. 2009;54:483-90.

81. Schroeter H, Heiss C, Balzer J, Kleinbongard P, Keen CL, Hollenberg NK, et al. (-)-Epicatechin mediates beneficial effects of flavanol-rich cocoa on vascular function in humans. Proc Natl Acad Sci U S A. 2006;103:1024-9.

82. Grassi D, Desideri G, Ferri C. Flavonoids: antioxidants against atherosclerosis. Nutrients. 2010;2:889-902.

83. Tangney CC, Rasmussen HE. Polyphenols, inflammation, and cardiovascular disease. Current atherosclerosis reports. 2013;15:324.

84. Rendeiro C, Vauzour D, Rattray M, Waffo-Teguo P, Merillon JM, Butler LT, et al. Dietary levels of pure flavonoids improve spatial memory performance and increase hippocampal brain-derived neurotrophic factor. PLoS One. 2013;8:e63535.

85. Williams RJ, Spencer JP. Flavonoids, cognition, and dementia: actions, mechanisms, and potential therapeutic utility for Alzheimer disease. Free Radic Biol Med. 2012;52:35-45.

86. D'Archivio M, Santangelo C, Scazzocchio B, Vari R, Filesi C, Masella R, et al. Modulatory effects of polyphenols on apoptosis induction: relevance for cancer prevention. Int J Mol Sci. 2008;9:213-28.

87. Chen C, Kong AN. Dietary cancer-chemopreventive compounds: from signaling and gene expression to pharmacological effects. Trends Pharmacol Sci. 2005;26:318-26.

88. Surh YJ. Cancer chemoprevention with dietary phytochemicals. Nat Rev Cancer. 2003;3:768-80.

89. Knekt P, Kumpulainen J, Jarvinen R, Rissanen $H$, Heliovaara M, Reunanen A, et al. Flavonoid intake and risk of chronic diseases. Am J Clin Nutr. 2002;76:560-8.

90. Boeing $\mathrm{H}$, Bechthold A, Bub A, Ellinger S, Haller D, Kroke A, et al. Critical review: vegetables and fruit in the prevention of chronic diseases. Eur J Nutr. 2012;51:637-63.

91. Dauchet L, Amouyel P, Hercberg S, Dallongeville J. Fruit and vegetable consumption and risk of coronary 
heart disease: a meta-analysis of cohort studies. J Nutr. 2006;136:2588-93.

92. Tabak C, Smit HA, Heederik D, Ocke MC, Kromhout D. Diet and chronic obstructive pulmonary disease: independent beneficial effects of fruits, whole grains, and alcohol (the MORGEN study). Clin Exp Allergy. 2001;31:747-55.

93. Peluso MR. Flavonoids attenuate cardiovascular disease, inhibit phosphodiesterase, and modulate lipid homeostasis in adipose tissue and liver. Exp Biol Med (Maywood). 2006;231:1287-99.

94. Serafini M, Peluso I, Raguzzini A. Flavonoids as anti-inflammatory agents. Proc Nutr Soc. 2010;69:273-8.

95. Lemmens KJA, Sthijns MMJPE, van der Vijgh WJF, Bast A, Haenen GRMM. The antioxidant flavonoid monoHER provides efficient protection and induces the innate Nrf2 mediated adaptation in endothelial cells subjected to oxidative stress. PharmaNutrition. 2014.

96. Latham LS, Hensen ZK, Minor DS. Chocolate--guilty pleasure or healthy supplement? J Clin Hypertens. 2014;16:101-6.

97. Desch S, Schmidt J, Kobler D, Sonnabend M, Eitel I, Sareban M, et al. Effect of cocoa products on blood pressure: systematic review and meta-analysis. Am J Hypertens. 2010;23:97-103.

98. Kenny TP, Keen CL, Schmitz HH, Gershwin ME. Immune effects of cocoa procyanidin oligomers on peripheral blood mononuclear cells. Exp Biol Med (Maywood). 2007;232:293-300.

99. Lanoue L, Green KK, Kwik-Uribe C, Keen CL. Dietary factors and the risk for acute infant leukemia: evaluating the effects of cocoa-derived flavanols on DNA topoisomerase activity. Exp Biol Med (Maywood). 2010;235:77-89.

100. Monagas M, Khan N, Andres-Lacueva C, Casas R, Urpi-Sarda M, Llorach R, et al. Effect of cocoa powder on the modulation of inflammatory biomarkers in patients at high risk of cardiovascular disease. Am J Clin Nutr. 2009;90:1144-50.

101. Stote KS, Clevidence BA, Novotny JA, Henderson T, Radecki SV, Baer DJ. Effect of cocoa and green tea on biomarkers of glucose regulation, oxidative stress, inflammation and hemostasis in obese adults at risk for insulin resistance. Eur J Clin Nutr. 2012;66:1153-9. 



\section{Chapter 2}

The flavanol (-)-epicatechin and its metabolites protect against oxidative stress in primary endothelial cells via a direct antioxidant effect

Erik J.B. Ruijters

Antje R. Weseler

Cécile Kicken

Guido R.M.M. Haenen

Aalt Bast

European Journal of Pharmacology, 2012, 715:147-153 


\section{Abstract}

Accumulating evidence suggests that foods rich in flavanols decrease the risk of developing cardiovascular diseases. Attenuation of oxidative stress was suggested to contribute to the cardiovascular benefit of flavanols. Up to now it was unclear whether flavanol metabolites can also protect cells from oxidative stress. The aim of the present study was to determine the potential contribution of several glucuronidated, methylated and sulfated metabolites of (-)-epicatechin (EC) and (+)-catechin (Cat) to the protection of human vascular endothelial cells (HUVECs) against oxidative stress.

The relative potency of the tested compounds to scavenge superoxide anion radicals showed that a free catechol moiety in the molecule is important for the direct antioxidant activity. EC and Cat $(0.5,1$ and $10 \mu \mathrm{M})$ were potent radical scavengers and provided protection against intracellular oxidative stress induced by hydrogen peroxide. Although the metabolites provided less intracellular protection compared to EC and Cat, the tested methylated and glucuronidated metabolites reduced oxidative stress significantly in HUVECS.

Our results indicate that the metabolites have a relevant contribution in the intracellular protection of EC and Cat against oxidative stress. Also, the direct antioxidant activity plays an important role in this protection. 


\section{Introduction}

Flavanols are a group of flavonoids found in high amounts in food and beverages such as wine, tea, apples, plums and cocoa beans. For example, $100 \mathrm{~g}$ of cocoa powder contains $158 \mathrm{mg}(-)$-epicatechin (EC) and $100 \mathrm{~g}$ of dark chocolate $70 \mathrm{mg}$ [1]. Various epidemiological, in vivo and in vitro studies suggest that these flavanols exert beneficial effects on the heart and cardiovascular system by e.g. lowering blood pressure, preventing LDL oxidation, inhibiting platelet aggregation and improving endothelial function [2-5].

Although reactive oxygen species (ROS) play a role in signal transduction, excessive ROS production leads to oxidative stress. Unbalanced ROS production has been implicated in the pathophysiology of cardiovascular diseases such as endothelial dysfunction, atherosclerosis and hypertension [6, 7]. ROS are generated during the reduction of oxygen and comprise two groups of molecules, namely (i) free radicals with relatively short biological half-lives, such as the superoxide anion radical $\left(\mathrm{O}_{2}{ }^{--}\right)$, and hydroxyl radical $(\cdot \mathrm{OH})$ and (ii) non-radicals, such as hydrogen peroxide $\left(\mathrm{H}_{2} \mathrm{O}_{2}\right)$, which are relatively less reactive and have a longer half-life than most free radicals [8].

The metabolism of flavanols has to be taken into account when studying the effect of flavanols on the cardiovascular system. Already in the small intestine EC is extensively metabolized to O-methyl-, glucuronide- and O-methylglucuronide-conjugates (figure 1). These metabolites and any native EC entering the portal vein are further metabolized in the liver. After intake of flavanol rich foods, EC and several of these metabolites are found in plasma $[9,10]$.

At first the beneficial effects of flavanols on the cardiovascular system were attributed to their direct antioxidant activity. More recently, the emphasis has shifted towards indirect modulation of various molecular processes like increasing endogenous antioxidant defense or attenuating ROS-producing systems [11-14]. The potential contribution of the direct antioxidant activity is increasingly debated. Moreover, the role of the metabolites in the protection of the cardiovascular system by (+)-catechin (Cat) and EC is yet not established. The aim of the present study was to determine the potential contribution of several glucuronidated, methylated and sulfated metabolites of EC and Cat (figure 1) to the protection of vascular endothelial cells against oxidative stress. Therefore, we first determined the superoxide radical scavenging activity of Cat, EC and several human metabolites. Subsequently, we assessed the potency of these compounds to reduce intracellular oxidative stress levels in human vascular endothelial cells (HUVECs). 


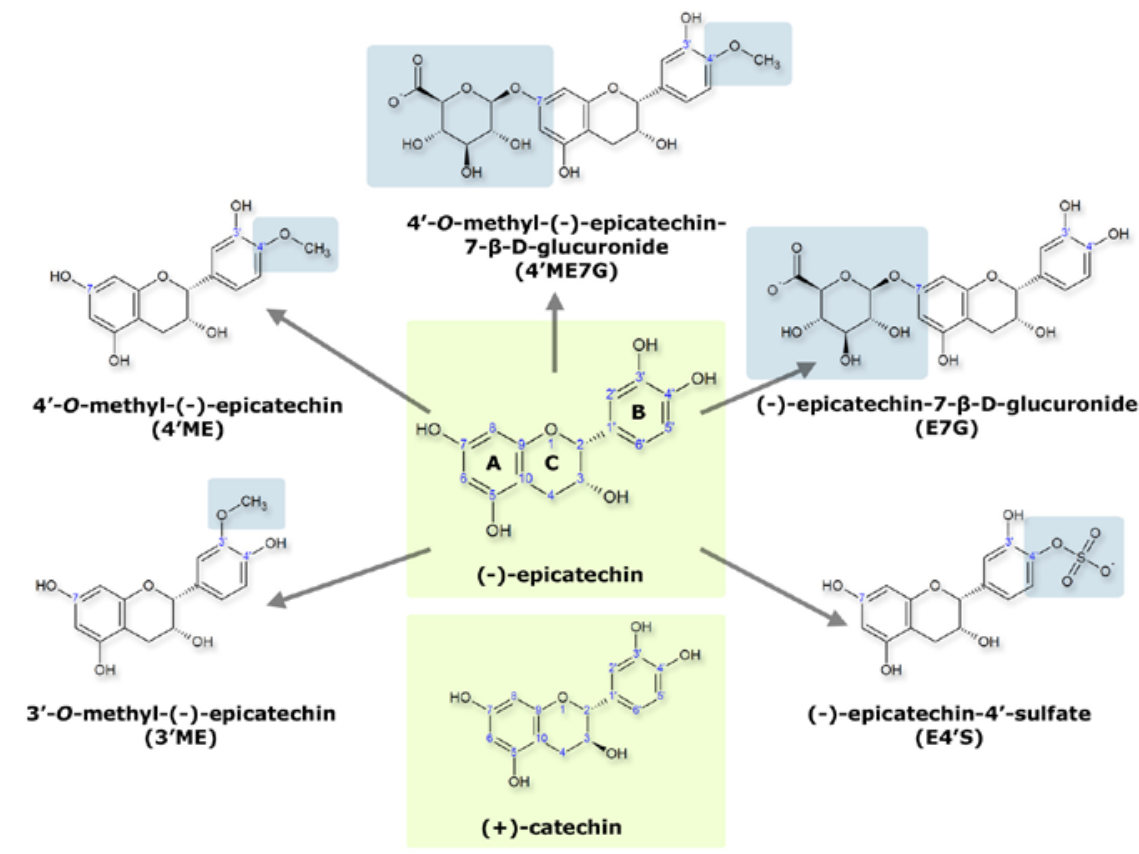

Figure 1. Chemical structure of (+)-catechin, (-)-epicatechin and several metabolites. Gray blocks highlight the groups substituted in the metabolites.

\section{Materials and Methods}

\section{Materials}

Primary human umbilical vein endothelial cells (HUVECs), endothelial basal medium (EBM) and endothelial growth medium 2 (EGM-2) SingleQuots were purchased from Lonza (Verviers, Belgium). Phosphate buffered Saline (PBS), Sodium pyruvate, reduced nicotinamide adenine dinucleotide (NADH), 2,4-dinitrophenylhydrazine (DNPH), nitro blue tetrazolium (NBT), xanthine, xanthine oxidase grade III, trichloric acid (TCA),

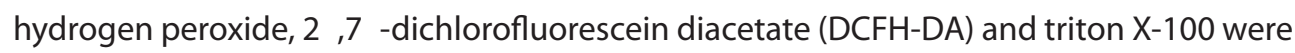
purchased from Sigma (St. Louis, MO, USA). 3-Morpholinosydnonimine hydrochloride (SIN1) was purchased from Invitrogen (Molecular Probes, Eugene, OR, USA). (-)-Epicatechin (EC) and (+)-catechin (Cat) were purchased from Extrasynthese (Genay, France). Flavanol metabolites were provided by Mars Incorporated (Hackettstown, NJ, USA). 10 mM stock solutions of EC, Cat, 3'-O-methyl-EC (3'ME), 4'-O-methyl-EC (4'ME), 4'-O-methyl-EC-7- $\beta$-Dglucuronide (4'ME7G), EC-7- $\beta$-D-glucuronide (E7G), and EC-4'-sulfate (E4'S) were prepared 
in 50 or $100 \%(\mathrm{v} / \mathrm{v})$ ethanol and $50 \mu \mathrm{l}$ aliquots were stored at $-80^{\circ} \mathrm{C}$ under argon until use. The dilutions of each flavanol were prepared immediately prior to experimental use.

\section{Cell culture}

HUVECs were cultured in EBM supplemented with EGM-2 SingleQuot bullet kit, containing $10 \mathrm{ml}$ fetal bovine serum (FBS), $0.5 \mathrm{ml}$ insulin-like growth factor, $0.5 \mathrm{ml}$ gentamicin/amphotericin, $0.5 \mathrm{ml}$ ascorbic acid, $0.5 \mathrm{ml}$ human recombinant epidermal growth factor, $0.5 \mathrm{ml}$ vascular endothelial growth factor, $2 \mathrm{ml}$ human fibroblast growth factor-b, $0.5 \mathrm{ml}$ heparin and $0.2 \mathrm{ml}$ hydrocortisone (Lonza, Verviers, Belgium). FBS was first heat inactivated at $56^{\circ} \mathrm{C}$ for 30 minutes prior to supplementation. All experiments were done with HUVECs in passage four and five.

\section{Superoxide anion radical scavenging assay}

The $\mathrm{O}_{2}^{--}$scavenging activity of flavanols and their metabolites was determined using the NBT assay. The reduction of NBT to formazan was measured in an $\mathrm{O}_{2}{ }^{--}$-generating system of xanthine and xanthine oxidase. First, $950 \mu \mathrm{l}$ reaction mix, containing $50 \mu \mathrm{M}$ NBT, 100 $\mu \mathrm{M}$ xanthine and $10 \mu \mathrm{M}$ flavanols in $50 \mathrm{mM}$ potassium phosphate buffer ( $\mathrm{pH}$ 7.4), was transferred to a cuvette. The formation of $\mathrm{O}_{2}{ }^{--}$was started by adding $50 \mu \mathrm{l} 400 \mathrm{mU} / \mathrm{ml}$ xanthine oxidase and increase in formazan was measured spectrophotometrically at 560 $\mathrm{nm}$ and $37^{\circ} \mathrm{C}$. Results are presented as relative decrease in NBT reduction as compared to the control without flavanols.

\section{Uric acid measurement}

To check for possible inhibition of the enzyme xanthine oxidase, the amount of uric acid formed during the reaction was measured using HPLC. The $\mathrm{O}_{2}^{--}$scavenging assay was performed as described above without NBT and reaction was stopped after 2 minutes by adding 1 volume of $10 \%$ TCA. After centrifugation, $10 \mu \mathrm{l}$ of supernatant was injected onto a HPLC system and separated on a reversed-phase column (Altima HP C18 AQ $5 \mu \mathrm{m}$ ) using $0.1 \%$ acetonitrile with a flow rate of $2 \mathrm{ml} / \mathrm{min}$. Uric acid was measured with an UV detector at $292 \mathrm{~nm}$ and quantified using a standard curve.

\section{DCFH assay}

The fluorescent probe of 2', 7'-dichlorfluorescein-diacetate (DCFH-DA) was used to quantify intracellular oxidative stress in HUVECs. When incubating cells with DCFHDA, this nonionic, nonpolar DCFH-DA crosses cell membranes and is enzymatically 
hydrolyzed by intracellular esterases to DCFH. In the presence of ROS, the non-fluorescent DCFH is oxidized to the highly fluorescent dichlorofluorescein (DCF). The intensity of DCF fluorescence corresponds to the level of intracellular ROS formation [15, 16]. HUVECs were seeded in a black/clear bottom 96-wells plate and grown for 24 hours. On the next day 50 $\mu \mathrm{l} 50 \mu \mathrm{M}$ DCFH-DA was added to the cells and incubated for 30 minutes at $37^{\circ} \mathrm{C}, 5 \% \mathrm{CO}_{2}$. Medium was removed and cells were washed with PBS to remove all extracellular DCFHDA. Cells were then exposed to the test compounds by adding $100 \mu \mathrm{l}$ serum-free medium containing $0.5,1$ or $10 \mu \mathrm{M}$ flavanols and one of the oxidative stress inducing compounds, i.e. hydrogen peroxide, xanthine with xanthine oxidase or SIN-1. Fluorescence of DCF was measured in a SpectraMax plate reader (Molecular Devices, Sunnyvale, CA, USA) with excitation and emission wavelengths of $485 \mathrm{~nm}$ and $535 \mathrm{~nm}$, respectively, at $37^{\circ} \mathrm{C}$ over a period of 60 minutes. Experiments were repeated in four wells.

\section{Interaction (-)-epicatechin and hydrogen peroxide}

Chemical interaction between $\mathrm{H}_{2} \mathrm{O}_{2}$ and $\mathrm{EC}$ was measured spectrophotometrically. EC $(100 \mu \mathrm{M})$ and $\mathrm{H}_{2} \mathrm{O}_{2}(800 \mu \mathrm{M})$ were incubated in serum-free medium at $37^{\circ} \mathrm{C}$ and a spectrum (220 - $500 \mathrm{~nm}$ ) was measured after 0,60 and 120 minutes. Relative concentration of EC was determined using the absorbance at $280 \mathrm{~nm}$.

\section{Cell viability}

HUVECs were seeded in a 96-wells plate and grown overnight. On the next day, medium was removed and cells were washed once with $100 \mu \mathrm{l}$ PBS and exposed to $100 \mu \mathrm{l}$ serumfree medium containing test compound for 3 hours. After exposure, $20 \mu$ of medium was transferred to a new 96-well plate to measure lactate dehydrogenase ( $L D H)$ activity. Fifty $\mu \mathrm{l}$ of $10 \mathrm{mg} / \mathrm{ml} \mathrm{NADH}$ in $0.75 \mathrm{mM}$ sodium pyruvate was added to the medium and incubated for 30 minutes at $37^{\circ} \mathrm{C}$. To determine the remaining amount of pyruvate, 50 $\mu l 0.2 \mathrm{mg} / \mathrm{ml}$ DNPH was added to the wells and incubated at room temperature in the dark for 20 minutes. To develop the color, $50 \mu \mathrm{l} 4 \mathrm{M} \mathrm{NaOH}$ was added and incubated for $5 \mathrm{~min}$. Absorbance was measured at $540 \mathrm{~nm}$ using a Spectramax plate reader (Molecular Devices, Sunnyvale, CA, USA) and viability was calculated relative to unexposed cells (100 $\%$ viability) with $0.1 \%(\mathrm{v} / \mathrm{v})$ triton $\mathrm{X}-100$ as a positive control.

\section{Expression of heme oxygenase 1}

The expression of heme oxygenase 1 ( $\mathrm{HO}-1)$ was assessed by quantitative Real Time PCR (qRT-PCR). Cells were seeded in a 24-well plate and grown overnight. After washing 
with PBS, cells were exposed to $300 \mu \mathrm{l}$ starvation medium containing $10 \mu \mathrm{M}$ flavanols +/- $100 \mathrm{MM} \mathrm{H}_{2} \mathrm{O}_{2}$ for 3 hours. After exposure, cells were trypsinized and collected in a 1.5 $\mathrm{ml}$ tube. RNA was extracted using the RNeasy mini kit (Qiagen, Venlo, The Netherlands) and quantity and purity measured using the NanoDrop system (Thermo Scientific, Rockford, IL, USA). Five hundred ng of RNA was reverse transcribed using the iScript cDNA Synthesis kit (Bio-RadHercules, CA, USA) and diluted 10 times with water. Two step qRTPCR was performed using $12.5 \mu \mathrm{l}$ SensiMix SYBR \& Fluorescein Kit (Bioline, London, UK) with $5 \mu \mathrm{l} \mathrm{CDNA}$, and $150 \mathrm{nM}$ of each primer in a $25 \mu \mathrm{l}$ reaction mixture. Primers: forward: 5'-CTTCTTCACCTTCCCCAACA-3', reverse: 5'-GCTCTGGTCCTTGGTGTCAT-3'. The cycling conditions consisted of an initial denaturation at $95^{\circ} \mathrm{C}$ for 10 minutes, followed by 40 alternating cycles at $95^{\circ} \mathrm{C}$ and $60^{\circ} \mathrm{C}$ for $15 \mathrm{sec}$. and $45 \mathrm{sec}$., respectively, using the iCycler system (Bio-Rad, Hercules, CA). Specificity of the reaction was checked by a melting curve. Results were evaluated using the $2^{-\Delta \Delta c t}$ method with $\beta$-actin as housekeeping gene and fold change was calculated relative to unexposed cells. As positive control $10 \mu \mathrm{M}$ sulforaphane (SP) was used as this is a known inducer of the Nrf2 pathway.

\section{Statistics}

Data are expressed as mean \pm SD. Statistical comparisons were performed by using a Mann-Whitney U test with Prism v5 (GraphPad Software, San Diego, CA, USA). A twotailed $\mathrm{P}$-value $<0.01$ or $<0.05$ was considered statistically significant.

\section{Results}

\section{Superoxide anion radical scavenging activity of flavanols and metabolites}

The flavanols Cat, EC and several human metabolites were able to scavenge $\mathrm{O}_{2}^{-{ }^{-}}$ generated by xanthine/xanthine oxidase (figure 2). The highest $\mathrm{O}_{2}^{--}$scavenging was observed with Cat $(29.1 \pm 1.5 \%)$ and EC $(28.7 \pm 3.1 \%)$, followed by E7G $(26.6 \pm 1.1 \%)$, E4'S (15.2 $\pm 3.9 \%), 4$ 'ME7G $(7.4 \pm 2.7 \%)$ and 4'ME $(7.0 \pm 2.4 \%)$. The 3'-methylated metabolite displayed no significant scavenging activity in the tested concentrations. No decrease in uric acid formation was detected, indication that the flavanols and metabolites did not inhibit the enzyme xanthine oxidase.

\section{Cell viability}

Cell viability was measured to verify that the incubation conditions did not result in direct 
cytotoxicity. Three hours incubation of HUVEC with $100 \mu \mathrm{M}$ flavanol metabolites or $1 \%$ (v/v) ethanol used to dissolve the flavanols did not elicit cell death (figure $3 \mathrm{~A}$ ). $\mathrm{H}_{2} \mathrm{O}_{2}$ up to a concentration of $200 \mu \mathrm{M}$ induced no significant LDH leakage, while concentrations of $500 \mu \mathrm{M}$ or higher resulted in significant cell death (figure 3B). Hydrogen peroxide was used in further experiments at a concentration of $100 \mu \mathrm{M}$ since this induces no direct cytotoxicity. Incubating cells with SIN-1 $(0-500 \mu \mathrm{M})$ or xanthine $(0.5 \mathrm{mM})$ and xanthine oxidase $(0-500 \mathrm{mU} / \mathrm{ml})$ for 3 hours did not result in LDH leakage (figure $3 C, \mathrm{D})$.

\section{Capacity of (-)-epicatechin to attenuate intracellular oxidative stress}

The intracellular antioxidant activity of EC was measured in HUVECs with various oxidative stress inducers, namely hydrogen peroxide $\left(\mathrm{H}_{2} \mathrm{O}_{2}\right), \mathrm{SIN}-1$ or the combination of xanthine and xanthine oxidase (figure 4). EC (10 $\mu \mathrm{M})$ significantly reduced intracellular oxidative stress induced by all of these inducers $(p<0.01)$

\section{Capacity of flavanol metabolites to attenuate hydrogen peroxide induced intracellular oxidative stress}

The flavanol metabolites showed a dose dependent protection against $\mathrm{H}_{2} \mathrm{O}_{2}$-induced oxidative stress (figure 5). Even at a concentration of $0.5 \mu \mathrm{M}$ the metabolites substantially attenuated intracellular oxidative stress levels. At a concentration of $1 \mu \mathrm{M}$, the ranking of the flavanols according to their potency to reduce oxidative stress within HUVECs is: Cat $(70.9 \pm 1.9 \%)>$ EC $(63.5 \pm 2.3 \%)>$ E7G $(47.4 \pm 2.5 \%)>3^{\prime} \mathrm{ME}(31.4 \pm 3.9 \%)>4^{\prime} \mathrm{ME}(22.7 \pm$ $4.9 \%)>4$ 'ME7G $(17.4 \pm 6.2 \%)>$ E4'S $(5.8 \pm 3.7 \%)$. A direct reaction of the flavanols with $\mathrm{H}_{2} \mathrm{O}_{2}$ in culture medium could be excluded (figure 6).

\section{Gene expression of heme oxygenase}

In the absence of $\mathrm{H}_{2} \mathrm{O}_{2}$, the flavanols and metabolites did not affect gene expression of $\mathrm{HO}-1$ after $3 \mathrm{~h}$ incubation (figure 7A). Exposure of cells to $100 \mu \mathrm{M} \mathrm{H}_{2} \mathrm{O}_{2}$ for 3 hour resulted in a 1.8-fold increase of HO-1 expression (figure 7B). This increase was diminished when 10 $\mu \mathrm{M}$ Cat, EC or metabolites was added to the medium. In contrast to the other metabolites E4'S increased HO-1 expression by 2.7-fold. 

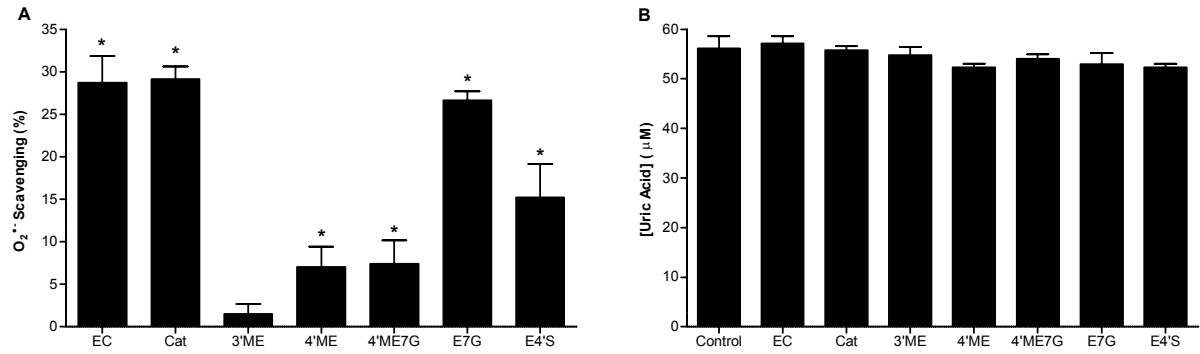

Figure 2. Superoxide radical scavenging activity of flavanol metabolites $(10 \mu \mathrm{M})$ was determined by measuring the formazan formation at $\lambda 560 \mathrm{~nm}$. (A) Data are represented as percent superoxide radical scavenging relative to control. (B) To test for possible enzyme inhibition by flavanols, the concentration of uric acid formed by xanthine oxidase was determined. (mean $\pm S D, n=4,{ }^{*} p<0.01$ ).

A

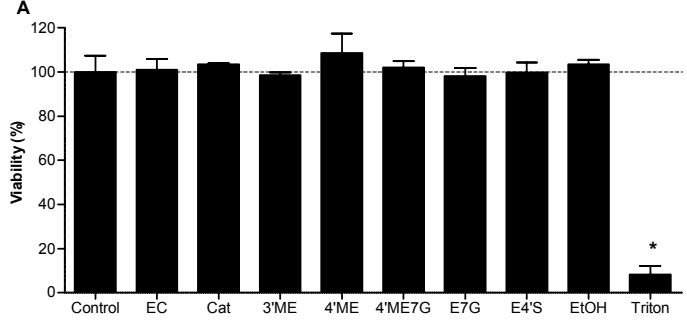

B

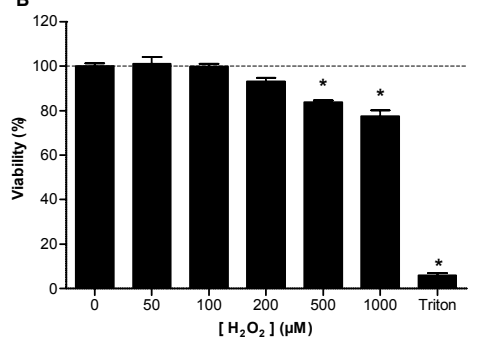

c

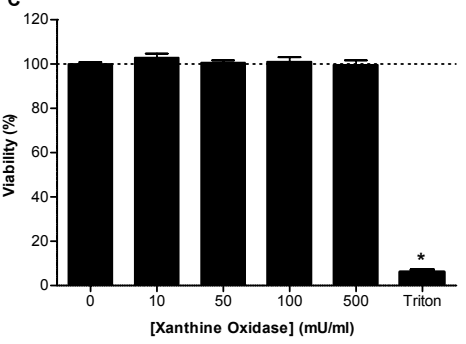

D

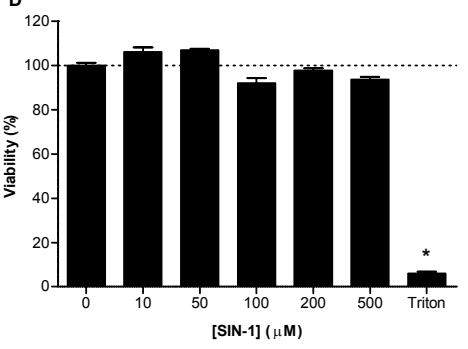

Figure 3. The effect of the incubation conditions on cell viability was checked by measuring LDH leakage. HUVECs were exposed to (A) $100 \mu \mathrm{M}$ flavanols; (B) $0-1000 \mu \mathrm{M} \mathrm{H}_{2} \mathrm{O}_{2}$; (C) $500 \mu \mathrm{M}$ xanthine and $0-500 \mathrm{mU} / \mathrm{ml}$ xanthine oxidase or (D) $0-500 \mu \mathrm{M}$ SIN-1 for 3 hours and LDH activity in the medium measured. Data is represented as percentage viability relative to control (unexposed cells). $0.1 \%$ Triton was used as positive control for LDH activity and $1 \%$ ethanol (EtOH) as solvent control (mean $\pm S D, n=4,{ }^{*} \mathrm{P}<0.01$ ). 
A
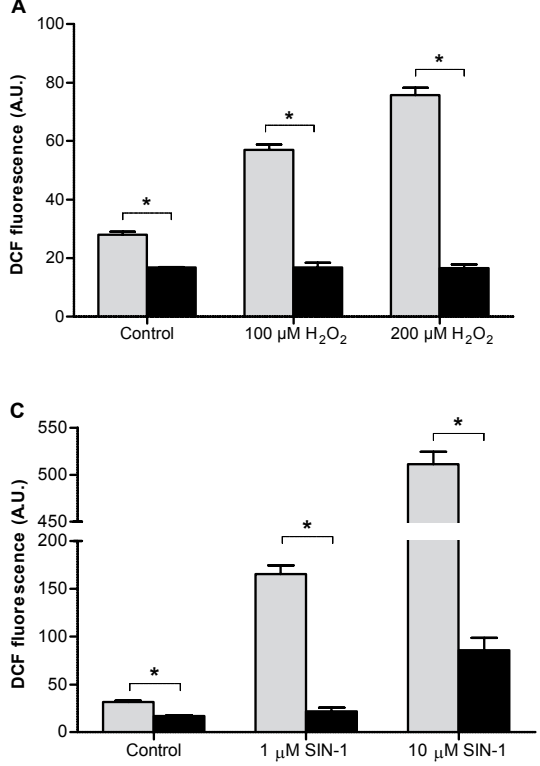

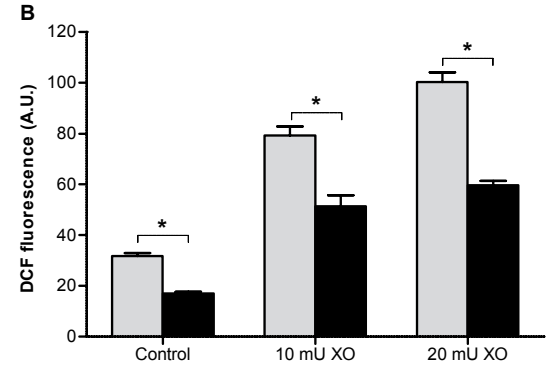

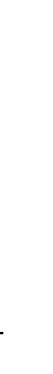

Figure 4. (-)-Epicatechin inhibits intracellular oxidative stress. HUVECs were pre-incubated with DCFH-DA and exposed to various inducers of oxidative stress with (black bars) or without (light bars) $\mathrm{EC}(10 \mu \mathrm{M})$ for 30 minutes. (A) 100 or $200 \mu \mathrm{M} \mathrm{H}_{2} \mathrm{O}_{2}$; (B) $100 \mu \mathrm{M}$ xanthine and 10 or $20 \mathrm{mU} / \mathrm{ml}$ xanthine oxidase; (C) 1 or $10 \mu \mathrm{M} \mathrm{SIN-1}$ (mean $\pm \mathrm{SD}, \mathrm{n}=4$, * $\mathrm{p}<0.01$ ).

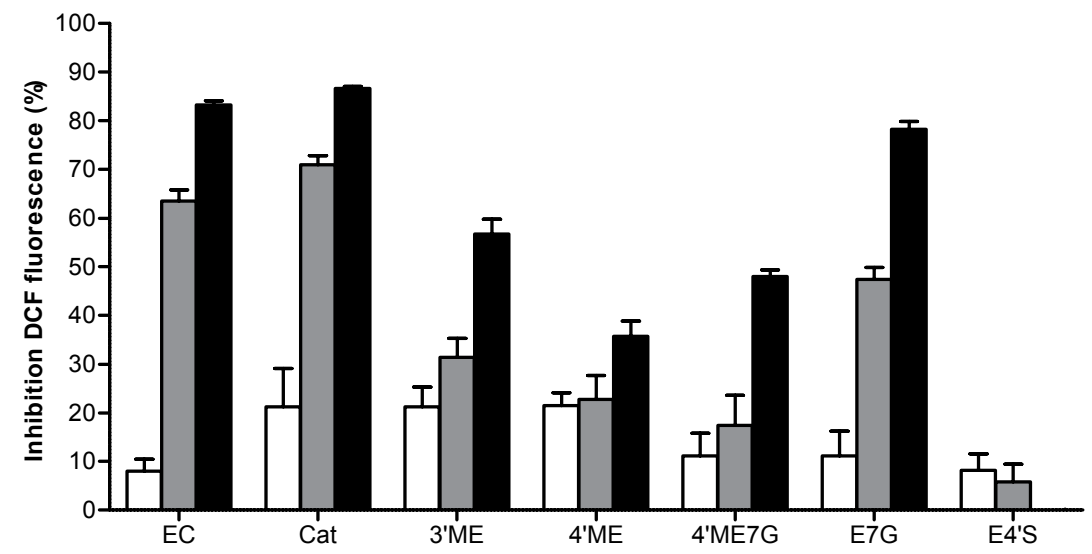

Figure 5. Flavanol metabolites inhibit intracellular oxidative stress induced by hydrogen peroxide. HUVECS were pre-incubated with DCFH-DA and exposed to $100 \mu \mathrm{M} \mathrm{H}_{2} \mathrm{O}_{2}$ and $0.5 \mu \mathrm{M}$ (white bars), $1 \mu \mathrm{M}$ (gray bars) or $10 \mu \mathrm{M}$ (black bars) of flavanol metabolites. DCF fluorescence was measured for 40 minutes in a plate reader at $37^{\circ} \mathrm{C}$. Bars represent percentage inhibition of DCF fluorescence compared to $\mathrm{H}_{2} \mathrm{O}_{2}$ exposed cells without flavanols. (mean $\pm \mathrm{SD}, \mathrm{n}=4$ ). 


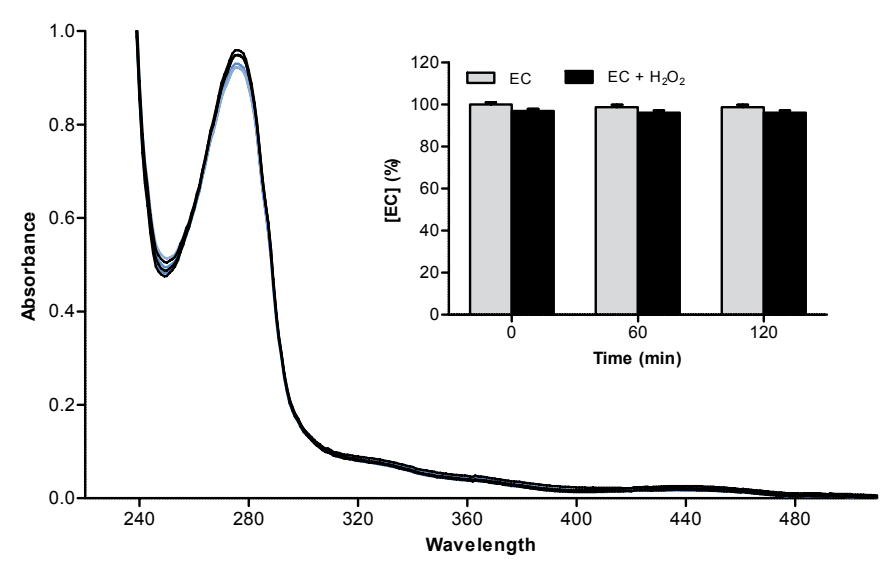

Figure 6. There is no chemical interaction of (-)-epicatechin with hydrogen peroxide. Absorbance spectrum $(220-500 \mathrm{~nm})$ was recorded for $\mathrm{EC}(100 \mu \mathrm{M}), \mathrm{H}_{2} \mathrm{O}_{2}(800 \mu \mathrm{M})$ and a mixture of EC and $\mathrm{H}_{2} \mathrm{O}_{2}$ after 0,60 and 120 minutes. Percentage EC was determined after 120 minutes by absorbance at 280 $\mathrm{nm}$ relative to $100 \mu \mathrm{MEC}$ at $\mathrm{t}=0$ (mean $\pm \mathrm{SD}, \mathrm{n}=4)$.
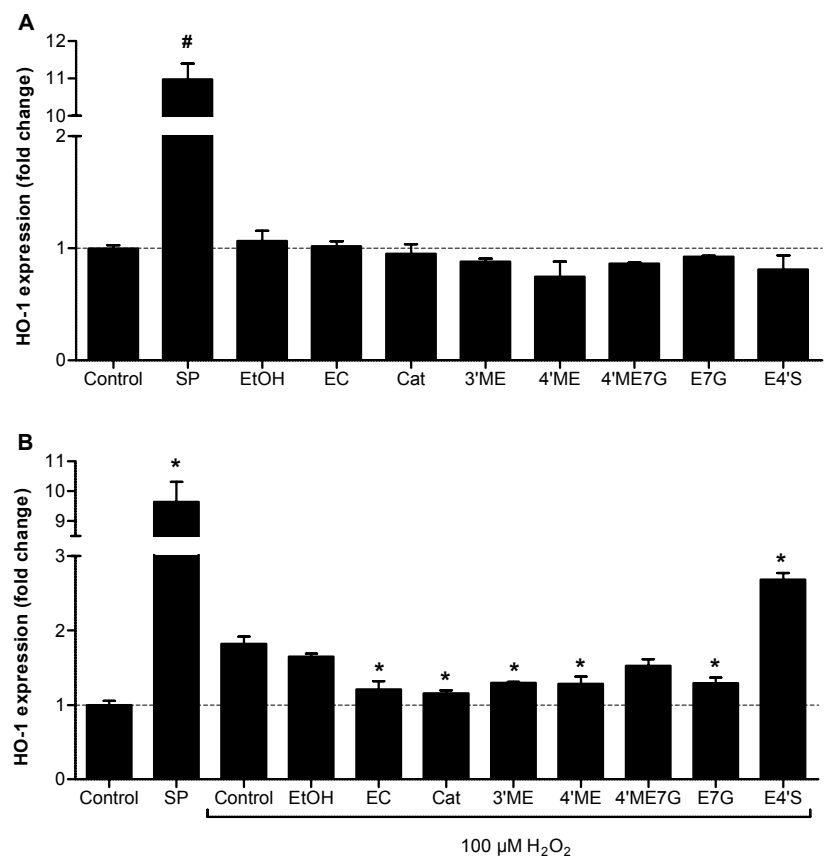

Figure 7. $\mathrm{HO}-1$ gene expression in HUVECs exposed to (A) $10 \mu \mathrm{M}$ flavanols or (B) $10 \mu \mathrm{M}$ flavanols and $100 \mu \mathrm{M} \mathrm{H}_{2} \mathrm{O}_{2}$ for 3 hours. Bars represent fold change ( $\left.2^{-\Delta \Delta C t}\right)$ compared to unexposed cells. $\beta$-actin was used as housekeeping gene, $10 \mu \mathrm{M}$ DL-sulforaphane (SP) as positive control and $1 \%$ ethanol as solvent control (mean $\pm S D, n=3, \# P<0.05$ vs. control ${ }^{*} p<0.05$ vs. control $+\mathrm{H}_{2} \mathrm{O}_{2}$ ). 


\section{Discussion}

Flavanols are potent antioxidants and their intake has been associated with improved cardiovascular health. To evaluate the possible contribution of their direct antioxidant activity to the suggested cardiovascular health benefit, we carefully determined the superoxide radical scavenging activity of flavanols and several human metabolites, as well as their intracellular antioxidant activity, in primary endothelial cells.

To induce oxidative stress in HUVECs we have chosen $\mathrm{H}_{2} \mathrm{O}_{2}$, which is relatively stable and thus enabled us to impose a reproducible oxidative stress upon the cells. $\mathrm{H}_{2} \mathrm{O}_{2}$ is a naturally occurring ROS which is constantly formed by endothelial cells through various enzymatic systems, e.g. via superoxide radicals formed by $\mathrm{NAD}(\mathrm{P}) \mathrm{H}$ oxidase (NOX) that dismutate to $\mathrm{H}_{2} \mathrm{O}_{2}$. Moreover, $\mathrm{H}_{2} \mathrm{O}_{2}$ can readily cross cell membranes and enter the cell through aquaporin channels [17]. Inside the cell, it activates a variety of redoxmediated signaling cascades by e.g. oxidation of critical thiol groups [18]. In addition, $\mathrm{H}_{2} \mathrm{O}_{2}$ is able to amplify ROS production through enhanced intracellular iron uptake, and activation of radical production by mitochondria, $N A D(P) H$ oxidase, xanthine oxidase and uncoupled eNOS $[7,19]$. The endogenous protection against oxidative stress is provided by enzymes such as peroxiredoxins, glutathione peroxidases, and catalase [20, 21]. When the production of ROS, such as $\mathrm{H}_{2} \mathrm{O}_{2}$, exceeds the capacity of these antioxidant defense systems, oxidative stress occurs. The concentration of $\mathrm{H}_{2} \mathrm{O}_{2}(100 \mu \mathrm{M})$ used in our experiments induced relatively mild oxidative stress within the cells without showing any signs of cell death.

In human vascular endothelial cells Cat and EC efficiently protected against the intracellular oxidative stress. Additionally, our results show that Cat and EC are potent scavengers of superoxide radicals. The catechol group in both molecules is generally regarded as the most important group for this activity [11]. The high scavenging activity substantiates the potential relevance of the direct antioxidant effect of Cat and EC.

In the debate on the biological activity of flavanols, the concentrations that can be reached in vivo are a major issue. Flavanols and metabolites are detected in the micromolar range in the digestive tract and in the nanomolar to low micromolar range in plasma. After oral ingestion, flavanols are rapidly metabolized in the small intestine and liver producing methoxylated, glucuronidated and sulfated compounds $[22,23]$. The peak concentration of flavanol metabolites is reached after approximately 2 hours, and they are eliminated after approximately 4 hours. A recent study, however, showed that E7G was measured in circulation for more than 10 hours after dark chocolate consumption [24]. Two studies showed that EC reaches plasma concentrations between 0.1 to $0.6 \mu \mathrm{M}$ after $2 \mathrm{~h}$ of 27 to 
80 gram dark chocolate consumption $[25,26]$. Holt et al. [27] even found that EC and Cat reached a peak concentration of $5.9 \mu \mathrm{M}$ and $0.16 \mu \mathrm{M}$ respectively in human plasma $2 \mathrm{~h}$ after ingestion of 20 to $30 \mathrm{~g}$ cocoa. Our data show protective effects of Cat and EC at a concentration as low as $0.5 \mu \mathrm{M}$, a level that apparently can be reached in human plasma after consumption of cocoa products. Similarly, in a recent review Fraga and Oteiza [28] argued that direct antioxidant activity of flavanols are of relevance in blood vessels and the digestive tract, since these tissues are exposed to relatively high concentrations of flavanols. Although a direct extrapolation of in vitro data into the pathophysiology of oxidative stress and cardiovascular diseases in humans remains difficult, our data suggest a beneficial effect of flavanols in these low micromolar concentrations.

Our results showed that the parent compounds EC and Cat have a superoxide radical scavenging activity superior to that of the metabolites. The 4'-sulfate metabolite showed superoxide radical scavenging activity that was approximately half of that of the parent compound. The reduction in scavenging activity can be explained by the substitution at one of the hydroxyl groups of the catechol moiety, reducing the scavenging activity of this moiety. Despite its still substantial scavenging activity, the 4'-sulfate provided no protection against intracellular oxidative stress. One of the effects of sulfation is that it renders molecules less lipid soluble which increases their renal excretion and prevents them to cross the cell membrane. The latter effect can explain the lack of protection of E4'S against intracellular oxidative stress.

Beside the 4'-sulfate, also the 7- $\beta$-D-glucuronide metabolite of EC was tested. E7G showed superoxide radical scavenging activity comparable with EC, which is probably due to the presence of a catechol moiety in both compounds. The glucuronyl moiety makes E7G very hydrophilic, preventing passive diffusion over cell membranes. Nevertheless, E7G added extracellularly did protect against intracellular oxidative stress. Possibly, this metabolite is taken up by a specific transporter or the glucuronyl moiety is removed by a $\beta$-glucuronidase. The presence of glucuronidase on endothelial cells has been reported [29] and flavonoid glucuronides are substrates for this enzyme [30].

Methylation generally makes compounds more lipophilic, improving their ability to cross cell membranes. However, as expected, O-methylation of the hydroxyl-groups of the catechol moiety drastically reduces the radical scavenging activity. Similar to our results, Duenas and colleagues [31] also noted that O-methylation decreased the antioxidant activity of EC compared to the parent compounds, but the methylated metabolites still retained some direct radical scavenging activity. Accordingly, our results showed that the methylated metabolites significantly decreased $\mathrm{H}_{2} \mathrm{O}_{2}$-induced oxidative stress levels 
in HUVECs. This protection was higher as expected from their relatively poor radical scavenging activity. Apparently, the protective effect of these methylated metabolites in the cells cannot only be explained by direct antioxidant activity.

The tested methylated flavanols have previously been shown to inhibit NADPH oxidase [14, 32]. One of these metabolites, 3'ME, has also been shown to prevent cell death induced by hydrogen peroxide. The mechanism involves suppression of caspase-3 activity [33]. Thus it is likely, that these or comparable indirect antioxidant activities might be involved in the observed protection against intracellular oxidative stress.

The protection against oxidative stress might also be achieved by inducing the innate antioxidant machinery via gene expression of the Nrf2 pathway. However, in our experiments neither Cat, EC nor their metabolites changed HO-1 gene expression, an important downstream target of the Nrf2 pathway, in non-stressed HUVECs at a concentration of $10 \mu \mathrm{M}$ after 3 hour exposure. Cat, EC and several metabolites did, however, attenuate the $\mathrm{H}_{2} \mathrm{O}_{2}$ induced $\mathrm{HO}-1$ expression. This decreased gene expression can be the result of decreased oxidative stress which further supports the hypothesis that EC-mediated reduction of intracellular oxidative stress may be achieved by direct radical scavenging. The E4'S metabolite increased HO-1 gene expression, indicative for a higher level of oxidative stress. This was confirmed in the DCFH assay in which the highest concentration $(10 \mu M)$ of this metabolite showed no inhibition of the $\mathrm{H}_{2} \mathrm{O}_{2}$ induced oxidative stress but rather a small increase.

In summary, our results show that Cat, EC and the tested glucuronidated and methylated metabolites protect primary endothelial cells against intracellular oxidative stress. The metabolites are likely to have a relevant contribution, but the mode of action of their protective effect is still not fully elucidated. Although the impact of the chemical reactivity and the observed cellular protection on cardiovascular health needs to be established, the present study substantiates that a direct antioxidant effect is involved in the intracellular defense against oxidative stress provided by EC and Cat. 
Epicatechin and its metabolites protect against oxidative stress 


\section{References}

1. Neveu V, Perez-Jimenez J, Vos F, Crespy V, du Chaffaut L, Mennen L, et al. Phenol-Explorer: an online comprehensive database on polyphenol contents in foods. Database (Oxford). 2010;2010:bap024.

2. Galleano M, Oteiza PI, Fraga CG. Cocoa, chocolate, and cardiovascular disease. J Cardiovasc Pharmacol. 2009;54:483-90.

3. Buijsse B, Weikert C, Drogan D, Bergmann M, Boeing H. Chocolate consumption in relation to blood pressure and risk of cardiovascular disease in German adults. Eur Heart J. 2010.

4. Corti R, Flammer AJ, Hollenberg NK, Luscher TF. Cocoa and cardiovascular health. Circulation. 2009;119:1433-41.

5. Arts IC, van De Putte B, Hollman PC. Catechin contents of foods commonly consumed in The Netherlands. 2. Tea, wine, fruit juices, and chocolate milk. J Agric Food Chem. 2000;48:1752-7.

6. Mikkelsen RB, Wardman P. Biological chemistry of reactive oxygen and nitrogen and radiation-induced signal transduction mechanisms. Oncogene. 2003;22:5734-54.

7. Cai H. Hydrogen peroxide regulation of endothelial function: origins, mechanisms, and consequences. Cardiovasc Res. 2005;68:26-36.

8. Weseler AR, Bast A. Oxidative stress and vascular function: implications for pharmacologic treatments. Curr Hypertens Rep. 2010;12:154-61.

9. Spencer JP, Schroeter H, Rechner AR, Rice-Evans C. Bioavailability of flavan-3-ols and procyanidins: gastrointestinal tract influences and their relevance to bioactive forms in vivo. Antioxid Redox Signal. 2001;3:1023-39.

10. Scalbert A, Williamson G. Dietary intake and bioavailability of polyphenols. J Nutr. 2000;130:2073S-85S.

11. Heim KE, Tagliaferro AR, Bobilya DJ. Flavonoid antioxidants: chemistry, metabolism and structure-activity relationships. J Nutr Biochem. 2002;13:572-84.

12. Martin MA, Serrano AB, Ramos S, Pulido MI, Bravo L, Goya L. Cocoa flavonoids up-regulate antioxidant enzyme activity via the ERK1/2 pathway to protect against oxidative stress-induced apoptosis in HepG2 cells. J Nutr Biochem. 2010;21:196-205.

13. Monagas M, Khan N, Andres-Lacueva C, Casas R, Urpi-Sarda M, Llorach R, et al. Effect of cocoa powder on the modulation of inflammatory biomarkers in patients at high risk of cardiovascular disease. Am J Clin Nutr. 2009;90:1144-50.

14. Steffen Y, Gruber C, Schewe T, Sies H. Mono-O-methylated flavanols and other flavonoids as inhibitors of endothelial NADPH oxidase. Arch Biochem Biophys. 2008;469:209-19.

15. Peshavariya HM, Dusting GJ, Selemidis S. Analysis of dihydroethidium fluorescence for the detection of intracellular and extracellular superoxide produced by NADPH oxidase. Free Radic Res. 2007;41:699-712.

16. Wang $\mathrm{H}$, Joseph JA. Quantifying cellular oxidative stress by dichlorofluorescein assay using microplate reader. Free Radic Biol Med. 1999;27:612-6.

17. Miller EW, Dickinson BC, Chang CJ. Aquaporin-3 mediates hydrogen peroxide uptake to regulate downstream intracellular signaling. Proc Natl Acad Sci U S A. 2010;107:15681-6.

18. Forman HJ, Fukuto JM, Torres M. Redox signaling: thiol chemistry defines which reactive oxygen and nitrogen species can act as second messengers. Am J Physiol Cell Physiol. 2004;287:C246-56.

19. Li WM, Liu HT, Li XY, Wu JY, Xu G, Teng YZ, et al. The effect of tetramethylpyrazine on hydrogen peroxideinduced oxidative damage in human umbilical vein endothelial cells. Basic Clin Pharmacol Toxicol. 2009;106:45-52.

20. Fisher AB. Redox signaling across cell membranes. Antioxid Redox Signal. 2009;11:1349-56.

21. Alia M, Ramos S, Mateos R, Bravo L, Goya L. Response of the antioxidant defense system to tert-butyl hydroperoxide and hydrogen peroxide in a human hepatoma cell line (HepG2). J Biochem Mol Toxicol. 2005;19:119-28.

22. Natsume M, Osakabe N, Oyama M, Sasaki M, Baba S, Nakamura Y, et al. Structures of (-)-epicatechin 
glucuronide identified from plasma and urine after oral ingestion of (-)-epicatechin: differences between human and rat. Free Radic Biol Med. 2003;34:840-9.

23. Schroeter $\mathrm{H}$, Heiss $\mathrm{C}$, Balzer J, Kleinbongard $\mathrm{P}$, Keen $\mathrm{CL}$, Hollenberg NK, et al. (-)-Epicatechin mediates beneficial effects of flavanol-rich cocoa on vascular function in humans. Proc Natl Acad Sci U S A. 2006;103:1024-9.

24. Actis-Goretta L, Leveques A, Giuffrida F, Romanov-Michailidis F, Viton F, Barron D, et al. Elucidation of (-)-epicatechin metabolites after ingestion of chocolate by healthy humans. Free Radic Biol Med. 2012;53:787-95.

25. Rein D, Lotito S, Holt RR, Keen CL, SchmitzHH, Fraga CG. Epicatechin in human plasma: in vivo determination and effect of chocolate consumption on plasma oxidation status. J Nutr. 2000;130:2109S-14S.

26. Wang JF, Schramm DD, Holt RR, Ensunsa JL, Fraga CG, Schmitz HH, et al. A dose-response effect from chocolate consumption on plasma epicatechin and oxidative damage. J Nutr. 2000;130:2115S-9S.

27. Holt RR, Lazarus SA, Sullards MC, Zhu QY, Schramm DD, Hammerstone JF, et al. Procyanidin dimer B2 [epicatechin-(4beta-8)-epicatechin] in human plasma after the consumption of a flavanol-rich cocoa. Am J Clin Nutr. 2002;76:798-804.

28. Fraga CG, Oteiza PI. Dietary flavonoids: Role of (-)-epicatechin and related procyanidins in cell signaling. Free Radic Biol Med. 2011;51:813-23.

29. Halle W, Hecker D. [Histochemical demonstration of beta-glucuronidase and leucine aminopeptidase in cultivated aortic endothelial cells (author's transl)]. Acta Histochem. 1981;68:188-92.

30. Bartholome R, Haenen G, Hollman CH, Bast A, Dagnelie PC, Roos D, et al. Deconjugation kinetics of glucuronidated phase II flavonoid metabolites by beta-glucuronidase from neutrophils. Drug Metab Pharmacokinet. 2010;25:379-87.

31. Duenas M, Gonzalez-Manzano S, Gonzalez-Paramas A, Santos-Buelga C. Antioxidant evaluation of O-methylated metabolites of catechin, epicatechin and quercetin. J Pharm Biomed Anal. 2010;51:443-9.

32. Steffen Y, Schewe T, Sies H. (-)-Epicatechin elevates nitric oxide in endothelial cells via inhibition of NADPH oxidase. Biochem Biophys Res Commun. 2007;359:828-33.

33. Spencer JP, Schroeter H, Kuhnle G, Srai SK, Tyrrell RM, Hahn U, et al. Epicatechin and its in vivo metabolite, 3'-O-methyl epicatechin, protect human fibroblasts from oxidative-stress-induced cell death involving caspase-3 activation. Biochem J. 2001;354:493-500. 



\section{Chapter 3}

The cocoa flavanol (-)-epicatechin protects the cortisol response

Erik J.B. Ruijters

Guido R.M.M. Haenen

Antje R. Weseler

Aalt Bast.

Pharmacological Research, 2014, 79:28-33 


\section{Abstract}

Various health benefits of the cocoa flavanol (-)-epicatechin (EC) have been attributed to its antioxidant and anti-inflammatory potency. In the present study we investigated whether EC is able to prevent deterioration of the anti-inflammatory effect of the glucocorticoid (GC) cortisol in the presence of oxidative stress.

It was found that cortisol reduces inflammation in differentiated monocytes. Oxidative stress extinguishes the anti-inflammatory effect of cortisol, leading to cortisol resistance. EC reduces intracellular oxidative stress as well as the development of cortisol resistance. This further deciphers the enigmatic mechanism of EC by which it exerts its anti-inflammatory and antioxidant action.

The observed effect of the cocoa flavanol EC will especially be of relevance in pathophysiological conditions with increased oxidative stress and consequential GC resistance and provides a fundament for the rational use of dietary antioxidants. 


\section{Introduction}

Flavanols are a group of flavonoids abundant in foods (e.g. apples and cocoa beans) and beverages (e.g. tea and wine). These flavanols are known to display anti-inflammatory as well as antioxidant effects and their intake is associated with beneficial health effects $[1,2]$. While the antioxidant effect is well documented, the mechanism of the antiinflammatory effect is enigmatic.

Inflammation is a vital process to maintain tissue in a healthy condition and to fight off infections. During this process, monocytes are attracted to the site of inflammation, transformed into macrophages and an array of inflammatory mediators, such as the cytokines tumor necrosis factor alpha (TNF- $\alpha$ ) and interleukin-1 $\beta$ (IL-1 $\beta$ ) and the chemokine interleukin-8 (IL-8), is produced [3-5]. These mediators further fuel inflammation by attracting more inflammatory cells and inducing the production of more inflammatory mediators. This feed-forward process is prone to overreact and progress into an unbalanced inflammatory pathological condition as seen in rheumatoid arthritis, inflammatory bowel disease, and chronic obstructive pulmonary disease (COPD).

Reactive oxygen species (ROS) play a role in signal transduction and are also produced during inflammation e.g. to kill microorganisms. Unbalanced levels of ROS, however, cause oxidative stress which induces tissue damage, accelerated aging, lipid peroxidation and impairment of various cellular functions [6]. Oxidative stress can also trigger the immune response via the NF-KB pathway and activator protein-1 (AP1) resulting in the production of pro-inflammatory cytokines [7]. In particular the lungs are exposed to various oxidants and pollutants, especially when smoking, leading to even higher levels of inflammation and oxidative stress, which may develop into COPD [5].

Inflammation can be mitigated by glucocorticoids (GCs). The endogenous GC cortisol is produced by the adrenal gland and binds to the glucocorticoid receptor (GR). The cortisol-GR complex translocates to the nucleus, where it activates the transcription of anti-inflammatory genes and suppresses pro-inflammatory gene transcription [8, 9]. In COPD and patients with severe asthma, the anti-inflammatory potency of GCs is often drastically reduced. This is known as GC resistance, which aggravates the level of inflammation and bears major clinical implications [10]. One of the clinical features of COPD is the occurrence of oxidative stress, which is best evidenced by the high levels of ROS in exhaled air [11, 12]. Moreover, oxidative stress is known to impair receptor function $[13,14]$.

In the present study we investigated if (-)-epicatechin (EC) is able to prevent the decline of the anti-inflammatory cortisol action induced by oxidative stress in human 
monocytes. The ability of epicatechin to preserve the endogenous GC response of cortisol links its antioxidant activity with its anti-inflammatory properties.

\section{Materials and methods}

\section{Chemicals}

Phorbol 12-myristate 13-acetate (PMA), cortisol, lipopolysaccharides (LPS), 2',7'-dichlorofluorescein-diacetate (DCFH-DA), sulforhodamine B (SRB), pyruvate, nicotinamide adenine dinucleotide (NADH), 2,4-dinitrophenylhydrazine (DNPH) and trichloric acid (TCA) were purchased from Sigma (St. Louis, MO, USA) and (-)-epicatechin (EC) was purchased from Extrasynthese (Genay, France). 7-Mono-O-( $\beta$-hydroxyethyl)rutoside (monoHER) was kindly provided by Novartis Consumer Health (Nyon, Switzerland). Roswell Park Memorial Institute 1640 (RPMI 1640) medium, fetal calf serum (FCS), phosphate buffered saline (PBS), penicillin, and streptomycin were obtained from Gibco (Life Technologies, Carlsbad, CA, USA).

\section{Cell culture}

The human monocyte cell line U937 (LGC standards, Teddington, UK) was cultured in RPMI 1640 medium supplemented with 10\% FCS, $50 \mathrm{U} / \mathrm{ml}$ penicillin and $50 \mu \mathrm{g} / \mathrm{ml}$ streptomycin in a humidified atmosphere with $5 \% \mathrm{CO}_{2}$ at $37^{\circ} \mathrm{C}$. Before exposure, cells were differentiated to macrophage like cells using $50 \mathrm{ng} / \mathrm{ml}$ PMA treatment for 4 hours. After incubation, cells were plated in a 24 -well plate $\left(4 \times 10^{5}\right.$ cells/well) and allowed to differentiate for $48 \mathrm{~h}$. Medium was changed to $1 \%$ FCS for a further overnight incubation. Cells were washed with PBS and all exposures were performed in medium without FCS. Cell viability was determined after each experiment.

\section{Cell viability}

To investigate the potential cytotoxic effect of the exposures, LDH leakage was measured in the medium and the amount of cell protein was determined. Twenty $\mu$ l of medium was transferred to a 96-well plate to measure lactate dehydrogenase (LDH) activity. Fifty $\mu$ l of $10 \mathrm{mg} / \mathrm{ml} \mathrm{NADH}$ in $0.75 \mathrm{mM}$ sodium pyruvate was added to the medium and incubated for $30 \mathrm{~min}$ at $37^{\circ} \mathrm{C}$. To determine the remaining amount of pyruvate, $50 \mu \mathrm{l} 0.2 \mathrm{mg} / \mathrm{ml}$ DNPH was added to the wells and incubated at room temperature in the dark for $20 \mathrm{~min}$. To develop the color, $50 \mu \mathrm{l} 4 \mathrm{M} \mathrm{NaOH}$ was added and absorbance was measured after 5 
min at $\lambda=540 \mathrm{~nm}$ using a Spectramax plate reader (Molecular Devices, Sunnyvale, CA, USA) and the LDH activity was quantified by using a range of standards.

Cell amount was determined using the SRB assay [15]. Cells were washed and fixed with $7 \%(\mathrm{~m} / \mathrm{V})$ TCA for $1 \mathrm{~h}$ at $4^{\circ} \mathrm{C}$. After 5 wash steps with water, cells were stained with SRB $(0.057 \%(\mathrm{~m} / \mathrm{V})$ for $20 \mathrm{~min}$ at room temperature. Cells were washed with $1 \%(\mathrm{~V} / \mathrm{V})$ acetic acid to remove unbound SRB and the SRB bound to cells was dissolved in $0.8 \mathrm{ml}$ TRIS buffer (10 mM, pH 10.5) and quantified by measuring absorbance at $\lambda=540 \mathrm{~nm}$. Viability was calculated relative to unexposed cells (100\% viability) and cells exposed to $0.1 \%(\mathrm{~V} / \mathrm{V})$ triton $\mathrm{X}-100$ (0\% viability).

\section{Inflammation}

Oxidative stress was induced for $1 \mathrm{~h}$ by incubating differentiated monocytes with $\mathrm{H}_{2} \mathrm{O}_{2}$ ( 3 pmol/cell, which equals the amount of $\mathrm{H}_{2} \mathrm{O}_{2}$ epithelial lung cells are exposed to, based on the concentration found in the exhaled air in COPD patients [12]). EC (1, 10 and $50 \mu \mathrm{M})$ or monoHER $(10 \mu \mathrm{M})$ was added during the incubation with $\mathrm{H}_{2} \mathrm{O}_{2}$. Control experiments demonstrated that there is no direct reaction between $\mathrm{EC}$ and $\mathrm{H}_{2} \mathrm{O}_{2}$ [2]. Cells were washed with PBS and incubated with LPS (1 ng/ml) +/- cortisol (100 nM, unless otherwise stated) for $16 \mathrm{~h}$. The cytokine concentrations in the medium were measured using a commercially available ELISA kit (Sanquin, Amsterdam, Netherlands) according to manufacturer's protocol.

\section{Intracellular oxidative stress}

The fluorescent probe of $2^{\prime}, 7^{\prime}$-dichlorofluorescein-diacetate (DCFH-DA) was used to quantify intracellular oxidative stress in differentiated monocytes. In the presence of ROS, the non-fluorescent DCFH is oxidized to the highly fluorescent dichlorofluorescein (DCF). The intensity of DCF fluorescence corresponds to the level of intracellular ROS formation. Cells were differentiated in a black/clear bottom 96-well plate and grown for 72 h. Fifty micromoles DCFH-DA was added to the cells and incubated for $30 \mathrm{~min}$. at $37^{\circ} \mathrm{C}, 5 \% \mathrm{CO}_{2}$. After washing, cells were exposed to $100 \mu$ l serum-free medium containing $\mathrm{H}_{2} \mathrm{O}_{2}+/-\mathrm{EC}$ or monoHER and DCF fluorescence was measured with excitation and emission wavelengths of $485 \mathrm{~nm}$ and $535 \mathrm{~nm}$, respectively, at $37^{\circ} \mathrm{C}$ over a period of $60 \mathrm{~min}$. Incubating cells with LPS (1 ng/ml) did not produce a significant increase in oxidative stress (data not shown). 


\section{Statistics}

Data are expressed as mean \pm SD or mean \pm SEM $(n=3-12)$. Statistical comparisons were performed using one-way ANOVA with Bonferoni post hoc test with Prism v5 (GraphPad Software, San Diego, CA, USA). P $<0.05$ was considered statistically significant.

\section{Results}

\section{The anti-inflammatory effect of cortisol}

First, the anti-inflammatory potential of cortisol was determined in monocytes differentiated to macrophages. The inflammatory response was induced by adding LPS (1 $\mathrm{ng} / \mathrm{ml}$ ) to the cells and quantified by measuring the concentration of IL- 8 and TNF- $\alpha$ in the medium. Cortisol efficiently repressed the IL-8 and TNF-a production in a concentration dependent manner (figure 1). At a concentration of $100 \mathrm{nM}$, cortisol completely inhibited the LPS response.

\section{Oxidative stress induces GC resistance}

The cells were subjected to oxidative stress before the anti-inflammatory effect of cortisol was assessed. It was found that oxidative stress reduced the anti-inflammatory potency of cortisol over the entire concentration range tested (1 - $300 \mathrm{nM})$. Hundred nanomolar of cortisol only partially reduced the LPS induced IL-8 release (52\%) after oxidative stress, while in the control experiment, without oxidative stress, the same concentration of cortisol fully blocked the pro-inflammatory LPS response (figure $1 \mathrm{~A}$ ). Without oxidative stress, $30 \mathrm{nM}$ cortisol completely inhibited TNF-a release. When oxidative stress was induced, $30 \mathrm{nM}$ cortisol only partially inhibited TNF-a production (53\%, figure 1B). These results indicate that oxidative stress impaired the GC response.

\section{(-)-Epicatechin prevents GC resistance}

To investigate the ability of flavanols to protect the anti-inflammatory response of cortisol against oxidative stress, EC $(0,1,10$ and $50 \mu \mathrm{M})$ was added to the cells during the pre-incubation with $\mathrm{H}_{2} \mathrm{O}_{2}$. EC at a concentration of $1 \mu \mathrm{M}$ partially protected against $\mathrm{GC}$ resistance. Fifty micromolar EC completely inhibited $\mathrm{H}_{2} \mathrm{O}_{2}$ induced $\mathrm{GC}$ resistance and reduced the IL-8 production to control level (figure $2 \mathrm{~A}$ ). A concentration of $1 \mu \mathrm{M} \mathrm{EC}$ reduced the TNF-a concentration back to control level without oxidative stress (figure $2 \mathrm{~B}$ ). Fifty micromolar of EC completely restored the cortisol response, as evidenced by the IL- 8 
and TNF-a release (figure 2 C). EC (50 $\mu \mathrm{M})$ itself had no effect on the LPS induced IL-8 and TNF-a production in control cells (data not shown).

A

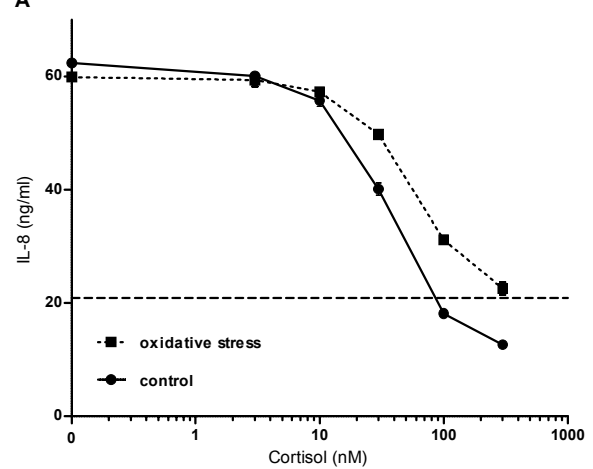

B

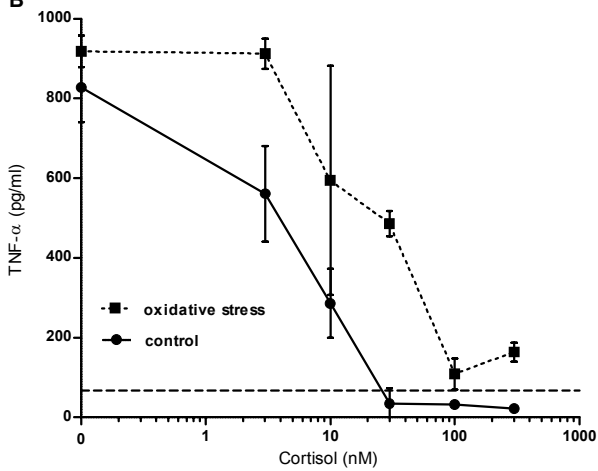

Figure 1. The anti-inflammatory effect of cortisol in control cells and cells subjected to oxidative stress. Differentiated monocytes were pre-incubated $1 \mathrm{~h}$ without (control) or with (oxidative stress) $\mathrm{H}_{2} \mathrm{O}_{2}(1 \mathrm{pmol} / \mathrm{cell})$ followed by $16 \mathrm{~h}$ exposure to LPS $(1 \mathrm{ng} / \mathrm{ml})$ and various concentrations of cortisol. Cell medium was collected and the pro-inflammatory cytokines IL-8 (A) and TNF- $a$ (B) were quantified (mean $\pm S D, N=3$ ). The horizontal dashed line represents the background level of IL-8 or TNF-a in cells without LPS or cortisol $(21 \pm 1.4 \mathrm{ng} / \mathrm{ml}$ and $67 \pm 25 \mathrm{pg} / \mathrm{ml}$ respectively).

\section{(-)-Epicatechin reduces intracellular oxidative stress}

In order to confirm the antioxidant activity of EC, the intracellular oxidative stress levels were assessed using the DCFH assay. Differentiated cells were loaded with the fluorescent probe DCFH-DA and then incubated with $\mathrm{H}_{2} \mathrm{O}_{2}+/-$ EC for $1 \mathrm{~h}$. The DCF fluorescence provides a measure for intracellular oxidative stress. EC completely reduced intracellular oxidative stress at a concentration of $1 \mu \mathrm{M}$, at a concentration of $50 \mu \mathrm{M}$ it even dropped below background levels (figure 2D).

\section{Cell viability}

Cell viability was assessed using the LDH and SRB assays at the end of the experiments. Exposing the cells to $\mathrm{H}_{2} \mathrm{O}_{2}$ and LPS under the used conditions did not result in increased $\mathrm{LDH}$ leakage or reduced amount of adherent cells (figure 3 ). This indicates that the treatments did not induce cell death. 


\section{MonoHER protects against GC resistance.}

To confirm the protective effects of flavonoids we tested the semi-synthetic flavonoid monoHER. MonoHER (10 $\mu \mathrm{M})$ completely attenuated the intracellular oxidative stress in the DCFH assay. Similar to EC, monoHER was able to preserve the GC response as depicted by a reduced IL-8 production (figure 4).
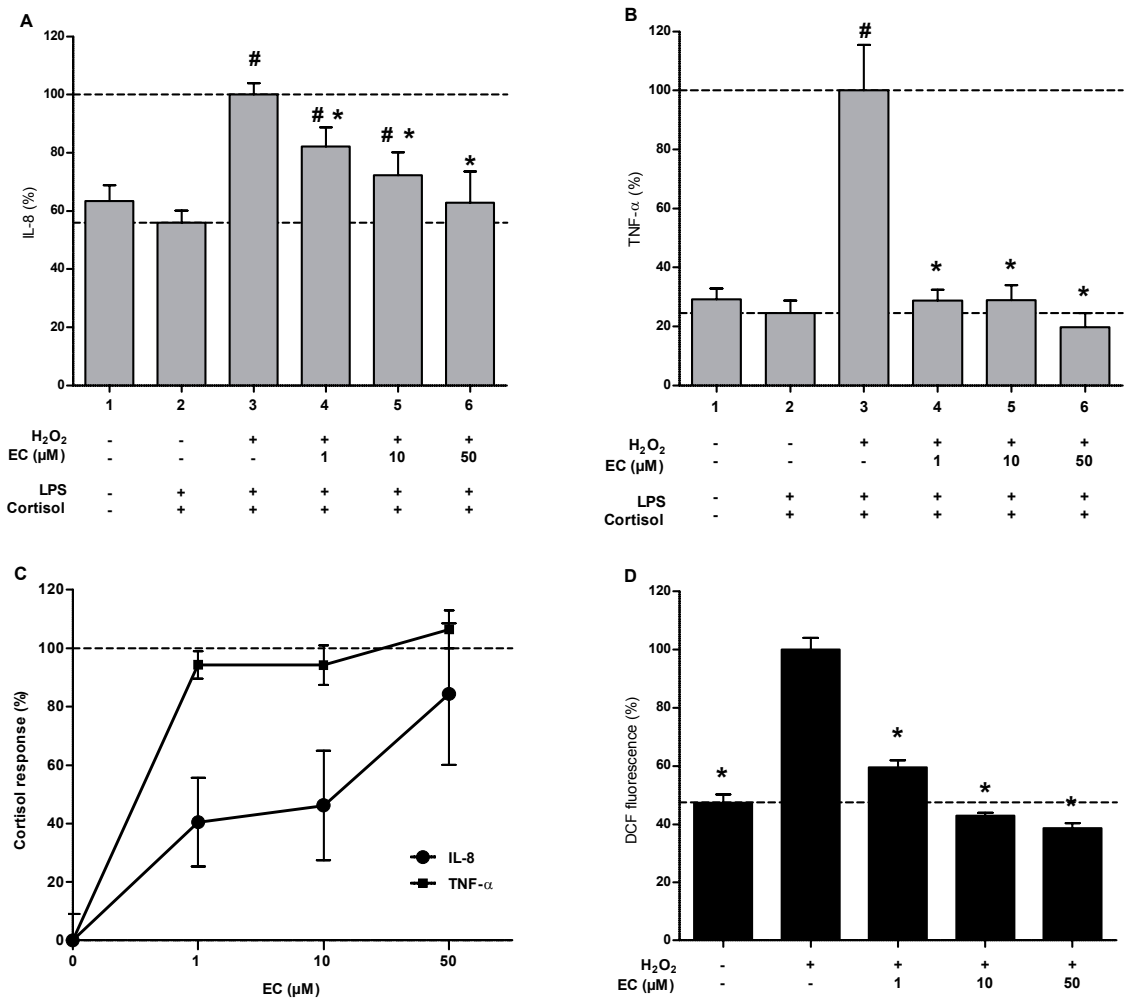

Figure 2. Prevention of oxidative stress-induced GC resistance by EC. Differentiated monocytes were pre-incubated with $\mathrm{H}_{2} \mathrm{O}_{2}(1 \mathrm{pmol} / \mathrm{cell})+/-\mathrm{EC}$ (concentration indicated in the graph) for $1 \mathrm{~h}$. Subsequently the cells were exposed to LPS $(1 \mathrm{ng} / \mathrm{ml})+/$ - cortisol $(100 \mathrm{nM})$ for $16 \mathrm{~h}$. Relative IL-8 (A) and TNF-a (B) concentrations (\%) in the medium were related to the control without EC (mean \pm $\mathrm{SEM}, \mathrm{N}=12, \# \mathrm{p}<0.05$ compared to column $2,{ }^{*} \mathrm{p}<0.05$ compared to column 3 ). The incubation with only LPS gave a relative increase in IL-8 concentration of $179 \pm 57 \%$ and pre-incubation with $50 \mu \mathrm{M}$ EC had no significant effect on this production ( $170 \pm 12 \%$, data not shown). (C) Concentrationdependent protection of the cortisol response by EC in cells subjected to oxidative stress (mean $\pm \mathrm{SEM}, \mathrm{N}=12$ ). (D) Reduction of intracellular oxidative stress by $\mathrm{EC}$. Differentiated monocytes were pre-incubated with DCFH-DA to allow the fluorescent probe to enter the cells. Cells were then exposed to $\mathrm{H}_{2} \mathrm{O}_{2}(1 \mathrm{pmol} / \mathrm{cell})+/$ - EC (concentration indicated in the graph) and fluorescence was measured after $60 \mathrm{~min}$. Data represent relative DCF fluorescence (\%) related to $\mathrm{H}_{2} \mathrm{O}_{2}$ exposure without EC (mean $\pm \mathrm{SD}, \mathrm{N}=8,{ }^{*} \mathrm{p}<0.05$ compared to $\mathrm{H}_{2} \mathrm{O}_{2}$ exposed cells). 

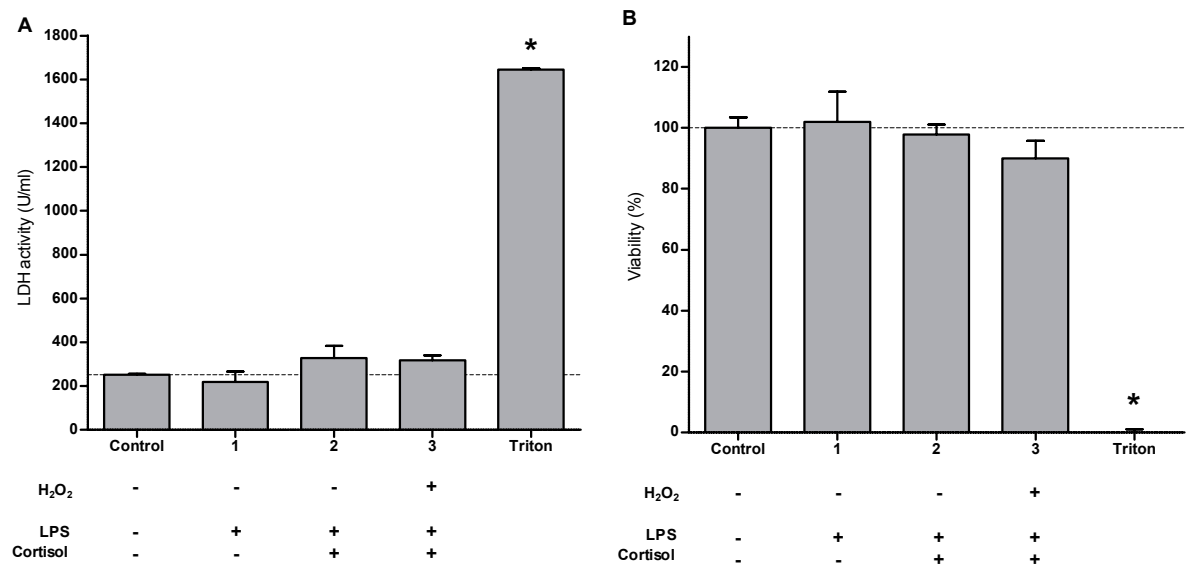

Figure 3. Cytotoxicity induced by $\mathrm{H}_{2} \mathrm{O}_{2}$ LPS and cortisol. Cytotoxicity was determined as LDH leakage to the medium $(A)$ and viability assessed by measuring total protein content $(B)$ relative to unexposed cells (100\%) (mean $\pm S D, N=4,{ }^{*} p<0.05$ compared to control).

A

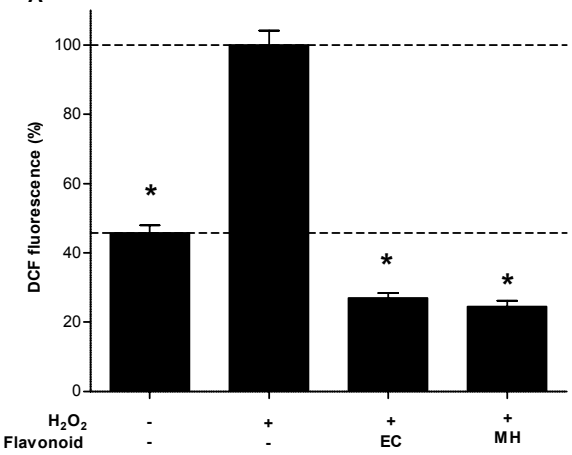

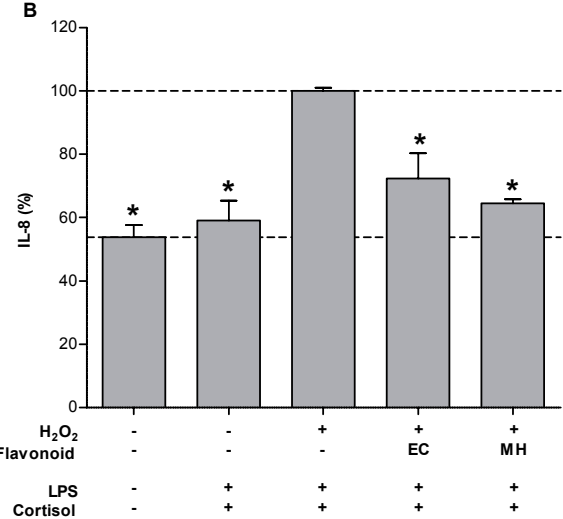

Figure 4. Protective effect of flavonoids (-)-epicatechin (EC) and monoHER (MH) against $\mathrm{H}_{2} \mathrm{O}_{2}$ induced oxidative stress and GC resistance. (A) Intracellular oxidative stress levels were determined using the DCFH assay. Cells were exposed to $\mathrm{H}_{2} \mathrm{O}_{2}(1 \mathrm{pmol} / \mathrm{cell})+/-$ flavonoid $(10 \mu \mathrm{M})$ and fluorescence measured after 60 minutes. Data represent relative DCF fluorescence (\%) compared to $\mathrm{H}_{2} \mathrm{O}_{2}$ exposure (mean $\pm \mathrm{SD}, \mathrm{N}=8$ ). (B) Differentiated monocytes were pre-incubated with $\mathrm{H}_{2} \mathrm{O}_{2}$ $(1 \mathrm{pmol} /$ cell $)+/$ - flavonoids $(10 \mu \mathrm{M})$ for $1 \mathrm{~h}$. Subsequently the cells were exposed to LPS $(1 \mathrm{ng} /$ $\mathrm{ml})+/$ - cortisol (100 nM) for $16 \mathrm{~h}$. Relative IL-8 concentration (\%) were determined in the medium compared to $\mathrm{H}_{2} \mathrm{O}_{2}$ pre-exposure without flavonoids (mean \pm SEM, N=6, ${ }^{*} \mathrm{p}<0.05$ compared to $\mathrm{H}_{2} \mathrm{O}_{2}$ exposed cells). 


\section{Discussion}

The endogenous GC cortisol reduces inflammation in differentiated monocytes. Oxidative stress extinguishes this anti-inflammatory effect of cortisol, leading to cortisol resistance. We show that the cocoa flavanol EC prevents this cortisol resistance and reduces intracellular oxidative stress.

Various health benefits of flavonoids, including EC, have been attributed to their antioxidant potency. In first instance their direct antioxidant effect was primarily considered. The effectiveness of this direct antioxidant activity has extensively been documented [2], and is confirmed in the present study. In addition, indirect antioxidant effects of flavonoids have been established that include the inhibition of radicalgenerating processes like the Fenton reaction trough iron chelation, the induction of antioxidant enzymes and possibly also epigenetic effects [16]. Moreover, antioxidant flavonoids do not act in isolation but cooperate with other antioxidants in an intricate network. For example, flavonoids can be recycled after scavenging by vitamin $\mathrm{C}$ or react with glutathione $[17,18]$ and some flavonoids can take over the antioxidant activity of vitamin E [19]. Especially the interaction with the endogenous antioxidant system will increase the ability of the body to adapt when homeostasis is challenged. It appears that flavonoids display multifarious modes of action and their additive and synergistic cooperation with endogenous compounds and defense systems [20] has upgraded them to bioactives rather than just antioxidants.

Another dimension of the pleotropic effect of flavonoids is their anti-inflammatory potential [21]. One of the mechanisms involved is prevention of the activation of the pro-inflammatory transcription factor NF-KB by ROS [7, 22]. In the present study no significant direct anti-inflammatory effect of $\mathrm{EC}$ is seen. The present study shows that also in their anti-inflammatory activity flavonoids do not act in isolation, and describes the cooperation of EC with the endogenous GC cortisol. Cortisol is produced by the body to mitigate inflammatory conditions. However, in diseases like COPD, ROS production is pronounced and GC resistance is known to develop in which the GCs fail to be efficacious. Consequently, the ability to cope with inflammatory triggers is greatly reduced. This bears major clinical implications and up to date no effective therapy for COPD has been developed [8-10]. By restoring pathways modulated by oxidative stress, compounds like theophylline and curcumin are able to reverse GC resistance [23, 24].

The present study demonstrates the potential synergy of EC with cortisol. Reduction of oxidative stress, and in this way protection of the cortisol response, appears to be a promising strategy to overcome $\mathrm{GC}$ resistance in patients [25]. This is further strengthened 
by the association of a high intake of antioxidants, like $\mathrm{N}$-acetyl cysteine [26-28] or vitamin $C$, with a reduction in the frequency of exacerbations and attenuated progression as well as a decrease in $\mathrm{H}_{2} \mathrm{O}_{2}$ exhalation in COPD [29]. This would imply that the antiinflammatory effect of flavonoids, such as EC, is directly linked to their anti-oxidant effect. This is corroborated by the result of monoHER, which efficiently protects monocytes from intracellular oxidative stress. Since it was previously shown that the ability to chelate iron contributes to the antioxidant effects of monoHER $[30,31]$, it is likely that in our model this mechanism is involved in the observed preservation of the cortisol response.

An anti-inflammatory effect of flavonoids is supported by a recent meta-analysis showing that flavonoids of various dietary sources reduce plasma levels of TNF-a and IL-6 [32]. Moreover, short-term intake of cocoa and green tea flavanols is reported to reduce the levels of 8-isoprostane, a marker for oxidative stress, and IL-6 [33]. In contrast, other studies failed to demonstrate similar effects [34,35], and the health benefits of antioxidant flavonoids are still debated [20].

It should be noted that studies are often performed in healthy volunteers with an adequate antioxidant shield and therefore the absence of oxidative stress. Evidently, a clear-cut effect of antioxidants is lacking in this population. A beneficial effect of flavonoids is expected in people suffering from a condition associated with oxidative stress $[7,21,36]$. Indeed, a positive correlation has been found between the severity of oxidative damage and inflammation and the beneficial effect of antioxidant flavonoid supplementation [7, 37]. Similarly, EC will display a health benefit when it can preserve and retain the ability of cortisol to cope with pro-inflammatory triggers and prevent overreactive inflammatory processes.

Our findings fit into the contemporary perception of health as being dynamic and defined as the ability to adapt to changes, rather than a static state of perfection. In this dynamic concept of health, a bioactive compound has a multitude of effects. Accumulation of these effects empower the buffering capacity of the body to maintain homeostasis and to prevent relatively mild but nevertheless insidious and persistent perturbations which may gradually progress into severe pathological conditions $[20,38$, 39]. The antioxidant activity of EC results in an indirect anti-inflammatory effect. More specifically, oxidative stress impairs the GC response, and preservation of the GC response by EC will result in an indirect anti-inflammatory effect. This progressively deciphers the enigmatic anti-inflammatory activity of the flavanol EC, and provides a fundament for the use of dietary antioxidants. 


\section{References}

1. Monagas M, Khan N, Andres-Lacueva C, Casas R, Urpi-Sarda M, Llorach R, et al. Effect of cocoa powder on the modulation of inflammatory biomarkers in patients at high risk of cardiovascular disease. Am J Clin Nutr. 2009;90:1144-50.

2. Ruijters EJ, Weseler AR, Kicken C, Haenen GR, Bast A. The flavanol (-)-epicatechin and its metabolites protect against oxidative stress in primary endothelial cells via a direct antioxidant effect. Eur J Pharmacol. 2013;715:147-53.

3. Chung KF. Cytokines in chronic obstructive pulmonary disease. The European respiratory journal Supplement. 2001;34:50s-9s.

4. Rickard AJ, Young MJ. Corticosteroid receptors, macrophages and cardiovascular disease. J Mol Endocrinol. 2009;42:449-59.

5. Bhatt SP, Dransfield MT. AECOPD: Acute Exacerbations of Chronic Obstructive Cardiopulmonary Disease? Am J Respir Crit Care Med. 2013;188:1046-8.

6. Roche N, Marthan R, Berger P, Chambellan A, Chanez P, Aguilaniu B, et al. Beyond corticosteroids: future prospects in the management of inflammation in COPD. Eur Respir Rev. 2011;20:175-82.

7. Boots AW, Haenen GR, Bast A. Health effects of quercetin: from antioxidant to nutraceutical. Eur J Pharmacol. 2008;585:325-37.

8. Whitehouse MW. Anti-inflammatory glucocorticoid drugs: reflections after 60 years. Inflammopharmacology. 2011;19:1-19.

9. Adcock IM, Barnes PJ. Molecular mechanisms of corticosteroid resistance. Chest. 2008;134:394-401.

10. Barnes PJ. Corticosteroid resistance in patients with asthma and chronic obstructive pulmonary disease. J Allergy Clin Immunol. 2013;131:636-45.

11. Ito K, Hanazawa T, Tomita K, Barnes PJ, Adcock IM. Oxidative stress reduces histone deacetylase 2 activity and enhances IL-8 gene expression: role of tyrosine nitration. Biochem Biophys Res Commun. 2004;315:240-5.

12. Dekhuijzen PN, Aben KK, Dekker I, Aarts LP, Wielders PL, van Herwaarden CL, et al. Increased exhalation of hydrogen peroxide in patients with stable and unstable chronic obstructive pulmonary disease. Am J Respir Crit Care Med. 1996;154:813-6.

13. Doelman CJ, Bast A. Oxygen radicals in lung pathology. Free Radic Biol Med. 1990;9:381-400.

14. Van der Vliet A, Bast A. Effect of oxidative stress on receptors and signal transmission. Chem Biol Interact. 1992;85:95-116.

15. Vichai V, Kirtikara K. Sulforhodamine B colorimetric assay for cytotoxicity screening. Nat Protoc. 2006;1:1112-6.

16. Sies H. Polyphenols and health: update and perspectives. Arch Biochem Biophys. 2010;501:2-5.

17. Moalin M, van Strijdonck GP, Bast A, Haenen GR. Competition between ascorbate and glutathione for the oxidized form of methylated quercetin metabolites and analogues: tamarixetin, 4'O-methylquercetin, has the lowest thiol reactivity. J Agric Food Chem. 2012;60:9292-7.

18. Jacobs H, Moalin M, Bast A, van der Vijgh WJ, Haenen GR. An essential difference between the flavonoids monoHER and quercetin in their interplay with the endogenous antioxidant network. PLoS One. 2010;5:e13880.

19. van Acker FA, Schouten O, Haenen GR, van der Vijgh WJ, Bast A. Flavonoids can replace alpha-tocopherol as an antioxidant. FEBS Lett. 2000;473:145-8.

20. Bast A, Haenen GR. Ten misconceptions about antioxidants. Trends Pharmacol Sci. 2013;34:430-6.

21. Weseler AR, Ruijters EJ, Drittij-Reijnders MJ, Reesink KD, Haenen GR, Bast A. Pleiotropic benefit of monomeric and oligomeric flavanols on vascular health--a randomized controlled clinical pilot study. PLoS One. 2011;6:e28460.

22. van den Berg R, Haenen GR, van den Berg H, Bast A. Transcription factor NF-kappaB as a potential 
biomarker for oxidative stress. Br J Nutr. 2001;86 Suppl 1:S121-7.

23. Marwick JA, Wallis G, Meja K, Kuster B, Bouwmeester T, Chakravarty P, et al. Oxidative stress modulates theophylline effects on steroid responsiveness. Biochem Biophys Res Commun. 2008;377:797-802.

24. Meja KK, Rajendrasozhan S, Adenuga D, Biswas SK, Sundar IK, Spooner G, et al. Curcumin restores corticosteroid function in monocytes exposed to oxidants by maintaining HDAC2. Am J Respir Cell Mol Biol. 2008;39:312-23.

25. Hakim A, Adcock IM, Usmani OS. Corticosteroid resistance and novel anti-inflammatory therapies in chronic obstructive pulmonary disease: current evidence and future direction. Drugs. 2012;72:1299-312.

26. Stey C, Steurer J, Bachmann S, Medici TC, Tramer MR. The effect of oral N-acetylcysteine in chronic bronchitis: a quantitative systematic review. Eur Respir J. 2000;16:253-62.

27. Dekhuijzen PN. Antioxidant properties of $\mathrm{N}$-acetylcysteine: their relevance in relation to chronic obstructive pulmonary disease. Eur Respir J. 2004;23:629-36.

28. Kasielski M, Nowak D. Long-term administration of $\mathrm{N}$-acetylcysteine decreases hydrogen peroxide exhalation in subjects with chronic obstructive pulmonary disease. Respir Med. 2001;95:448-56.

29. Eisner MD, Anthonisen N, Coultas D, Kuenzli N, Perez-Padilla R, Postma D, et al. An official American Thoracic Society public policy statement: Novel risk factors and the global burden of chronic obstructive pulmonary disease. Am J Respir Crit Care Med. 2010;182:693-718.

30. Haenen GRMM, Jansen FP, Bast A. The Antioxidant Properties of 5 O-(Beta-Hydroxyethyl)-Rutosides of the Flavonoid Mixture Venoruton. Phlebology. 1993;8:10-7.

31. van Acker SA, van Balen GP, van den Berg DJ, Bast A, van der Vijgh WJ. Influence of iron chelation on the antioxidant activity of flavonoids. Biochem Pharmacol. 1998;56:935-43.

32. Peluso I, Raguzzini A, Serafini M. Effect of flavonoids on circulating levels of TNF-alpha and IL-6 in humans: a systematic review and meta-analysis. Mol Nutr Food Res. 2013;57:784-801.

33. Stote KS, Clevidence BA, Novotny JA, Henderson T, Radecki SV, Baer DJ. Effect of cocoa and green tea on biomarkers of glucose regulation, oxidative stress, inflammation and hemostasis in obese adults at risk for insulin resistance. Eur J Clin Nutr. 2012;66:1153-9.

34. Duthie SJ, Jenkinson AM, Crozier A, Mullen W, Pirie L, Kyle J, et al. The effects of cranberry juice consumption on antioxidant status and biomarkers relating to heart disease and cancer in healthy human volunteers. Eur J Nutr. 2006;45:113-22.

35. Moller P, Loft S, Alfthan G, Freese R. Oxidative DNA damage in circulating mononuclear blood cells after ingestion of blackcurrant juice or anthocyanin-rich drink. Mutat Res. 2004;551:119-26.

36. Boots AW, Wilms LC, Swennen EL, Kleinjans JC, Bast A, Haenen GR. In vitro and ex vivo anti-inflammatory activity of quercetin in healthy volunteers. Nutrition. 2008;24:703-10.

37. Boots AW, Drent M, de Boer VC, Bast A, Haenen GR. Quercetin reduces markers of oxidative stress and inflammation in sarcoidosis. Clin Nutr. 2011;30:506-12.

38. Weseler AR, Bast A. Pleiotropic-acting nutrients require integrative investigational approaches: the example of flavonoids. J Agric Food Chem. 2012;60:8941-6.

39. Editorial. What is health? The ability to adapt. Lancet. 2009;373:781. 



\section{Chapter 4}

The anti-inflammatory efficacy of dexamethasone

is protected by (-)-epicatechin

Erik J.B. Ruijters

Guido R.M.M. Haenen

Antje R. Weseler

Aalt Bast

PharmaNutrition, 2014, 2:47-52 


\section{Abstract}

Dexamethasone and other glucocorticoids (GCs) are used in the treatment of chronic inflammatory diseases. However, in diseases like chronic obstructive pulmonary disease GC resistance can develop. Our study examines (-)-epicatechin, a dietary compound known to display anti-inflammatory action, as adjuvant to prevent $\mathrm{GC}$ resistance.

The anti-inflammatory potency of dexamethasone was determined in a carefully characterized system of monocytes differentiated to macrophage-like cells. The LPS induced IL-8 release was measured after pre-incubation with $\mathrm{H}_{2} \mathrm{O}_{2}$ and (-)-epicatechin. We show that dexamethasone could efficiently suppress LPS induced inflammation and that exposure to $\mathrm{H}_{2} \mathrm{O}_{2}$ induced $\mathrm{GC}$ resistance. The anti-inflammatory effect of dexamethasone was protected by (-)-epicatechin in the oxidant exposed cells.

These results show that the natural antioxidant (-)-epicatechin may be used as adjuvant therapy to restore or preserve the efficacy of GC drugs and thereby improving the treatment of inflammation. 


\section{Introduction}

Inflammation helps to fights off diseases, to repair tissue damage and ultimately to restore homeostasis. It is a self-perpetuating feed-forward process that, once activated, produces more pro-inflammatory mediators increasing the inflammatory response. Inflammation attracts immune cells and induces the local production of several cytokines (e.g. TNFa) and chemokines (e.g. IL-8) [1]. However, when insufficiently controlled, it will lead to chronic increased inflammation and pathological aberrations.

Chronic inflammatory diseases, such as chronic obstructive pulmonary disease (COPD) rheumatoid arthritis (RA) and inflammatory bowel disease (IBD), are treated with glucocorticoid (GC) drugs like budesonide, prednisolone and dexamethasone $[2,3]$. A major problem is the development of GC resistance that drastically limits the pharmacotherapeutic options for these diseases [4-6]. One of the causes that have been identified to contribute to the development of GC resistance is oxidative stress [7-9]. Oxidative stress accompanies inflammation and aggravates the inflammatory response $[10,11]$. Inflammatory mediators activate nuclear factor kappa-light-chain-enhancer of activated B cells (NF-kB), leading to cytokine production and leucocyte activation. This in turn increases reactive oxygen species (ROS) production which leads to antioxidant depletion and oxidative stress, which subsequently can activate NF-KB again [12]. This cumulates in a downward spiral fueled by inflammation and oxidative stress that continuously reinforce each other.

The flavanol (-)-epicatechin (EC) belongs to the flavonoids and is present in food and beverages like apples, plumes, cocoa and tea. Various studies suggest beneficial effect on the cardiovascular system [13]. These health benefits have been attributed to its antioxidants and anti-inflammatory action [14-16].

The antioxidant activity of EC is well documented. Recent results corroborate that a direct antioxidant effect is involved in the intracellular defense against oxidative stress provided by EC $[17,18]$. The anti-inflammatory effect of flavonoids is, in contrary to the antioxidant effect, still enigmatic. Several studies indicate a direct anti-inflammatory effect of EC [19]. The present study was designed to carefully characterize a macrophagelike-cell-system to examine the impact of oxidative stress and antioxidant protection by EC on the anti-inflammatory response of the GC drug dexamethasone. 


\section{Materials and methods}

\section{Chemicals}

Phorbol 12-myristate 13-acetate (PMA), dexamethasone, lipopolysaccharides (LPS), 2', 7'-dichlorofluorescein-diacetate (DCFH-DA), xylenol orange, $\mathrm{H}_{2} \mathrm{SO}_{4}$ and $\left(\mathrm{NH}_{4}\right)_{2}$ Fell $\left(\mathrm{SO}_{4}\right)_{2}$ were purchased from Sigma (St. Louis, MO, USA). (-)-Epicatechin (EC) was purchased from Extrasynthese (Genay, France). Roswell Park Memorial Institute 1640 (RPMI 1640) medium, fetal calf serum (FCS), phosphate buffered saline (PBS), penicillin, and streptomycin were obtained from Gibco (Life Technologies, Carlsbad, CA, USA).

\section{Cell culture}

The human monocyte cell line U937 (ATCC CRL-1593.2, LGC standards, Teddington, UK) was cultured in RPMI 1640 medium supplemented with 10\% FCS and $50 \mathrm{U} / \mathrm{ml}$ penicillin and $50 \mu \mathrm{g} / \mathrm{ml}$ streptomycin in a humidified atmosphere with $5 \% \mathrm{CO}_{2}$ at $37^{\circ} \mathrm{C}$. Before exposure, cells were differentiated to macrophage-like cells using $50 \mathrm{ng} / \mathrm{ml}$ PMA treatment for 4 hours. After incubation, cells were plated in a 24 well plate $\left(4 \times 10^{5}\right.$ cells/ well) and allowed to differentiate for $48 \mathrm{hr}$. Medium was changed to $1 \%$ FCS for a further overnight incubation. Cells were washed with PBS and all exposures were performed in medium without FCS. Cell viability was assessed after exposures by measuring lactate dehydrogenase (LDH) activity in the medium and total cell proteins using the sulforhodamine B (SRB) assay as described previously [18]. Cell viability after exposures remained above $90 \%$.

\section{Intracellular oxidative stress}

The fluorescent probe of 2', 7'-dichlorofluorescein-diacetate (DCFH-DA) was used to quantify intracellular oxidative stress in differentiated monocytes. In the presence of ROS, the non-fluorescent DCFH is oxidized to the highly fluorescent dichlorofluorescein (DCF). The intensity of DCF fluorescence corresponds to the level of intracellular ROS formation. Cells were differentiated in a black/clear bottom 96-well plate and grown for 72 hours. Fifty $\mu \mathrm{M}$ DCFH-DA was added to the cells and incubated for $30 \mathrm{~min}$. at $37^{\circ} \mathrm{C}, 5 \% \mathrm{CO}_{2}$. After washing, cells were exposed to $100 \mu \mathrm{l}$ serum-free medium containing $\mathrm{H}_{2} \mathrm{O}_{2}+/-\mathrm{EC}$ and DCF fluorescence was measured with excitation and emission wavelengths of $485 \mathrm{~nm}$ and $535 \mathrm{~nm}$, respectively, at $37^{\circ} \mathrm{C}$ over a period of $60 \mathrm{~min}$. 


\section{$\mathrm{H}_{2} \mathrm{O}_{2}$ stability in the culture medium}

The concentration of $\mathrm{H}_{2} \mathrm{O}_{2}$ in the medium of differentiated monocytes was determined using a modification of the ferrous oxidation xylenol orange assay [20]. This assay is based on the ability of peroxides to oxidize the ferrous $\mathrm{Fe}^{2+}$ ions to ferric $\mathrm{Fe}^{3+}$ ions, which react with xylenol orange to a colored complex. Cells were exposed to $800 \mu \mathrm{M} \mathrm{H}_{2} \mathrm{O}_{2}$ and a sample of medium was taken at various time points ( $0-60 \mathrm{~min}$ ). For the measurement, a total of $900 \mu \mathrm{l}$ of reaction solution was prepared containing $420 \mu \mathrm{l}$ of $25 \mathrm{mM} \mathrm{H}_{2} \mathrm{SO}_{4^{\prime}}, 30 \mu \mathrm{l}$ sample and the reaction was started by adding $450 \mu$ reaction buffer ( $200 \mathrm{mM}$ sorbitol, $200 \mu \mathrm{M}$ xylenol orange, $25 \mathrm{mM} \mathrm{H}_{2} \mathrm{SO}_{4}$ and $0.5 \mathrm{mM}\left(\mathrm{NH}_{4}\right)_{2}$ Fell $\left(\mathrm{SO}_{4}\right)_{2}$. The reaction mix was incubated at room temperature for $45 \mathrm{~min}$ and absorbance measured at $560 \mathrm{~nm}$. The concentrations of peroxides were calculated using $\mathrm{H}_{2} \mathrm{O}_{2}$ standard solutions.

\section{Determination of inflammation and GC resistance}

Oxidative stress was induced by incubating differentiated monocytes with $\mathrm{H}_{2} \mathrm{O}_{2}$ (100$800 \mu \mathrm{M})$ for 10-240 min. EC $(1,10,50 \mu \mathrm{M})$ was added during the incubation with $\mathrm{H}_{2} \mathrm{O}_{2}$. Control experiments demonstrated that there is no direct reaction between $E C$ and $\mathrm{H}_{2} \mathrm{O}_{2}$ in PBS or RPMI medium [17]. Cells were washed with PBS and incubated with LPS (10 ng/ $\mathrm{ml}$ ) +/-dexamethasone (1-100 $\mathrm{nM}$ ) for $16 \mathrm{~h}$ (figure 1). The cytokine concentrations in the medium were measured using a commercially available ELISA kit (Sanquin, Amsterdam, Netherlands) according to manufacturer's protocol.

\section{Statistics}

Data are expressed as mean \pm SD or mean \pm SEM. Statistical comparisons were performed by using a Mann-Whitney $U$ test or ANOVA following Dunnett's multiple comparison test with Prism v5 (GraphPad Software, San Diego, CA, USA). A two-tailed P-value $<0.05$ was considered statistically significant.

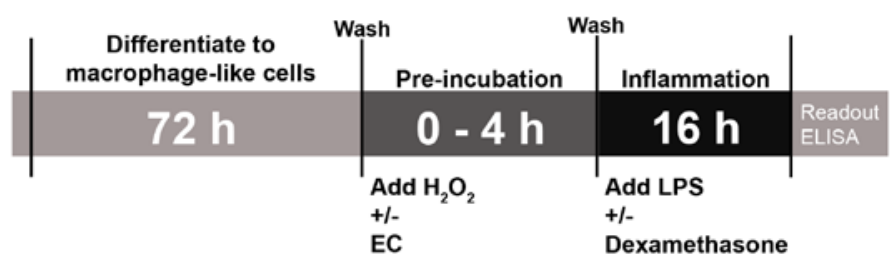

Figure 1. Graphical representation of cell exposures. Monocytes were first differentiated to macrophage-like cells for $72 \mathrm{~h}$. Cells were then pre-treated with $\mathrm{H}_{2} \mathrm{O}_{2}+/$ - epicatechin (EC) followed by lipopolysaccharides (LPS) +/- dexamethasone exposure overnight. 


\section{Results}

\section{Effect of differentiation and LPS concentration on the inflammatory response}

To differentiate the monocyte cell line U937 to macrophage-like cells, the monocytes were incubated for $4 \mathrm{~h}$ with PMA (50 $\mathrm{ng} / \mathrm{ml}$ ). LPS was used to evoke an inflammatory response. Inflammation was quantified by measuring the release of the inflammatory chemokine IL-8 in the medium. The U937 monocytes differentiated to macrophage-like cells produced 500 times more IL- 8 than the undifferentiated cells, indicating that the inflammatory response is much more pronounced in differentiated macrophage-like cells (figure 2A). The inflammatory response to 2,10 and $50 \mathrm{ng} / \mathrm{ml}$ LPS on the differentiated cells is depicted in figure $2 B$.

\section{Anti-inflammatory potency of dexamethasone}

The anti-inflammatory GC drug dexamethasone concentration dependently attenuated the LPS induced IL-8 production in differentiated cells. Thirty nanomolar of dexamethasone reduced the IL-8 production to control level (figure $3 \mathrm{~A}$ ).
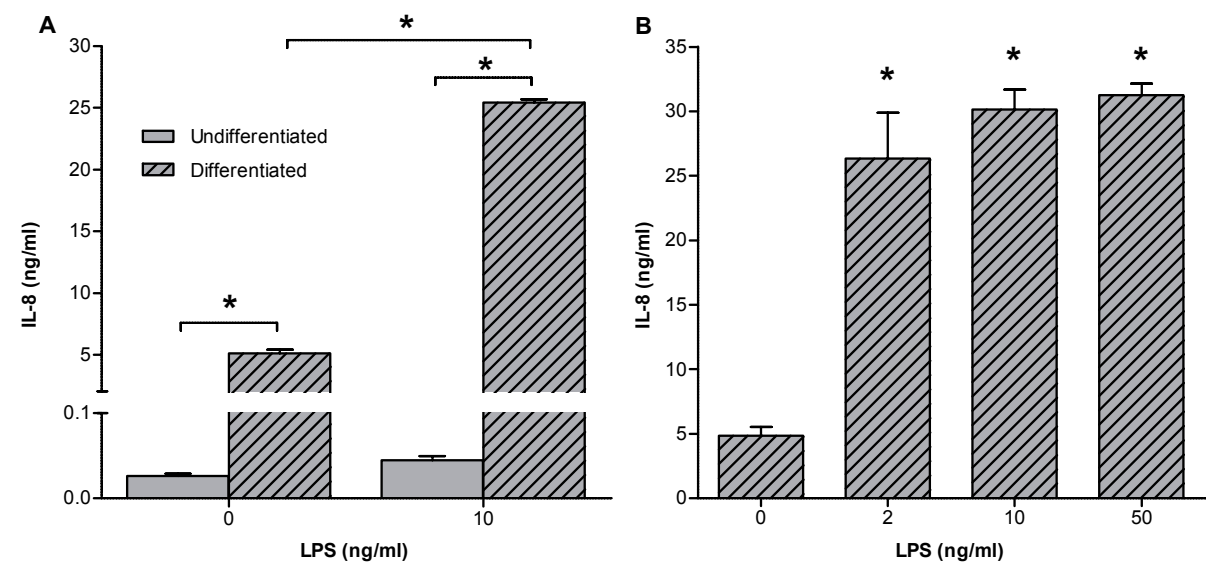

Figure 2. Effect of differentiation and lipopolysaccharides (LPS) concentration on the inflammatory response. U937 cells were exposed to LPS for $16 \mathrm{~h}$ and IL-8 concentration in medium was measured. (A) differentiated and undifferentiated cells, (B) differentiated cells exposed to LPS $(2-50 \mathrm{ng} / \mathrm{ml})$. Data depict the concentration IL-8 in the medium, ${ }^{*} p<0.05$ compared to $0 \mathrm{ng} / \mathrm{ml}$ LPS (mean \pm SD, $\mathrm{N}=3$ ). 


\section{Oxidative stress reduces the anti-inflammatory potency of dexamethasone}

To determine the effect of oxidative stress on the anti-inflammatory effect of dexamethasone, differentiated cells were incubated for $4 \mathrm{~h}$ with several concentrations of $\mathrm{H}_{2} \mathrm{O}_{2}$ prior to LPS and dexamethasone treatment (figure 1). Oxidative stress induced by $\mathrm{H}_{2} \mathrm{O}_{2}$ reduced the anti-inflammatory potency of dexamethasone concentration dependently (figure 3B). At a concentration of $800 \mu \mathrm{M} \mathrm{H}_{2} \mathrm{O}_{2}$, IL-8 concentration doubled
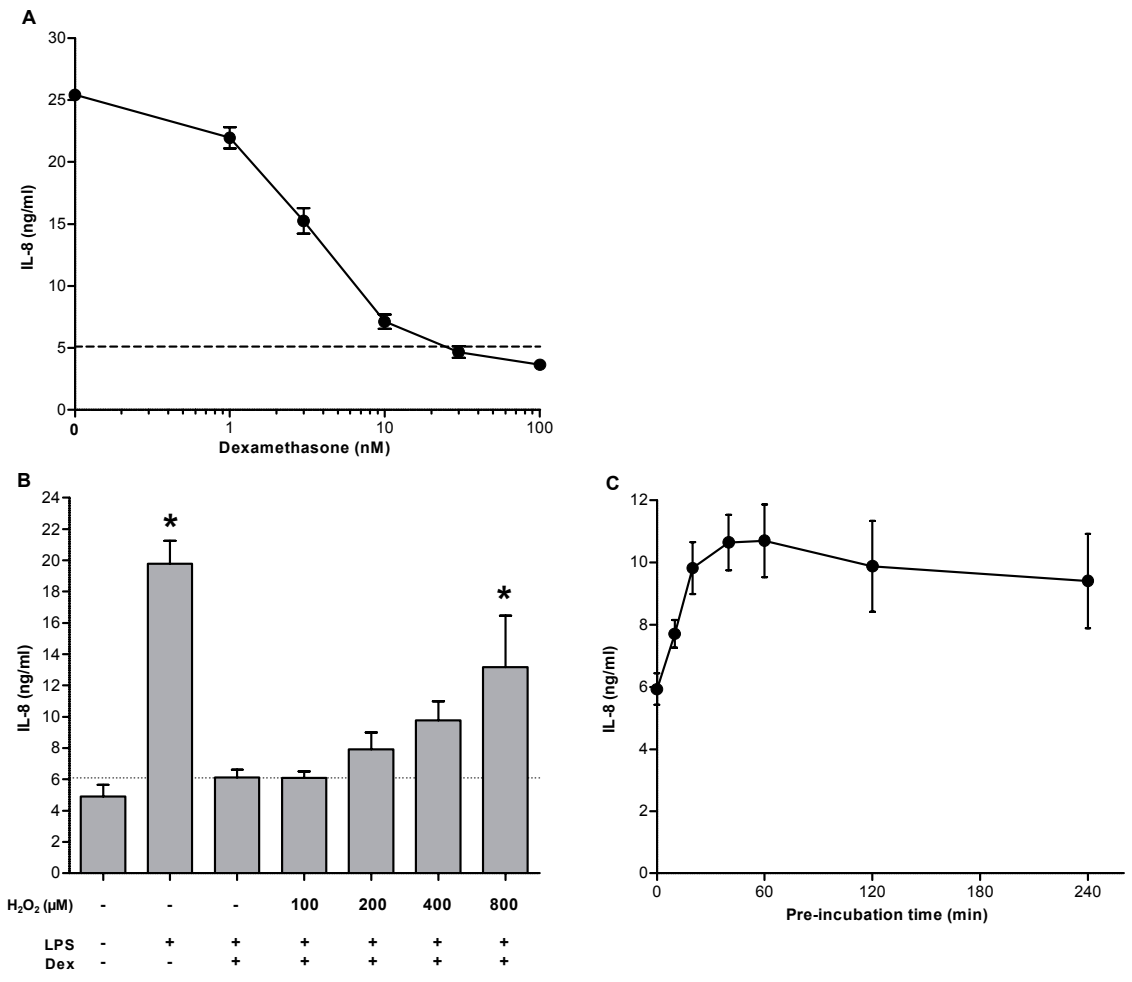

Figure 3. Anti-inflammatory efficacy of dexamethasone (Dex). (A) Concentration dependent anti-inflammatory effect of dexamethasone. Differentiated U937 cells were incubated with lipopolysaccharides (LPS) $(10 \mathrm{ng} / \mathrm{ml})$ and several concentrations of dexamethasone $(0-100 \mathrm{nM})$ for $16 \mathrm{~h}$. The level of inflammation was assessed by measuring the IL-8 concentration in the medium. At concentrations $\geq 30 \mathrm{nM}$, dexamethasone efficiently inhibits inflammation and decreased the IL-8 production to control level $(5.1 \mathrm{ng} / \mathrm{ml}$, represented by the dashed line). (B) Effect of oxidative stress on the anti-inflammatory response of dexamethasone. Differentiated U937 cells were exposed to $\mathrm{H}_{2} \mathrm{O}_{2}(0-800 \mu \mathrm{M})$ for $4 \mathrm{~h}$ and subsequently exposed to LPS and dexamethasone for $16 \mathrm{~h}$. IL-8 concentration ( ${ }^{*} p<0.05$ compared to column 3, Dunnett's test). (C) Development of oxidative stress induced glucocorticoid resistance in time. Differentiated U937 cells were pre-incubated with $\mathrm{H}_{2} \mathrm{O}_{2}(800 \mu \mathrm{M})$ for $10-240$ min and subsequently exposed to the combination of LPS and dexamethasone for $16 \mathrm{~h}$. Data are expressed as mean IL-8 concentration $\pm S D, N=3$. 
compared to cells without $\mathrm{H}_{2} \mathrm{O}_{2}$ treatment, indicative for the development of $\mathrm{GC}$ resistance. This corresponds to a 50\% reduction in anti-inflammatory potency of dexamethasone. To determine the required incubation time to induce oxidative stress induced GC resistance, cells were exposed to $\mathrm{H}_{2} \mathrm{O}_{2}(800 \mu \mathrm{M})$ for various incubation times. Subsequently, the antiinflammatory potency of dexamethasone was determined. The reduction of the antiinflammatory response in time, revealing the development of glucocorticoid resistance, was deduced form the increase in IL-8 concentration. The IL-8 concentration plateaued after 60 min (figure 3C). Therefore, a 60 minute incubation with $\mathrm{H}_{2} \mathrm{O}_{2}(800 \mu \mathrm{M})$ was selected as standard condition for oxidative stress induced GC resistance.

\section{Stability of $\mathrm{H}_{2} \mathrm{O}_{2}$ in cell medium}

To investigate the oxidative burden imposed upon the cells, the concentration of $\mathrm{H}_{2} \mathrm{O}_{2}$ in the cell medium was measured in time. $\mathrm{H}_{2} \mathrm{O}_{2}(800 \mu \mathrm{M})$ was stable in PBS for 60 min, in RPMI medium there was only a small decrease in $\mathrm{H}_{2} \mathrm{O}_{2}$ concentration in time. In the presence of cells, however, a rapid decline in $\mathrm{H}_{2} \mathrm{O}_{2}$ concentration was observed. Already after 5 min the concentration was halved and after 30 min hardly any $\mathrm{H}_{2} \mathrm{O}_{2}$ was detected (figure 4).

\section{Intracellular antioxidant effect of EC}

To assess intracellular oxidative stress, DCFH was used. During oxidative stress, DCFH is converted in the fluorescent product DCF. Exposure of DCFH loaded and differentiated cells to $\mathrm{H}_{2} \mathrm{O}_{2}(800 \mu \mathrm{M})$ gradually increased fluorescence, demonstrating that $\mathrm{H}_{2} \mathrm{O}_{2}$ causes intracellular oxidative stress. At $60 \mathrm{~min}$ the increase of fluorescence appeared to level off. EC efficiently reduced the development of fluorescence concentration-dependently (figure 5). Based on the recorded fluorescence, $1 \mu \mathrm{M}$ already diminished intracellular oxidative stress and $10 \mu \mathrm{M}$ EC reduced intracellular oxidative stress even below control level.

\section{EC protects the anti-inflammatory potency of dexamethasone in oxidant exposed cells}

As shown in previous experiments, oxidative stress induced GC resistance in the differentiated cells; pre-incubation with $\mathrm{H}_{2} \mathrm{O}_{2}$ doubled the LPS induced IL-8 production in the presence of dexamethasone. EC was able to protect the anti-inflammatory potency of dexamethasone in $\mathrm{H}_{2} \mathrm{O}_{2}$ exposed cells (figure 6). The protective effect of EC appeared to be time dependent. EC $(10 \mu \mathrm{M})$ reduced $\mathrm{GC}$ resistance by $50 \%$ at 60 and $120 \mathrm{~min}$ 
pre-incubation. At 240 min no protective effect was seen. EC itself did not reduce the LPS induced inflammatory response in the control experiment where the cells were not exposed to $\mathrm{H}_{2} \mathrm{O}_{2}$ (data not shown). This indicates that $\mathrm{EC}$ displayed no significant direct anti-inflammatory effect in the experimental setup.

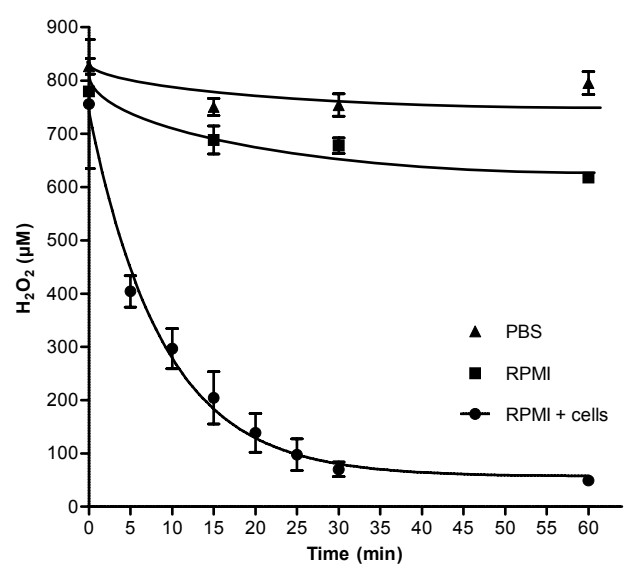

Figure 4. $\mathrm{H}_{2} \mathrm{O}_{2}$ concentration in the cell medium. Concentration of $\mathrm{H}_{2} \mathrm{O}_{2}$ in PBS, RPMI medium and medium with differentiated U937 cells was measured after several time points (mean $\pm S D, N=12$ ).

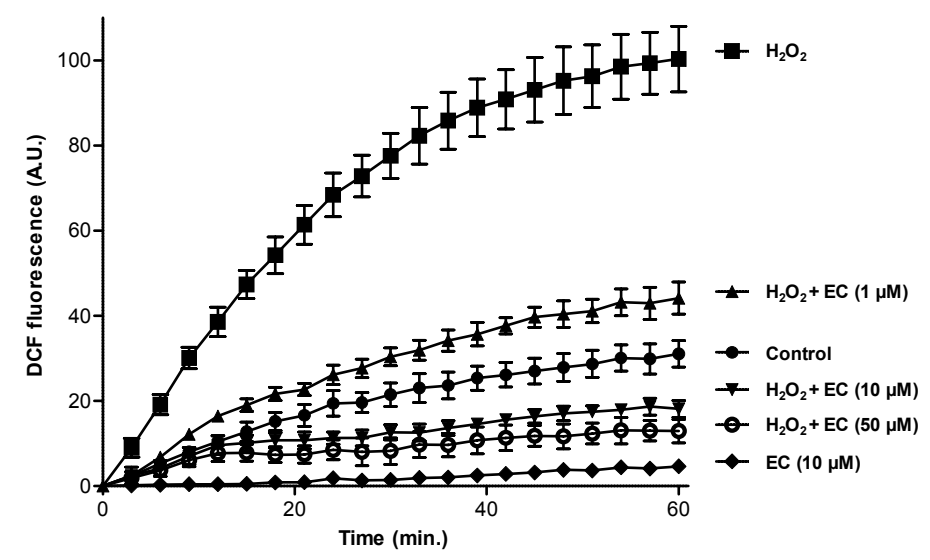

Figure 5. Intracellular antioxidant effect of epicatechin (EC). Differentiated U937 cells were loaded with the fluorescent probe DCFH. Subsequently, cells were exposed to EC $(10 \mu M)$ or $\mathrm{H}_{2} \mathrm{O}_{2}(800 \mu M)$ $+/-\mathrm{EC}(1-50 \mu \mathrm{M})$ and DCF fluorescence measured in time (mean $\pm \mathrm{SD}, \mathrm{N}=4)$. 
A

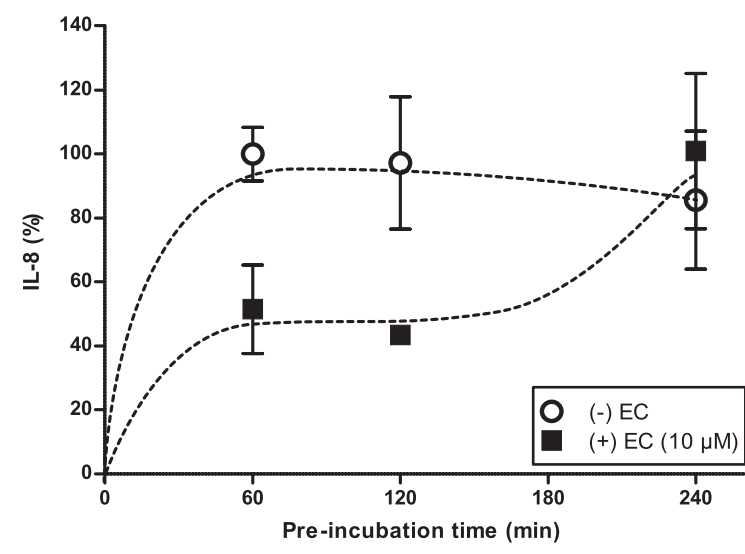

B

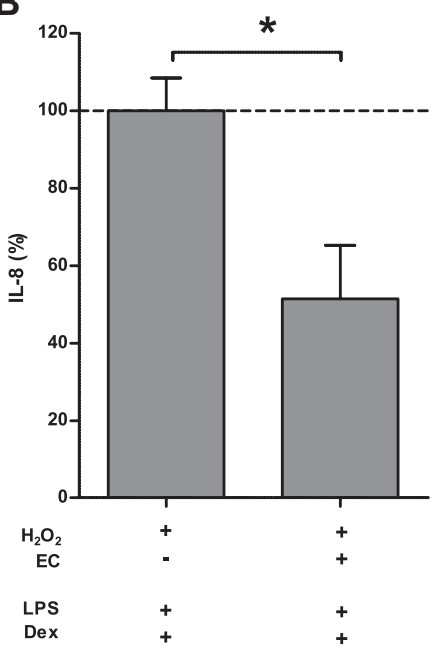

Figure 6. Epicatechin (EC) prevents oxidative stress induced glucocorticoid resistance. Differentiated U937 cells were pre-incubated with $\mathrm{H}_{2} \mathrm{O}_{2}(800 \mu \mathrm{M})+/-\mathrm{EC}(10 \mu \mathrm{M})$ for 60 - 240 min. and subsequently exposed to lipopolysaccharides (LPS) $(10 \mathrm{ng} / \mathrm{ml})$ and dexamethasone $(10 \mathrm{nM})$ for 16 h. (A) Concentrations IL-8 (\%) after various pre-incubation periods. (B) IL-8 concentration (\%) in medium after 60 min pre-incubation $\left({ }^{*} \mathrm{p}<0.05\right.$ Mann-Whitney $U$ test, mean $\left.\pm S E M, N=6\right)$. 


\section{Discussion}

This study was designed to carefully characterize a macrophage-like-cell-system and examine the protection of the anti-inflammatory efficacy of dexamethasone by EC. We found that that in the developed macrophage-like cell system dexamethasone is a potent anti-inflammatory drug. Addition of $\mathrm{H}_{2} \mathrm{O}_{2}$ to these cells resulted in oxidative stress that induced GC resistance evidenced by the reduced anti-inflammatory potential of dexamethasone. In line with results obtained with the endogenous GC cortisol, we observed that the anti-inflammatory efficacy of the drug dexamethasone is partly protected by the flavanol EC.

Dexamethasone is a synthetic GC that belongs to the group of drugs that is first choice in the pharmacotherapy of various inflammatory diseases [21]. The potency of dexamethasone is illustrated in this study by the efficient reduction of the inflammatory response in the cultured macrophage-like cells. However, a major impediment in the clinical application of these drugs is the occurrence of GC resistance [22]. In diseases like COPD, GC resistance hampers the efficacy of these anti-inflammatory drugs, which bears major clinical implications [23].

Inflammation and oxidative stress usually go hand in hand and a dynamic cross talk between both patho-physiological processes exists [24]. In the present study we focused on the inhibitory effect of oxidative stress on the anti-inflammatory efficacy of dexamethasone. In our in vitro model of differentiated monocytes, $\mathrm{H}_{2} \mathrm{O}_{2}$ was used to induce oxidative stress. This ROS was selected because it is found at relatively high concentrations in exhaled condensate of patients with COPD [25], a condition we mimicked by exposing the cells to $800 \mu \mathrm{M} \mathrm{H}_{2} \mathrm{O}_{2} \cdot \mathrm{H}_{2} \mathrm{O}_{2}$ is one of the molecules produced by inflammatory cells to combat pathogens like bacteria [26]. Adding $\mathrm{H}_{2} \mathrm{O}_{2}(800 \mu \mathrm{M})$ to the medium did induce intracellular oxidative stress, leading to GC resistance. The differentiated U937 cells appear to withstand the hostile environment because this $\mathrm{H}_{2} \mathrm{O}_{2}$ concentration did not result in cell death. Apparently, these anti-inflammatory cells are equipped with an efficient defense. The $\mathrm{H}_{2} \mathrm{O}_{2}$ concentration in the cell medium decreased relatively quickly. After 60 min practically all the $\mathrm{H}_{2} \mathrm{O}_{2}$ was decomposed and the DCF fluorescence, used to monitor intracellular oxidative stress, reached a plateau (figure 5). Interestingly, the development of GC resistance also paralleled the time profile of the $\mathrm{H}_{2} \mathrm{O}_{2}$ concentration in the medium and the time course of oxidative stress. This association confirms the link between $\mathrm{H}_{2} \mathrm{O}_{2}$-induced intracellular oxidative stress and the development of $\mathrm{GC}$ resistance. So a relative short exposure to $\mathrm{H}_{2} \mathrm{O}_{2}$ triggers the occurrence of GC resistance that seems to persist over a long period of time. 
Several mechanisms for the induction of GC resistance have been proposed. Akim et al [27] recently reported that oxidative stress reduces protein expression responsible for transport of the glucocorticoid receptor (GR) into the nucleus and prevents it from exerting its action. Alternative mechanisms for $\mathrm{GC}$ resistance include: decreased histone deacetylase 2 (HDAC2) activity, preventing repression of pro-inflammatory genes [28]; increased expression of the transcriptionally inactive GR $\beta$ [29]; reduced binding affinity, translocation or stability of GRa, PI3K signaling activation preventing the transcription of anti-inflammatory proteins [30]; and increased pro-inflammatory gene expression [31]. To prevent or attenuate GC resistance, HDAC2 has attracted special interest. Curcumin and theophylline improve GC response, presumably by restoring HDAC2 activity [32]. ROS suppress HDAC2 activity, which can lead to GC resistance. In fact, in COPD the ROS production is pronounced and frequently GC resistance develops. Preventing oxidative stress with antioxidants appears to be a promising strategy to prevent the development of GC resistance.

The results obtained corroborate that oxidative stress induced by $\mathrm{H}_{2} \mathrm{O}_{2}$ leads to $\mathrm{GC}$ resistance in differentiated monocytes. In addition, EC appears to protect against the induction of $\mathrm{GC}$ resistance; ten $\mu \mathrm{M} \mathrm{EC}$ reduced the effect of $\mathrm{H}_{2} \mathrm{O}_{2}$ on the anti-inflammatory response of dexamethasone by $50 \%$. This shows the potential of EC as an adjuvant in GC treatment.

Several studies indicate that EC can also display a direct anti-inflammatory effect [19]. A direct anti-inflammatory effect was not observed in the present experimental setup in the macrophage-like cell system. This further substantiates the connection of the observed anti-inflammatory effect of EC with its antioxidant activity. Next to this indirect anti-inflammatory effect, a direct anti-inflammatory effect will also add to the effectiveness of EC as adjuvant of GC pharmacotherapy. This would help to interrupt the downward spiral of inflammation and oxidative stress.

Two specific aspects in this study also gained our attention. One is the extent of protection against oxidative stress did not correlate with the extend of the protection against GC resistance. The flavanol EC at a concentration of $10 \mu \mathrm{M}$ completely protected against intracellular oxidative stress in the cells, while it only partially protected against $\mathrm{GC}$ resistance. The other is that the protection of $\mathrm{EC}$ against $\mathrm{H}_{2} \mathrm{O}_{2}$-induced $\mathrm{GC}$ resistance is temporary. Over a period of $1 \mathrm{~h}$ intracellular oxidative stress increases and GC resistance develops. EC partially protects against the $\mathrm{H}_{2} \mathrm{O}_{2}$ induced $\mathrm{GC}$ resistance over a period of $2 \mathrm{~h}$. After $4 \mathrm{~h}$ the GC resistance is prominent and no protective effect of EC observed. In this respect it is important to consider that EC is a food compound and not a drug. 
Drugs act on a specific target, such as an enzyme or receptor, and induce a strong effect. This is in contrast to food-derived compounds such as EC. Their action is not specific but multifarious [33-35]. A bioactive, like EC, exerts relative subtle and non-pharmacological effects, therefore the partial and temporary outcome on GC resistance could have been anticipated. The advantage of the subtle and the time-dependent nature of the effect of bioactives, like EC, is that overt toxicity is unlikely to occur. Moreover, compliance as well as acceptance of a nutritional intervention is expected to be relatively high.

\section{Conclusions}

In this study we show that the anti-inflammatory efficacy of dexamethasone in monocytes exposed to oxidants is partially protected by EC. This bears therapeutic potential for chronic inflammatory diseases that are accompanied with GC resistance. It opens new therapeutic avenues in which antioxidants, either as supplement or from the diet, are applied as adjuvant therapy to restore or preserve the efficacy of GC drugs. 


\section{References}

1. Rickard AJ, Young MJ. Corticosteroid receptors, macrophages and cardiovascular disease. J Mol Endocrinol. 2009;42:449-59.

2. Hakim A, Adcock IM, Usmani OS. Corticosteroid resistance and novel anti-inflammatory therapies in chronic obstructive pulmonary disease: current evidence and future direction. Drugs. 2012;72:1299-312.

3. De ludicibus S, Franca R, Martelossi S, Ventura A, Decorti G. Molecular mechanism of glucocorticoid resistance in inflammatory bowel disease. World J Gastroenterol. 2011;17:1095-108.

4. Yang N, Ray DW, Matthews LC. Current concepts in glucocorticoid resistance. Steroids. 2012;77:1041-9.

5. Farrell RJ, Kelleher D. Glucocorticoid resistance in inflammatory bowel disease. J Endocrinol. 2003;178:33946.

6. Whitehouse MW. Anti-inflammatory glucocorticoid drugs: reflections after 60 years. Inflammopharmacology. 2011;19:1-19.

7. Milara J, Navarro A, Almudever P, Lluch J, Morcillo EJ, Cortijo J. Oxidative stress-induced glucocorticoid resistance is prevented by dual PDE3/PDE4 inhibition in human alveolar macrophages. Clin Exp Allergy. 2011;41:535-46.

8. Adcock IM, Barnes PJ. Molecular mechanisms of corticosteroid resistance. Chest. 2008;134:394-401.

9. Roche N, Marthan R, Berger P, Chambellan A, Chanez P, Aguilaniu B, et al. Beyond corticosteroids: future prospects in the management of inflammation in COPD. Eur Respir Rev. 2011;20:175-82.

10. Hazewindus M, Haenen GRMM, Weseler AR, Bast A. The anti-inflammatory effect of lycopene complements the antioxidant action of ascorbic acid and a-tocopherol. Food Chem. 2012;132:954-8.

11. Rahman I, Biswas SK, Kirkham PA. Regulation of inflammation and redox signaling by dietary polyphenols. Biochem Pharmacol. 2006;72:1439-52.

12. van den Berg R, Haenen GR, van den Berg H, Bast A. Transcription factor NF-kappaB as a potential biomarker for oxidative stress. Br J Nutr. 2001;86 Suppl 1:S121-7.

13. Steinberg FM, Bearden MM, Keen CL. Cocoa and chocolate flavonoids: implications for cardiovascular health. J Am Diet Assoc. 2003;103:215-23.

14. Corcoran MP, McKay DL, Blumberg JB. Flavonoid basics: chemistry, sources, mechanisms of action, and safety. J Nutr Gerontol Geriatr. 2012;31:176-89.

15. Soobrattee MA, Neergheen VS, Luximon-Ramma A, Aruoma OI, Bahorun T. Phenolics as potential antioxidant therapeutic agents: mechanism and actions. Mutat Res. 2005;579:200-13.

16. Peluso I, Raguzzini A, Serafini M. Effect of flavonoids on circulating levels of TNF-alpha and IL-6 in humans: a systematic review and meta-analysis. Mol Nutr Food Res. 2013;57:784-801.

17. Ruijters EJ, Weseler AR, Kicken C, Haenen GR, Bast A. The flavanol (-)-epicatechin and its metabolites protect against oxidative stress in primary endothelial cells via a direct antioxidant effect. Eur J Pharmacol. 2013;715:147-53.

18. Ruijters EJ, Haenen GR, Weseler AR, Bast A. The cocoa flavanol (-)-epicatechin protects the cortisol response. Pharmacol Res. 2014;79:28-33.

19. Del Rio D, Rodriguez-Mateos A, Spencer JP, Tognolini M, Borges G, Crozier A. Dietary (poly)phenolics in human health: structures, bioavailability, and evidence of protective effects against chronic diseases. Antioxid Redox Signal. 2013;18:1818-92.

20. Gulden M, Jess A, Kammann J, Maser E, Seibert H. Cytotoxic potency of $\mathrm{H} 2 \mathrm{O} 2$ in cell cultures: impact of cell concentration and exposure time. Free Radic Biol Med. 2010;49:1298-305.

21. Buttgereit F. A fresh look at glucocorticoids how to use an old ally more effectively. Bull NYU Hosp Jt Dis. 2012;70 Suppl 1:26-9.

22. Rhen T, Cidlowski JA. Antiinflammatory action of glucocorticoids--new mechanisms for old drugs. $\mathrm{N}$ Engl J Med. 2005;353:1711-23.

23. Barnes PJ, Adcock IM. Glucocorticoid resistance in inflammatory diseases. Lancet. 2009;373:1905-17. 
24. Mittal M, Siddiqui MR, Tran K, Reddy SP, Malik AB. Reactive Oxygen Species in Inflammation and Tissue Injury. Antioxid Redox Signal. 2014;20:1126-67.

25. Dekhuijzen PN, Aben KK, Dekker I, Aarts LP, Wielders PL, van Herwaarden CL, et al. Increased exhalation of hydrogen peroxide in patients with stable and unstable chronic obstructive pulmonary disease. Am J Respir Crit Care Med. 1996;154:813-6.

26. Segal AW. How neutrophils kill microbes. Annu Rev Immunol. 2005;23:197-223.

27. Hakim A, Barnes PJ, Adcock IM, Usmani OS. Importin-7 mediates glucocorticoid receptor nuclear import and is impaired by oxidative stress, leading to glucocorticoid insensitivity. FASEB J. 2013;27:4510-9.

28. Ito K, Hanazawa T, Tomita K, Barnes PJ, Adcock IM. Oxidative stress reduces histone deacetylase 2 activity and enhances IL-8 gene expression: role of tyrosine nitration. Biochem Biophys Res Commun. 2004;315:240-5.

29. Li LB, Leung DY, Martin RJ, Goleva E. Inhibition of histone deacetylase 2 expression by elevated glucocorticoid receptor beta in steroid-resistant asthma. Am J Respir Crit Care Med. 2010;182:877-83.

30. Rossios C, To Y, Osoata G, Ito M, Barnes PJ, Ito K. Corticosteroid insensitivity is reversed by formoterol via phosphoinositide-3-kinase inhibition. Br J Pharmacol. 2012;167:775-86.

31. Barnes PJ. Glucocorticosteroids: current and future directions. Br J Pharmacol. 2011;163:29-43.

32. Meja KK, Rajendrasozhan S, Adenuga D, Biswas SK, Sundar IK, Spooner G, et al. Curcumin restores corticosteroid function in monocytes exposed to oxidants by maintaining HDAC2. Am J Respir Cell Mol Biol. 2008;39:312-23.

33. Bast A, Haenen GR. Ten misconceptions about antioxidants. Trends Pharmacol Sci. 2013;34:430-6.

34. Boots AW, Haenen GR, Bast A. Health effects of quercetin: from antioxidant to nutraceutical. Eur J Pharmacol. 2008;585:325-37.

35. Weseler AR, Bast A. Pleiotropic-acting nutrients require integrative investigational approaches: the example of flavonoids. J Agric Food Chem. 2012;60:8941-6. 



\section{Chapter 5}

Food-derived bioactives can protect the anti-inflammatory activity of cortisol by antioxidant-dependent and -independent mechanisms

Erik J.B. Ruijters

Guido R.M.M. Haenen

Mathijs Willemsen

Antje R. Weseler

Aalt Bast

In preparation. 


\section{Abstract}

In chronic inflammatory diseases the anti-inflammatory effect of glucocorticoids (GCs) is often decreased, leading to GC resistance. Inflammation is related with increased levels of reactive oxygen species (ROS), leading to oxidative stress which is thought to contribute to the development of GC resistance.

Plant-derived compounds like flavonoids are known for their ability to protect against ROS. In this exploratory study we screened a broad range of food derived bioactives for their antioxidant and anti-inflammatory effects in order to investigate whether their antioxidant effects are associated with the ability to preserve the anti-inflammatory effects of cortisol. The anti-inflammatory potency of the test compounds was assessed by measuring the oxidative stress-induced GC resistance in human macrophage-like cells. Cells were pre-treated with $\mathrm{H}_{2} \mathrm{O}_{2}(0.8 \mathrm{mM})$ with and without bioactives and then exposed to lipopolysaccharides (LPS) $(10 \mathrm{ng} / \mathrm{ml})$ and cortisol $(100 \mathrm{nM})$. Level of inflammation was deducted from the concentration of interleukin-8 (IL-8) in the medium. Intracellular oxidative stress was measured using the fluorescent probe 2', 7'-dichlorofluorescein (DCFH).

We found that most of the dietary bioactives display antioxidant and antiinflammatory action through the protection of the cortisol response. All compounds, except for quercetin, revealing antioxidant activity also protect the cortisol response. This indicates that the antioxidant activity of compounds plays an important role in the protection of the GC response. However, next to the antioxidant activity of the bioactives, also other mechanisms seem to be involved in this protective, anti-inflammatory effect. 


\section{Introduction}

Our diet contains a wide variety of antioxidants and other bioactives which can help to preserve health. These health benefits have been extensively documented in literature and various modes of action have been proposed [1-4]. It is increasingly realized that a bioactive has a multitude of subtle effects via diverse cellular and molecular targets that become integrated in an overall, physiologically relevant response [5]. One of the best documented activity of flavonoids, an important group of bioactives, is their ability to protect against reactive oxygen species (ROS) [6-9].

ROS are generated during the reduction of oxygen and can be derived from sources as diverse as mitochondria, activated inflammatory cells, drugs and cigarette smoke. ROS comprise two groups of molecules namely (i) free radicals with relatively short biological half-lives, such as superoxide anion $\left(\mathrm{O}_{2}{ }^{-}\right)$and hydroxyl radical $(\cdot \mathrm{OH})$ and (ii) nonradicals, such as hydrogen peroxide $\left(\mathrm{H}_{2} \mathrm{O}_{2}\right)$ and hypochlorous acid $(\mathrm{HOCl})$, which are relatively less reactive and has a longer half-life than free radicals [10]. ROS are noxious molecules and can damage virtually any cellular components. Beside the oxidative stress-mediated direct damage by ROS, also the induction of inflammation by ROS has been implicated in the etiology of numerous diseases [10-12].

Inflammation is a natural process to combat infections and help in wound healing. During this process immune cells are attracted to the area of inflammation and various cytokines (e.g. tumor necrosis factor alpha (TNF-a) and chemokines (e.g. interleukin-8 (IL-8)) are produced. It is a feed forward process that can spin out of control leading to a chronic inflammatory response. Inflammatory mediators activate NF-KB, initiating cytokine production and leucocyte activation. This in turn increases ROS production, resulting in antioxidant depletion and oxidative stress, which further stimulates nuclear factor kappa-light-chain-enhancer of activated B cells (NF-kB) [13, 14].

Glucocorticoids (GCs) are the most effective anti-inflammatory drugs available for the treatment of many chronic inflammatory and immune diseases, including inflammatory bowel disease (IBD) and chronic obstructive pulmonary disease (COPD). The antiinflammatory effect of GCs is often decreased in these diseases, leading to GC resistance and a state of chronic inflammation [15-17]. These chronic inflammatory diseases are also associated with an increased level of oxidative stress, which is thought to contribute to the development of GC resistance [18]. This again illustrates how closely inflammation and oxidative stress are intertwined.

In previous research we showed that the cocoa flavanol (-)-epicatechin (EC) was able to preserve the anti-inflammatory effect of the endogenous GC cortisol [19] and the 
synthetic GC dexamethasone in oxidant-exposed human macrophages [20]. These results revealed that the antioxidant activity of EC prevents the development of GC resistance in macrophage-like cells. In the present study we examined a wide array of bioactives, with a focus on flavonoids and some of their metabolites, for their antioxidant and antiinflammatory effect, i.e. the preservation of the anti-inflammatory effect of cortisol, in oxidant-exposed cells and correlated this to their antioxidant activity. Our data will enhance the understanding of the structural relation between antioxidant activity of dietary bioactives and their potency to protect the cortisol response.

\section{Materials and methods}

\section{Chemicals}

Phorbol 12-myristate 13-acetate (PMA), lipopolysaccharides (LPS) 2', 7'-dichlorofluoresceindiacetate (DCFH-DA), quercetin, chrysin, genistein, ( \pm )-taxifolin, curcumin, resveratrol and theophylline were purchased from Sigma (St. Louis, MO, USA). Roswell Park Memorial Institute 1640 (RPMI 1640) medium, fetal calf serum (FCS), phosphate buffered saline (PBS), penicillin, and streptomycin were obtained from Gibco (Life Technologies, Carlsbad, CA, USA). (-)-Epicatechin (EC), quercetin-3-O-glucuronide (Q3G), quercetin3-O-methyl (Q3M) were purchased from Extrasynthese (Genay, France). 7-mono-O-( $\beta$ hydroxyethyl)-rutoside (monoHER) was kindly provided by Novartis Consumer Health (Nyon, Switzerland). The flavanol metabolites 3'-O-methyl-EC (3'ME), 4'-O-methyl-EC (4'ME), 4'-O-methyl-EC-7- $\beta$-D-glucuronide (4'ME7G), EC-7- $\beta$-D-glucuronide (E7G), and EC-4'-sulfate (E4'S) were provided by Mars Incorporated (Hackettstown, NJ, USA) Stock solutions of 2-10 mM of compounds were prepared in 50 or $100 \%$ (v/v) ethanol and 50 $\mu \mathrm{l}$ aliquots were stored at $-80^{\circ} \mathrm{C}$ until use. The dilutions of each flavanol were prepared immediately prior to experimental use.

\section{Cell culture}

The human monocyte cell line U937 (LGC standards, Teddington, UK) was cultured in RPMI 1640 medium supplemented with $10 \%$ FCS and $50 \mathrm{U} / \mathrm{ml}$ penicillin and $50 \mu \mathrm{g} / \mathrm{ml}$ streptomycin in a humidified atmosphere with $5 \% \mathrm{CO}_{2}$ at $37{ }^{\circ} \mathrm{C}$. Before exposure, cells were differentiated to macrophage like cells using $50 \mathrm{ng} / \mathrm{ml}$ PMA treatment for 4 hours. After incubation, cells were plated in a 24 well plate $\left(4 \times 10^{5}\right.$ cells/well) and allowed to differentiate for $48 \mathrm{hr}$. Medium was changed to $1 \%$ FCS for a further overnight incubation. 
Cells were washed with PBS and all exposures were performed in medium without FCS. After each experiment, cell amount was determined using the sulforhodamine B (SRB) assay as previously described [19].

\section{Intracellular oxidative stress}

The fluorescent probe of 2', 7'-dichlorofluorescein-diacetate (DCFH-DA) was used to quantify intracellular oxidative stress in differentiated monocytes. In the presence of ROS, the non-fluorescent DCFH is oxidized to the highly fluorescent dichlorofluorescein (DCF). The intensity of DCF fluorescence corresponds to the level of intracellular ROS formation. Cells were differentiated in a black/clear bottom 96-well plate and grown for 72 hours. Fifty $\mu \mathrm{M}$ DCFH-DA was added to the cells and incubated for $30 \mathrm{~min}$. at $37^{\circ} \mathrm{C}, 5 \% \mathrm{CO}_{2}$. After washing, cells were exposed to $100 \mu \mathrm{l}$ serum-free medium containing $\mathrm{H}_{2} \mathrm{O}_{2}+$ - bioactive and DCF fluorescence was measured with excitation and emission wavelengths of 485 $\mathrm{nm}$ and $535 \mathrm{~nm}$, respectively, at $37^{\circ} \mathrm{C}$ over a period of $60 \mathrm{~min}$.

\section{Determination of inflammation and GC resistance}

Oxidative stress was induced by incubating differentiated monocytes with $\mathrm{H}_{2} \mathrm{O}_{2}(800 \mu \mathrm{M})$ for 60 min. Bioactives $(10 \mu M)$ were added during the incubation with $\mathrm{H}_{2} \mathrm{O}_{2}$. Cells were washed with PBS and incubated with LPS (10 ng/ml) +/- cortisol (100 nM) for $16 \mathrm{~h}$. The interleukin-8 (IL-8) concentrations in the medium were measured using a commercially available ELISA kit (Sanquin, Amsterdam, Netherlands) according to manufacturer's protocol.

\section{Statistics}

Data are expressed as mean \pm SD or mean \pm SEM. Statistical comparisons were performed by using a Mann-Whitney $U$ test or ANOVA following Dunnett's multiple comparison test with Prism v5 (GraphPad Software, San Diego, CA, USA). A two-tailed P-value $<0.05$ was considered statistically significant. 


\section{Results}

\section{Antioxidant effect of bioactives and protection against GC resistance}

A wide array of dietary compounds was tested for their protective effect against oxidative stress and GC resistance in differentiated U937 cells (table 1). The bioactives efficiently protected the cells against oxidative stress induced GC resistance in order of potency: Cur $(100 \pm 10 \%) \geq \operatorname{Res}(99 \pm 14 \%) \geq \operatorname{Chr}(97 \pm 9 \%) \geq \operatorname{Gen}(92 \pm 13 \%) \geq \mathrm{MH}(71 \pm 16 \%) \geq$ Theo $(69 \pm 13 \%) \geq \operatorname{Tax}(56 \pm 11 \%) \geq$ EC (49 $\pm 44 \%)$ (figure 1). Res, Gen, MH, Tax, Q, and EC also protected against oxidative stress and reduced DCF fluorescence even below background levels. The bioactives that displayed antioxidant activity also protected the GC response of cortisol, except for Q. Although Q reduced intracellular stress even below background level, this flavonol did not reduce the LPS induced IL-8 production in the macrophagelike cells. This lack of protection indicates that more mechanisms are involved in the development and prevention of GC resistance. This is also illustrated by the compounds Theo, Chr and Cur which show the opposite: little to no antioxidant activity but efficient protection of the GC response by $69 \%, 97 \%$ and $100 \%$, respectively.

\section{Antioxidant effect of flavonoid metabolites and protection against GC resistance}

Several metabolites were investigated for their antioxidant and GC-protective effect (figure 2). Metabolism, i.e. methylation, glucuronidation or sulfation, especially at the 3'- and 4'-carbon, results in a reduced antioxidant capacity. This was illustrated by the increased DCF fluorescence compared to the parent compound EC. However, the protective effect of the metabolites against GC resistance was similar to the protection by EC. Although Q appeared to enhance the IL-8 production in our cell model, its 3-O-methyl and 3-O-glucuronide metabolite reduced IL-8 release by $57 \%$ and $55 \%$ respectively. Both $\mathrm{Q}$ metabolites thus provide protection against oxidative stress-induced GC resistance (figure 3). 
Table 1. Antioxidant effect and protection of the cortisol response by bioactives

\begin{tabular}{|c|c|c|c|c|}
\hline Class & Compound & Abbr. & $\begin{array}{c}\text { Anti- } \\
\text { oxidant } \\
\text { effect* }\end{array}$ & $\begin{array}{l}\text { Protection } \\
\text { of cortisol } \\
\text { response ** }\end{array}$ \\
\hline \multirow[t]{6}{*}{ Flavanol } & (-)-epicatechin & $\mathrm{EC}$ & $86 \pm 11$ & $49 \pm 44$ \\
\hline & 3'-O-methyl(-)-epicatechin & 3'ME & $67 \pm 13$ & $36 \pm 53$ \\
\hline & 4'-O-methyl(-)-epicatechin & $4^{\prime} \mathrm{ME}$ & $56 \pm 14$ & $39 \pm 31$ \\
\hline & (-)-epicatechin-7- $\beta$-D-glucuronide & E7G & $69 \pm 7$ & $42 \pm 46$ \\
\hline & $\begin{array}{l}\text { 4'-O-methyl(-)-epicatechin-7- } \beta \text {-D- } \\
\text { glucuronide }\end{array}$ & 4'ME7G & $39 \pm 21$ & $35 \pm 46$ \\
\hline & (-)-epicatechin-4'-sulfate & E4'S & $27 \pm 12$ & $41 \pm 12$ \\
\hline \multicolumn{5}{|c|}{ Flavanonol } \\
\hline & $( \pm)$-Taxifolin & Tax & $78 \pm 3$ & $56 \pm 11$ \\
\hline
\end{tabular}

Flavone<smiles>O=c1cc(-c2ccccc2)oc2ccccc12</smiles>

Chrysin

Chr

$14 \pm 2 \quad 97 \pm 9$<smiles>COOCOCCO</smiles>

7-mono-O-( $\beta$-hydroxyethyl)-rutoside

$\mathrm{MH}$

$88 \pm 2 \quad 71 \pm 16$

Quercetin

Q

$100 \pm 2$

$-30 \pm 47$

3-O-methyl-quercetin

Q3M

$57 \pm 6$

Quercetin-3-O-glucuronide

Q3G

$55 \pm 24$

Isoflavone<smiles>O=c1c(-c2ccccc2)coc2ccccc12</smiles>

Genistein

Gen

$83 \pm 3$

$92 \pm 13$

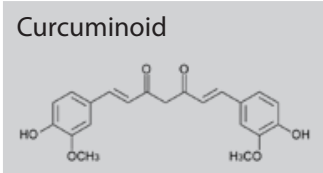

Curcumin

Cur

$-4 \pm 6$

$100 \pm 10$

\section{Stilbenoid}<smiles>Oc1ccc(C=Cc2cccc(O)c2)cc1</smiles>

Resveratrol

Res

$57 \pm 3$

$99 \pm 14$

Methylxanthine<smiles>Cn1c(=O)c2[nH]cnc2n(C)c1=O</smiles>

Theophylline

Theo

$11 \pm 4$

$69 \pm 13$

* \% reduction of intracellular oxidative stress compared to $\mathrm{H}_{2} \mathrm{O}_{2}$ incubation without bioactives

** \% reduction of IL-8 concentration in medium compared to $\mathrm{H}_{2} \mathrm{O}_{2}+\mathrm{LPS}+\mathrm{CS}$ incubation without bioactives 

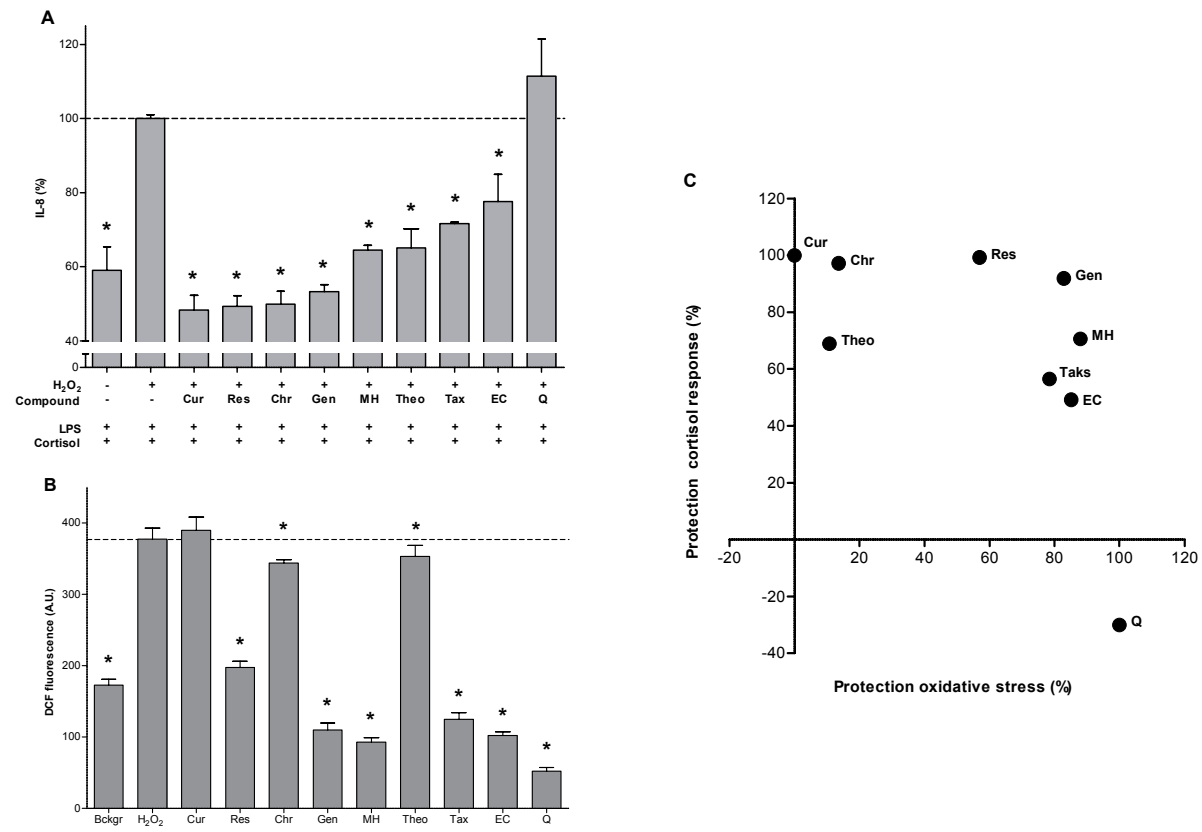

Figure 1. Effect of bioactives on intracellular oxidative stress and glucocorticoid resistance arranged in accordance to their ability to restore the anti-inflammatory effect of cortisol. A) IL-8 levels (\%) in medium after cells were pre-incubated with $\mathrm{H}_{2} \mathrm{O}_{2}(800 \mu \mathrm{M})+/$ - bioactives $(10 \mu \mathrm{M})$ for 1 $\mathrm{h}$ and subsequently exposed to LPS $(10 \mathrm{ng} / \mathrm{ml})$ and cortisol $(100 \mathrm{nM})$ for $16 \mathrm{~h}(\mathrm{~N}=6$, mean $\pm \mathrm{SEM})$. B) Intracellular oxidative stress levels. Differentiated monocytes were incubated with DCFH for 45 min and then exposed to $\mathrm{H}_{2} \mathrm{O}_{2}(800 \mu \mathrm{M})+/$ - bioactives $(10 \mu \mathrm{M})$ and fluorescence was recorded for $1 \mathrm{~h}$ $\left(\mathrm{N}=4\right.$, mean $\pm \mathrm{SD},{ }^{*} \mathrm{p}<0.05$ Dunnett's). C) Correlation of the ability to reduce intracellular oxidative stress and to protect the cortisol response. 

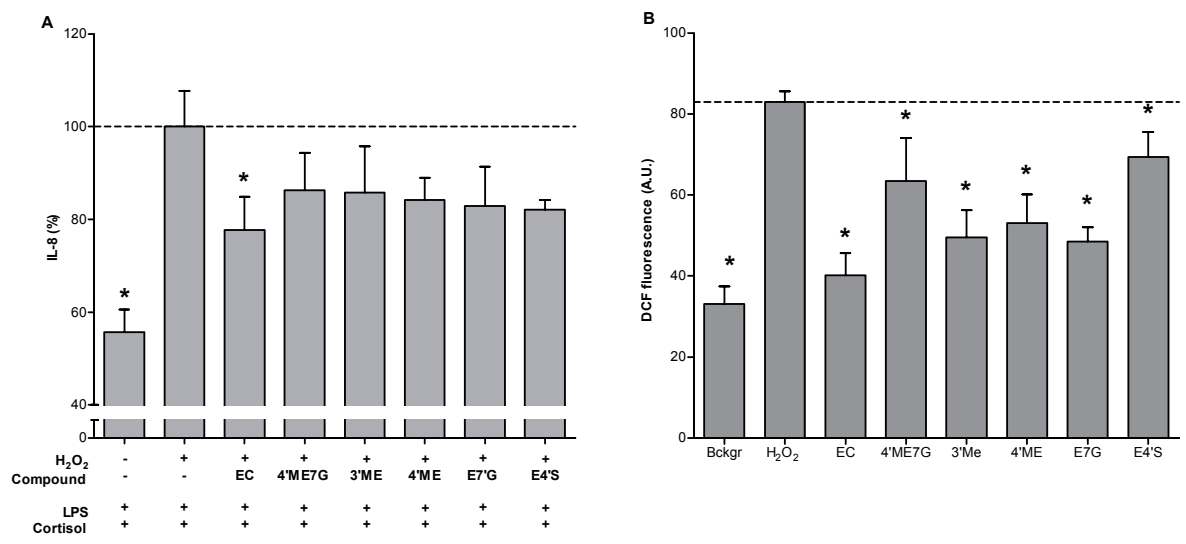

Figure 2. Effect of the flavanol EC and several metabolites on intracellular oxidative stress and glucocorticoid resistance. A) Cells were pre-incubated with $\mathrm{H}_{2} \mathrm{O}_{2}(800 \mu \mathrm{M})+/-$ flavanols $(10 \mu \mathrm{M})$ for $1 \mathrm{~h}$ and subsequently exposed to LPS $(10 \mathrm{ng} / \mathrm{ml})$ and cortisol $(100 \mathrm{nM})$ for $16 \mathrm{~h}$. IL-8 levels (\%) were measured in the cell medium ( $N=6$, mean $\pm \mathrm{SEM})$. B) Intracellular oxidative stress. Differentiated monocytes were incubated with DCFH for 45 min, exposed to $\mathrm{H}_{2} \mathrm{O}_{2}(800 \mu \mathrm{M})+/-$ flavanols and fluorescence was measured for $1 \mathrm{~h}\left(\mathrm{~N}=4\right.$, mean $\pm \mathrm{SD},{ }^{*} \mathrm{p}<0.05$ Dunnett's).

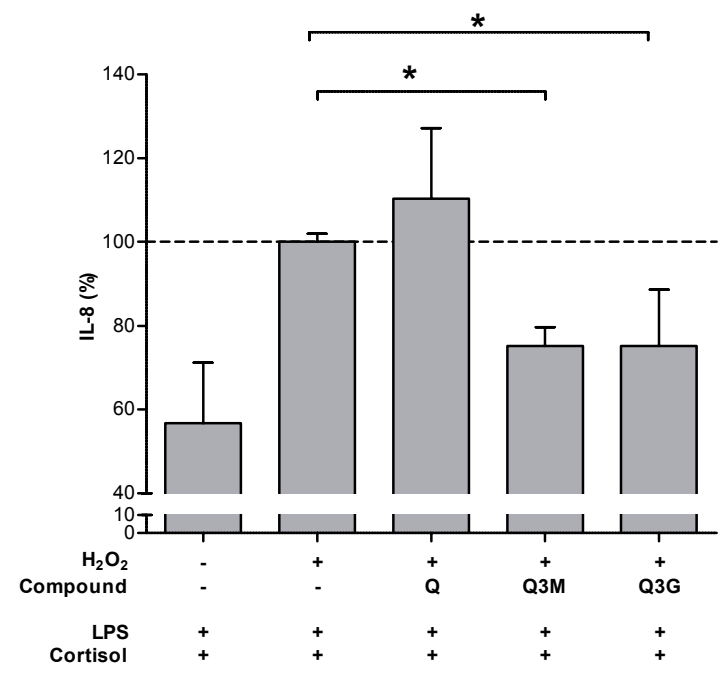

Figure 3. Effect of quercetin $(\mathrm{Q})$ metabolites on cortisol response. Cells were pre-incubated with $\mathrm{H}_{2} \mathrm{O}_{2}(800 \mu \mathrm{M})+/-\mathrm{Q}$ metabolites $(10 \mu \mathrm{M})$ for $1 \mathrm{~h}$ and subsequently exposed to LPS $(10 \mathrm{ng} / \mathrm{ml})$ and cortisol (100 $\mathrm{nM}$ ) for $16 \mathrm{~h}$ and IL-8 levels (\%) measured in the cell medium ( $\mathrm{N}=6$, mean $\pm S D,{ }^{*} \mathrm{p}<0.05$ Mann-Whitney U test). 


\section{Discussion}

Bioactives from dietary sources have numerous health benefits which are achieved via a multitude of subtle effects. Best understood is the antioxidant activity, which could also contribute to the myriad of effects like their anti-inflammatory potential. In this exploratory study we determined the antioxidant effect and the capacity to protect the GC response of a wide array of food-derived compounds. Correlation of these data revealed to what extend these effects are interrelated for the structurally different compounds. Additionally, metabolites of the flavanol EC and the flavonol Q were tested, since flavonoids are extensively metabolized in the gastro-intestinal tract and upon entering the circulation [21, 22].

We found that most of the food-derived bioactives displayed antioxidant and antiinflammatory activity through the protection of the cortisol response. All compounds, except for $\mathrm{Q}$, showing antioxidant activity also protected the cortisol response. This indicates that the antioxidant activity of compounds plays an important role in the protection of the $\mathrm{GC}$ response. Since $\mathrm{H}_{2} \mathrm{O}_{2}$-induced oxidative stress impaired the antiinflammatory effect of cortisol, the antioxidant activity of EC could be directly linked to the protection of the GC response in our previous study [19]. Compounds like EC, MH, Gen and Tax display prominent antioxidant effects and provide protection to the GC response. The only exception seems to be $Q$, which showed a high antioxidant activity but no protection of the GC response. This finding was unexpected since other studies have reported anti-inflammatory effects of $Q[23,24]$. The absence of the anti-inflammatory activity in our test system may be explained by the fact that in an environment high in oxidants $\mathrm{Q}$ may be converted into thiol-reactive quinone products as a result of the radical scavenging. These quinones can react with protein thiols causing reduction or loss of their function $[25,26]$.

The bioactives Cur, Chr and Theo display little to no antioxidant activity but protect the $\mathrm{GC}$ response, indicating that the protection against oxidative stress is not the only way to maintain the anti-inflammatory effect of GCs. This is also corroborated by the results of the metabolites of EC. Although EC metabolites have a reduced antioxidant capacity, as illustrated by an increase in intracellular oxidative stress compared to the parent compound EC, the cortisol response is partially protected by these metabolites. Apparently more molecular mechanisms could be involved in the protection of the GC response.

Several investigated bioactives, including their metabolites, are known for these pleiotropic cellular and molecular effects. Previous studies have shown that curcumin 
and theophylline improve GC response, presumably by restoring HDAC2 activity [27, 28]. Another mechanism to increase the anti-inflammatory effects of glucocorticoids is the inhibition of the enzyme phosphodiesterase 4 (PDE4) [29]. Flavonoids have been reported to exert beneficial effects on the cardiovascular system by the inhibition of PDE which elevates cyclic adenosine monophosphate (cAMP) levels and leads to an activation of the CAMP-dependent protein kinase A (PKA) [30]. As a consequence microvascular leakage is diminished, and trafficking and release of cytokines and chemokines from inflammatory cells is inhibited [31]. Another possible mode of action is the activation of peroxisome proliferator activated receptor a (PPARa). PPARs are transcription factors belonging to the nuclear hormone receptor family and play a central role in the regulation of lipid, lipoprotein and glucose metabolism. PPARs have also been identified as important regulators of inflammatory gene expression $[32,33]$. Activated PPAR can inhibit the pro-inflammatory transcription factor NF-KB, and it has been demonstrated that various isoflavones are potent PPARa and PPARY agonists [34]. By activating PPARa, these isoflavones can reduce the NF- $\mathrm{KB}$ mediated pro-inflammatory gene expression and attenuate the inflammatory response. To what extend all these different mechanisms are involved in the action of the investigated compounds needs to be addressed in further studies.

In summary we show that various food-derived bioactives have antioxidant and antiinflammatory activity by protecting the anti-inflammatory effect of cortisol in human macrophages exposed to oxidative stress. Next to the antioxidant activity of the bioactives, also other mechanisms seem to be involved in this protective, anti-inflammatory effect. This opens new options for the treatment of inflammation, and chronic inflammatory diseases, by boosting the anti-inflammatory effect of the endogenous GC cortisol.

The absence of a direct correlation between the antioxidant effect and the capacity to protect the cortisol response suggests that also other molecular mechanisms are involved in the activity of the investigated nutritionally relevant bioactives. The observation that a wide variety of plant derived food compounds, including metabolites, are able to preserve the endogenous GC response opens new possibilities for dietary approaches specifically targeted for patients with chronic inflammatory diseases. 


\section{References}

1. Keen CL, Holt RR, Oteiza PI, Fraga CG, Schmitz HH. Cocoa antioxidants and cardiovascular health. Am J Clin Nutr. 2005;81:298S-303S.

2. Robbins RJ, Kwik-Uribe C, Hammerstone JF, Schmitz HH. Analysis of flavanols in foods: what methods are required to enable meaningful health recommendations? J Cardiovasc Pharmacol. 2006;47 Suppl 2:S1108; discussion S9-21.

3. Williamson G, Manach C. Bioavailability and bioefficacy of polyphenols in humans. II. Review of 93 intervention studies. Am J Clin Nutr. 2005;81:243S-55S.

4. Heiss C, Keen CL, Kelm M. Flavanols and cardiovascular disease prevention. Eur Heart J. 2010;31:2583-92.

5. Weseler AR, Bast A. Pleiotropic-acting nutrients require integrative investigational approaches: the example of flavonoids. J Agric Food Chem. 2012;60:8941-6.

6. Pellegrini N, Serafini M, Colombi B, Del Rio D, Salvatore S, Bianchi M, et al. Total antioxidant capacity of plant foods, beverages and oils consumed in Italy assessed by three different in vitro assays. J Nutr. 2003;133:2812-9.

7. Heim KE, Tagliaferro AR, Bobilya DJ. Flavonoid antioxidants: chemistry, metabolism and structure-activity relationships. J Nutr Biochem. 2002;13:572-84.

8. Duenas M, Gonzalez-Manzano S, Gonzalez-Paramas A, Santos-Buelga C. Antioxidant evaluation of O-methylated metabolites of catechin, epicatechin and quercetin. J Pharm Biomed Anal. 2010;51:443-9.

9. Boots AW, Haenen GR, Bast A. Health effects of quercetin: from antioxidant to nutraceutical. Eur J Pharmacol. 2008;585:325-37.

10. Weseler AR, Bast A. Oxidative stress and vascular function: implications for pharmacologic treatments. Curr Hypertens Rep. 2010;12:154-61.

11. Sundar IK, Yao H, Rahman I. Oxidative stress and chromatin remodeling in chronic obstructive pulmonary disease and smoking-related diseases. Antioxid Redox Signal. 2013;18:1956-71.

12. Van der Vliet A, Bast A. Effect of oxidative stress on receptors and signal transmission. Chem Biol Interact. 1992;85:95-116.

13. Rickard AJ, Young MJ. Corticosteroid receptors, macrophages and cardiovascular disease. J Mol Endocrinol. 2009;42:449-59.

14. Mittal M, Siddiqui MR, Tran K, Reddy SP, Malik AB. Reactive Oxygen Species in Inflammation and Tissue Injury. Antioxid Redox Signal. 2014;20:1126-67.

15. Barnes PJ, Adcock IM. Glucocorticoid resistance in inflammatory diseases. Lancet. 2009;373:1905-17.

16. Yang N, Ray DW, Matthews LC. Current concepts in glucocorticoid resistance. Steroids. 2012;77:1041-9.

17. Keenan CR, Salem S, Fietz ER, Gualano RC, Stewart AG. Glucocorticoid-resistant asthma and novel antiinflammatory drugs. Drug Discov Today. 2012;17:1031-8.

18. Ito K, Hanazawa T, Tomita K, Barnes PJ, Adcock IM. Oxidative stress reduces histone deacetylase 2 activity and enhances IL-8 gene expression: role of tyrosine nitration. Biochem Biophys Res Commun. 2004;315:240-5.

19. Ruijters EJ, Haenen GR, Weseler AR, Bast A. The cocoa flavanol (-)-epicatechin protects the cortisol response. Pharmacol Res. 2014;79:28-33.

20. Ruijters EJB, Haenen GRMM, Weseler AR, Bast A. The anti-inflammatory efficacy of dexamethasone is protected by (-)-epicatechin. PharmaNutrition. 2014;2:47-52.

21. Monagas M, Urpi-Sarda M, Sanchez-Patan F, Llorach R, Garrido I, Gomez-Cordoves C, et al. Insights into the metabolism and microbial biotransformation of dietary flavan-3-ols and the bioactivity of their metabolites. Food Funct. 2010;1:233-53.

22. Rodriguez-Mateos A, Toro-Funes N, Cifuentes-Gomez T, Cortese-Krott M, Heiss C, Spencer JP. Uptake and metabolism of (-)-epicatechin in endothelial cells. Arch Biochem Biophys. 2014.

23. Boots AW, Wilms LC, Swennen EL, Kleinjans JC, Bast A, Haenen GR. In vitro and ex vivo anti-inflammatory 
activity of quercetin in healthy volunteers. Nutrition. 2008;24:703-10.

24. Angeloni C, Hrelia S. Quercetin reduces inflammatory responses in LPS-stimulated cardiomyoblasts. Oxid Med Cell Longev. 2012;2012:837104.

25. Boots AW, Li H, Schins RP, Duffin R, Heemskerk JW, Bast A, et al. The quercetin paradox. Toxicol Appl Pharmacol. 2007;222:89-96.

26. Lemmens KJ, Vrolijk MF, Bouwman FG, van der Vijgh WJ, Bast A, Haenen GR. The Minor Structural Difference between the Antioxidants Quercetin and 4'O-Methylquercetin Has a Major Impact on Their Selective Thiol Toxicity. Int J Mol Sci. 2014;15:7475-84.

27. Meja KK, Rajendrasozhan S, Adenuga D, Biswas SK, Sundar IK, Spooner G, et al. Curcumin restores corticosteroid function in monocytes exposed to oxidants by maintaining HDAC2. Am J Respir Cell Mol Biol. 2008;39:312-23.

28. Cosio BG, Tsaprouni L, Ito K, Jazrawi E, Adcock IM, Barnes PJ. Theophylline restores histone deacetylase activity and steroid responses in COPD macrophages. J Exp Med. 2004;200:689-95.

29. Ortiz JL, Milara J, Lluch J, De Diego A, Sanz C, Cortijo J. Phosphodiesterase-4 inhibition improves corticosteroid insensitivity in pulmonary endothelial cells under oxidative stress. Allergy. 2013;68:64-73.

30. Peluso MR. Flavonoids attenuate cardiovascular disease, inhibit phosphodiesterase, and modulate lipid homeostasis in adipose tissue and liver. Exp Biol Med (Maywood). 2006;231:1287-99.

31. Ejiofor S, Turner AM. Pharmacotherapies for COPD. Clinical medicine insights Circulatory, respiratory and pulmonary medicine. 2013;7:17-34.

32. Bougarne N, Paumelle R, Caron S, Hennuyer N, Mansouri R, Gervois P, et al. PPARalpha blocks glucocorticoid receptor alpha-mediated transactivation but cooperates with the activated glucocorticoid receptor alpha for transrepression on NF-kappaB. Proc Natl Acad Sci U S A. 2009;106:7397-402.

33. Neher MD, Weckbach S, Huber-Lang MS, Stahel PF. New insights into the role of peroxisome proliferatoractivated receptors in regulating the inflammatory response after tissue injury. PPAR research. 2012;2012:728461.

34. Matin A, Gavande N, Kim MS, Yang NX, Salam NK, Hanrahan JR, et al. 7-Hydroxy-benzopyran-4-one derivatives: a novel pharmacophore of peroxisome proliferator-activated receptor alpha and -gamma (PPARalpha and gamma) dual agonists. J Med Chem. 2009;52:6835-50. 



\section{Chapter 6}

Pleiotropic benefit of monomeric and oligomeric flavanols on vascular health - A randomized controlled clinical pilot study

Antje R. Weseler

Erik J.B. Ruijters

Marie-José Drittij-Reijnders

Koen D. Reesink

Guido R.M.M. Haenen

Aalt Bast

PLoS ONE, 2011, 6(12) 


\section{Abstract}

Cardiovascular diseases are expanding to a major social-economic burden in the Western World and undermine man's deep desire for healthy ageing. Epidemiological studies suggest that flavanol-rich foods (e.g. grapes, wine, chocolate) sustain cardiovascular health. For an evidenced-based application, however, sound clinical data on their efficacy are strongly demanded.

In a double-blind, randomized, placebo-controlled intervention study we supplemented 28 male smokers with $200 \mathrm{mg}$ per day of monomeric and oligomeric flavanols (MOF) from grape seeds. At baseline, after 4 and 8 weeks we measured macroand microvascular function and a cluster of systemic biomarkers for major pathological processes occurring in the vasculature: disturbances in lipid metabolism and cellular redox balance, and activation of inflammatory cells and platelets.

In the MOF group serum total cholesterol and LDL decreased significantly $(P \leq 0.05)$ by $5 \%(n=11)$ and $7 \%(n=9)$, respectively in volunteers with elevated baseline levels. Additionally, after 8 weeks the ratio of glutathione to glutathione disulphide in erythrocytes rose from baseline by $22 \%(n=15, P<0.05)$ in MOF supplemented subjects. We also observed that MOF supplementation exerts anti-inflammatory effects in blood towards ex vivo added bacterial endotoxin and significantly reduces expression of inflammatory genes in leukocytes. Conversely, alterations in macro- and microvascular function, platelet aggregation, plasma levels of nitric oxide surrogates, endothelin-1, C-reactive protein, fibrinogen, prostaglandin F2alpha, plasma antioxidant capacity and gene expression levels of antioxidant defense enzymes did not reach statistical significance after 8 weeks MOF supplementation. However, integrating all measured effects into a global, so-called vascular health index revealed a significant improvement of overall vascular health by MOF compared to placebo $(\mathrm{P} \leq 0.05)$.

Our integrative multi-biomarker approach unveiled the pleiotropic vascular health benefit of an 8 weeks supplementation with $200 \mathrm{mg} / \mathrm{d}$ MOF in humans. 


\section{Introduction}

Cardiovascular diseases (CVD) are expanding to a major social-economic burden in the Western World [1, 2]. Despite a diverse disease pattern in advanced states, the early onset of CVD is characterized by the occurrence of several general pathophysiological mechanisms. Persistently increased levels of inflammation and oxidative stress, elevated serum lipid levels as well as the development of a prothrombotic state crucially contribute to the occurrence of an impaired vascular function [3]. Chronic cigarette smoking is one of the lifestyle factors that essentially fuels and exaggerates these processes. It is well established that cigarette smoke contains large quantities of free radicals and pro-oxidant compounds [4] and additionally increases endogenous free radical production by the activation of macrophages and neutrophils, uncoupling endothelial nitric oxide synthase (eNOS) and mitochondrial transport chain [5-7]. As a consequence markers of oxidative stress and inflammation are significantly elevated in the systemic circulation of smokers compared to non-smokers [8-12]. Heightened serum lipid levels and the activation of platelets further promote the manifestation of a proatherogenic state in smokers $[13,14]$ and contribute to the development of endothelial dysfunction in coronary and peripheral conductance and resistance vessels $[15,16]$. Furthermore, dietary antioxidants like vitamin $C$ have been shown to improve or even reverse proatherogenic, proinflammatory and prothrombotic conditions in smokers $[17,18]$.

In search of strategies which are able to sustain long-term cardiovascular health and are easily implementable in peoples' everyday life, dietary supplementation may indeed offer valuable opportunities. Epidemiological studies performed over the past decades underpin that a traditional Mediterranean diet reduces the risk of CVD [19, 20]. Since polyphenols, in particular monomeric and oligomeric flavan-3-ols (MOF) consisting of up to 5 flavanol units, are an integral part of this diet, these compounds have been widely studied in vitro and in vivo in order to elucidate their mechanism of action to prevent CVD [21-24]. The seeds of grapes (Vitis vinifera L.) are in particular rich in MOF. Since grape seed extracts consist of different mixtures of MOF and other polyphenols, a thorough analysis of their composition is indispensable for characterizing the active principle. Moreover, various MOF are supposed to modulate diverse (patho)physiological processes, which requires the assessments of multiple clinical endpoints. Beyond such multifaceted mechanisms of action, nutrients, in contrast to drugs, are known to modulate human's body function in a subtle manner. As a consequence, the classical way of proving clinical effectiveness by the assessment of a single primary end point does not adequately reflect the mode of action of these compounds and frequently fails to unveil significant effects 
[25]. Therefore, the present pilot study aimed to investigate the pleiotropic effects of a relatively low dose supplementation with a well characterized MOF composition from grape seeds in the human vasculature in a holistic manner.

The meticulous selection of outcome parameters led to a spectrum of makers that comprised established as well as novel cardiovascular risk factors and systemic biomarkers reflecting the most essential pathomechanisms in the human vasculature on a functional and (sub)cellular level. The integration of the changes in these biomarkers into a vascular health index enabled us to demonstrate the beneficial effects of MOF on vascular health in general. This is the first trial that applies an integrative biomarker approach in order to determine the health effects of a dietary supplementation in the human vasculature.

\section{Material and methods}

\section{Subjects and study design}

The study was designed as a randomized, placebo-controlled, double-blind trial and conducted at the Maastricht University and Academic Hospital Maastricht, The Netherlands. Non-obese men were eligible when they were between 30 and 60 years old and smoked $\geq 10$ cigarettes per day for at least 5 years. Exclusion criteria were a history or presence of any metabolic, cardiovascular and/or malignant disease, excessive consumption of alcohol (>28 consumptions, i.e. approximately $250 \mathrm{~g} /$ week), a vegetarian/ vegan life style, medically prescribed diet or slimming diet and the use of any supplement and functional food containing vitamins, antioxidants and/or polyphenolic compounds for 4 weeks before and during the study. Thirty-three eligible subjects were included and randomized in the study. Five subjects dropped out either before or after the 1st study visit due to personal reasons which were not related to the study.

All subjects gave their written informed consent prior to their participation. The study was approved by the Medical Ethical Committee of the Maastricht University and Academic Hospital Maastricht, The Netherlands and conducted in accordance with the World Medical Association Declaration of Helsinki of 1975 as revised in 2008.

Subjects were randomly assigned to one of the two test groups under taking into account that the groups became balanced with respect to the number of cigarettes smoked per day.

The two parallel supplementation regimes consisted of capsules containing either $100 \mathrm{mg}$ MOF from Vitis vinifera L. seeds (MASQUELIER's ${ }^{\circledR}$ Original OPCs) or an equivalent 
amount of microcrystalline cellulose (placebo). The composition of the verum capsules regarding its standardized MOF content is shown in Table 1. The MOF and the placebo material were provided by International Nutrition Company (INC) BV, Loosdrecht, The Netherlands, in indistinguishable opaque capsules which were packaged in blisters and boxes labeled with the treatment code. Subjects and investigators were blinded for the treatment code until data analysis was completed. The subjects were asked to daily take 2 capsules with a glass of water in the morning directly before breakfast and to note the time of intake in their study diary. In addition, subjects were instructed not to change their daily eating, smoking and life style habits and to record all potential deviations in their study diary on a daily base. Every 2 weeks subjects were invited for a control visit at the investigational site in order to control their well-being and the occurrence of potential adverse events. At these occasions a comparable number of subjects of both test groups reported discomfort from common cold, headache, nausea, and shoulder and ankle injury during the 8 study weeks. All these events were classified by the subjects as mild and were not related to the intervention. The intake of the test capsules was checked based on the entries in the study diary and the blisters returned. These controls revealed full intake compliance in both test groups (median, 100\%).

The outcome parameters were measured prior to the start of the supplementation (baseline), and after 4 and 8 weeks of supplementation in the morning after an overnight fast and refraining from smoking and drinking alcohol- and/or caffeine-containing drinks for at least $12 \mathrm{~h}$ in advance.

Table 1. Composition of monomeric and oligomeric flavanols isolated from grape (Vitis vinifera L.) seeds and incorporated in the verum test capsules.

\begin{tabular}{ll}
\hline Compound & Amount \% (wt:wt) \\
\hline Total catechins & $\mathbf{2 5 . 6}$ \\
(+)-catechin & 10.9 \\
(-)-epicatechin & 12.2 \\
(-)-epicatechin-3-O-gallate & 2.5 \\
Total dimers & $\mathbf{2 7 . 5}$ \\
proanthocyanidin B1 & 7.7 \\
proanthocyanidin B2 & 8.3 \\
proanthocyanidin B3 & 2.8 \\
proanthocyanidin B4 & 1.6 \\
proanthocyanidin B2-gallate & 7.1 \\
Total tri-, tetra- and pentameric & $\mathbf{4 6 . 9}$ \\
proanthocyanidins & \\
\hline
\end{tabular}


The vascular function measurements took place in a quiet, air-conditioned room of the Academic Hospital Maastricht with a constant temperature of $23^{\circ} \mathrm{C}$. After arrival, subjects rested in supine position for at least 15 min before the measurements commenced. The sequence of the vascular function measurements was for each subject at random, but remained the same for every individual on the three test sessions.

Subsequent to the vascular measurements venous blood was collected. Plasma and serum were obtained by centrifugation at $800 \mathrm{~g}$ and $4^{\circ} \mathrm{C}$ for $10 \mathrm{~min}$ and immediately processed as described for the individual parameter. Plasma samples for the quantification of the trolox equivalent antioxidant capacity (TEAC), 8-isoprostaglandine F2a (8-isoPGF2a), nitrate and nitrite (NOx) and endothelin-1 (ET-1) concentrations were stored at $-80^{\circ} \mathrm{C}$ until analysis.

\section{Sample size}

A conclusive sample size calculation was infeasible for the effects of an 8 weeks MOF supplementation on our primary study parameter, i.e. vascular function assessed as either brachial artery flow-mediated dilation (FMD) or Laser-Doppler-flowmetry (LDF) due to a lack of effect magnitude. In persons at low risk of coronary heart disease, an increase in FMD of $1.4 \%$ lowered their Framingham risk by $1 \%$ [26]. Assuming a variance of $1.8 \%$ for the change in brachial FMD, we would be able to detect a change of $1.4 \%$ in FMD in a group of $n=[2 \sigma(z a+z \beta) 2](\mu x-\mu y) 2=15$ subjects with a power of $80 \%(\beta=0.20 ; z \beta=0.84)$ and an $a$-value of $0.05(z a=1.96)$ upon the MOF supplementation.

\section{Measurement of macrovascular function}

Macrovascular function was assessed as flow-mediated dilation (FMD) of the brachial artery in accordance with the recommendations of the International Brachial Artery Reactivity Task Force [27]. FMD values were calculated as the maximal increase in diameter relative to the baseline diameter (in percentage).

\section{Measurement of microvascular function}

Microvascular function was assessed by measuring skin blood flow responses by means of Laser-Doppler-flowmetry (LDF) following iontophoretical application of 9 subsequent dosages of either acetylcholine (ACh), a mix of ACh and L-NG-monomethyl-arginine (L-NMMA) or sodium nitroprusside (SNP) using the Periflux System 5000 (Perimed AB, Stockholm, Sweden). Maximal blood flow perfusion (in percentage of baseline blood flow) and dosage interval resulting in half maximal blood flow response (ED50) were 
determined from the accumulative blood flow response curves by visual inspection.

\section{Measurement of biochemical vascular parameters}

Plasma NOx concentrations were determined by the Griess method as described by Giustarini et al. [28]. Plasma ET-1 was measured by a commercially available radioimmunoassay kit (S2024, Bachem, Switzerland) after plasma extraction by passage through SepPak C18 cartridges (Waters, Netherlands). Arginase activity in erythrocytes was measured following a modified Schimke's method as described by Corraliza and colleagues [29].

\section{Measurement of serum lipid levels}

Total cholesterol (tChol), low-density lipoprotein cholesterol (LDL), high density lipoprotein cholesterol (HDL) and triglycerides (TG) were quantified by means of enzymatic colorimetric assays on a Roche/Hitachi Modular analyzer (Roche Diagnostics $\mathrm{GmbH}$, Mannheim, Germany).

\section{Measurement of platelet function}

Platelet function was measured in platelet-rich plasma by classical light transmission aggregometry, using a Chronolog aggregometer (Chrono-log Corporation, Havertown, $\mathrm{PA}, \mathrm{USA})$. Collagen (1.5 mg/L) induced platelet aggregation (CPA) and rate (CPAR) as well as adenosine diphosphate (ADP, $10 \mu \mathrm{M})$ induced percentage aggregation (APA) and rate (APAR) were measured in triplicate per subject and time point in the study.

\section{Measurement of plasma fibrinogen}

Fibrinogen (Fib) plasma concentrations were determined on a STA-R Evolution analyzer (Roche Diagnostics GmbH, Mannheim, Germany).

\section{Measurement of systemic inflammatory parameters}

The inflammatory resistance of subjects' blood was investigated ex vivo as described by Swennen et al. [30], with some minor modification. Freshly collected heparinized blood was aliquoted into 24-well sterile plates and diluted 1:4 with RPMI 1640 (Invitrogen). Cytokine production in the blood was induced by the addition of $100 \mathrm{ng} / \mathrm{mL}$ LPS (O26:B6, Sigma). After incubating the plates in $5 \% \mathrm{CO} 2$ at $37^{\circ} \mathrm{C}$ for $6 \mathrm{~h}$, the cell-free supernatant was collected by centrifugation $\left(19,720 \mathrm{~g}, 10 \mathrm{~min}, 4^{\circ} \mathrm{C}\right)$ and stored at $-80^{\circ} \mathrm{C}$ until quantification of the cytokines. Tumor necrosis factor (TNF)- $a$ and interleukin (IL)-10 were quantified 
by means of commercially available ELISA kits (PeliKine Compact human ELISA kits, CLB/ Sanquin). The limits of sensitivity were $1 \mathrm{pg} / \mathrm{mL}$ for both cytokines.

C-reactive protein (CRP) serum concentrations were measured by particle-enhanced immunoturbidimetry on a Roche/Hitachi Modular analyzer (Roche Diagnostics GmbH, Mannheim, Germany).

\section{Measurement of redox state parameters}

Plasma antioxidant capacity was quantified as TEAC according to Fischer et al. [31] and corrected for plasma uric acid concentrations. Glutathione and glutathione disulphide (GSH/GSSG) concentrations in erythrocytes were assessed as described by Julicher et al. [32] and Griffith [33]. Plasma total 8-iso-PGF2a concentrations were determined after alkaline hydrolysis and solid phase extraction by using a commercially available enzyme immunoassay (Cayman Chemical Company, Ann Arbor, MI, USA).

\section{Real-time (RT)-Polymerase chain reaction (PCR)}

Expression of genes coding for inflammatory mediators and redox enzymes in whole blood were measured by real-time RT-PCR. In order to preserve RNA freshly collected whole blood was added to RNALater ${ }^{\oplus}$ (Ambion, Austin, TX, USA) and stored at $-80^{\circ} \mathrm{C}$. Total RNA was isolated from whole blood using RiboPure-Blood kit (Ambion, Austin TX, USA) and A260/280 measured to determine concentration and purity. 500 ng of total RNA was reverse transcribed using iScript cDNA synthesis kit (Bio-Rad, Hercules, CA, USA) followed by DNA digestion with DNase I. Quantitative real-time PCR (qPCR) was performed in a total volume of $25 \mu \mathrm{l}$ containing $5 \mu \mathrm{l}$ cDNA, $2.5 \mu \mathrm{l}(3 \mu \mathrm{M})$ of each primer and $12.5 \mu \mathrm{l}$ SensiMix SYBR \& Fluorescein Kit (Quantace, London, UK). The cycling conditions comprised an initial denaturation step at $95^{\circ} \mathrm{C}$ for $10 \mathrm{~min}$. followed by 40 cycles of $15 \mathrm{sec}$. at $95^{\circ} \mathrm{C}$ and 45 sec. at $60^{\circ} \mathrm{C}$ using an iCycler (Bio-Rad, Hercules, CA, USA). Data were expressed as relative gene expression values (RE) by calculating for each time point in the study the $\Delta \mathrm{Ct}$ values under consideration of glyceraldehyde-3-phosphate dehydrogenase (GAPDH) as housekeeping gene and normalizing the values at 4 and 8 weeks for baseline $\Delta C t$ values.

\section{Calculation of the vascular health index (VHI)}

As an integrative measure of the diverse effects of the MOF supplementation on vascular health, the VHI was established. This index was calculated per subject after 4 and 8 weeks intervention by adding up the percentage change from baseline of those parameters for which it was expected that an increase indicates a beneficial effect on cardiovascular 
health. The percentage change from baseline of parameters for which it was expected that a decrease reflects a beneficial health effect were subtracted. The gene expression data were not taken into account, because up- or down-regulation of the assessed genes could not be unambiguously related to health benefits. These considerations led to the construction of the following formula:

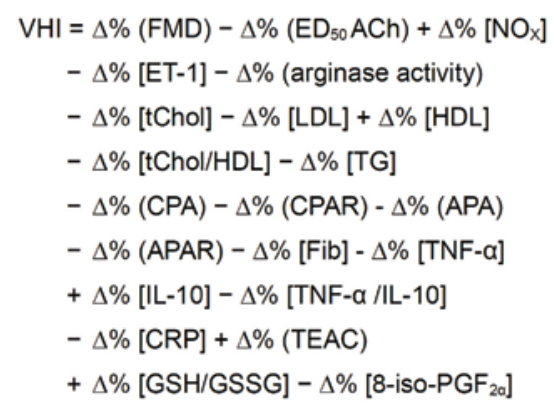

\section{Statistical methods}

All data were tested for normal distribution by visual inspection of the histograms, taking into account the outcomes of the Kolmogorov-Smirnov- and Shapiro-Wilk- tests. Normally distributed data are presented as mean \pm SEM. If log-transformation did not result in a normal distribution, data are given as median and range (tables) or $10^{\text {th }}$ and $90^{\text {th }}$ percentiles (figures).

Changes after 4 and 8 weeks intervention with respect to baseline were appraised within a test group by one-tailed paired-samples t-tests in case of normally distributed data and by Wilcoxon Signed Ranks tests in case of not normally distributed data.

Differences between the test groups at each of the 3 time points (baseline, 4 and 8 weeks) as well as in the changes after 4 and 8 weeks with respect to baseline were tested by two-tailed independent samples t-tests in case of normally distributed data and MannWhitney U-tests in case of not normally distributed data. Level of significance was set at $P \leq 0.05$. Statistical analyses were performed using PASW statistics 17.0 (SPSS Inc, Chicago, IL, USA) and GraphPad Prism ${ }^{\circledast}$ (Graphpad Software, Inc., San Diego, CA, USA). 
Table 2. Primer sequences used for the RT-PCR experiments.

\begin{tabular}{|c|c|c|}
\hline Gene $^{1}$ & Forward-primer $5^{\prime}-3^{`}$ & Reverse-primer $5^{\circ}-3^{`}$ \\
\hline CAT1 & GACTGACCAGGGCATCAAAAA & CGGATGCCATAGTCAGGATCTT \\
\hline GAPDH & GCACCACCAACTGCTTAGCA & TGGCAGTGATGGCATGGA \\
\hline GPX1 & CCCGTGCAACCAGTTTGG & CGGACGTACTTGAGGGAATTCA \\
\hline GPX4 & CCTTTGCCGCCTACTGAAG & CACAGCGCCAGTCGTCC \\
\hline GSR & CAAGCTGGGTGGCACTTG & TTGGAAAGCCATAATCAGCA \\
\hline HMOX1 & СТТСТТСАССТТССССААСА & GCTCTGGTCCTTGGTGTCAT \\
\hline ICAM1 & CTGAGCAATGTGCAAGAAGATAGC & CCCGTTCTGGAGTCCAGTACA \\
\hline IL-1 $\beta$ & TCCCCAGCCCTTTTGTTGA & TTAGAACCAAATGTGGCCGTG \\
\hline IL-6 & AGTGAGGAACAAGCCAGAGC & GTCAGGGGTGGTTATTGCAT \\
\hline IL-8 & GGACAAGAGCCAGGAAGAAA & AAATTTGGGGTGGAAAGGTT \\
\hline IL-10 & GCTGTCATCGATTTCTTCCC & CTCATGGCTTTGTAGATGCCT \\
\hline NFKBIA & CTACACCTTGCCTGTGAGCA & TCCTGAGCATTGACATCAGC \\
\hline NOS2 & TTCAAGACCAAATTCCACCAG & ATTCTGCTGCTTGCTGAGGT \\
\hline SOD2 & ATCAGGATCCACTGCAAGGAA & CGTGCTCCCACACATCAATC \\
\hline TNF-a & TCAATCGGCCCGACTATCTC & CAGGGCAATGATCCCAAAGT \\
\hline VCAM1 & TGGGAAAAACAGAAAAGAGGTG & GTCTCCAATCTGAGCAGCAA \\
\hline
\end{tabular}

'CAT, catalase; GAPDH, glyceraldehyde-3-phosphate dehydrogenase; GPX1, glutathione peroxidase 1 ; GPX4, glutathione peroxidase 4; GSR, glutathione reductase; HMOX1, hemeoxygenase 1; ICAM1, intercellular adhesion molecule 1; IL-1 $\beta$, interleukin 1 beta; IL-6, interleukin 6; IL-8, interleukin 8; IL-10, interleukin 10; NFKBIA, nuclear factor of kappa light polypeptide gene enhancer in B-cells inhibitor alpha; NOS2, nitric oxide synthase 2; SOD2, superoxide dismutase 2; TNF-a, tumor necrosis factor alpha; VCAM1, vascular adhesion molecule 1. 
Table 3. Clinical characteristics of the study population. ${ }^{1}$

\begin{tabular}{|c|c|c|c|c|}
\hline & Time (weeks) & MOF $(n=15)$ & Placebo $(n=13)$ & $P$ value $^{2}$ \\
\hline Age (y) & 0 & $46(30-58)$ & $48(30-60)$ & 0.982 \\
\hline BMI $\left(\mathrm{kg} / \mathrm{m}^{2}\right)$ & 0 & $24 \pm 1$ & $25 \pm 1$ & 0.221 \\
\hline Years of smoking & 0 & $28(14-45)$ & $29(15-45)$ & 0.982 \\
\hline Cigarettes/day & 0 & $17(10-28)$ & $15(9-30)$ & 0.799 \\
\hline Pack years & 0 & $19(7-62)$ & $18(9-54)$ & 0.928 \\
\hline \multirow[t]{3}{*}{$\mathrm{SBP}(\mathrm{mmHg})$} & 0 & $114(103-124)$ & 115 (102-149) & 0.580 \\
\hline & 4 & $115(101-136)$ & $114(100-154)$ & 0.771 \\
\hline & 8 & $115(100-134)$ & $108(100-150)$ & 0.240 \\
\hline \multirow[t]{3}{*}{$\mathrm{DBP}(\mathrm{mmHg})$} & 0 & $74(60-85)$ & 76 (59-99) & 0.695 \\
\hline & 4 & $71(61-85)$ & $74(58-100)$ & 0.942 \\
\hline & 8 & $72(56-84)$ & 73 (58-99) & 0.645 \\
\hline \multirow[t]{3}{*}{ tChol (mM) } & 0 & $5.7(4.0-7.1)$ & $5.7(3.6-8.5)$ & 0.945 \\
\hline & 4 & $5.7(4.0-6.3)$ & $5.5(4.5-8.8)$ & 0.730 \\
\hline & 8 & $5.9(3.8-6.8)$ & $5.7(3.6-8.8)$ & 0.800 \\
\hline \multirow[t]{3}{*}{$\mathrm{LDL}(\mathrm{mM})$} & 0 & $3.8 \pm 0.2$ & $3.9 \pm 0.3$ & 0.890 \\
\hline & 4 & $3.7 \pm 0.2$ & $3.8 \pm 0.3$ & 0.601 \\
\hline & 8 & $3.8 \pm 0.2$ & $3.8 \pm 0.3$ & 0.821 \\
\hline \multirow[t]{3}{*}{$\mathrm{HDL}(\mathrm{mM})$} & 0 & $1.2 \pm 0.1$ & $1.3 \pm 0.1$ & 0.418 \\
\hline & 4 & $1.2 \pm 0.1$ & $1.4 \pm 0.1$ & 0.305 \\
\hline & 8 & $1.2 \pm 0.1$ & $1.4 \pm 0.1$ & 0.190 \\
\hline \multirow[t]{3}{*}{ tChol/HDL ratio } & 0 & $4.8(2.9-8.8)$ & $4.0(2.9-9.5)$ & 0.433 \\
\hline & 4 & $4.9(2.6-6.1)$ & $4.0(2.7-8.5)$ & 0.344 \\
\hline & 8 & $4.9(2.9-7.5)$ & $4.3(2.8-9.8)$ & 0.299 \\
\hline \multirow[t]{3}{*}{ TG (mM) } & 0 & $1.2(0.9-4.0)$ & $1.4(0.8-4.3)$ & 0.872 \\
\hline & 4 & $1.6(0.9-3.7)$ & $1.5(0.8-3.6)$ & 0.549 \\
\hline & 8 & $1.6(0.6-2.8)$ & $1.4(0.7-4.5)$ & 0.533 \\
\hline \multirow[t]{3}{*}{ CRP (mg/l) } & 0 & $2(0-6)$ & $1(0-5)$ & 0.196 \\
\hline & 4 & $2(0-10)$ & $1(0-6)$ & 0.317 \\
\hline & 8 & $2(0-6) 1$ & $1(0-6)$ & 0.055 \\
\hline \multirow[t]{3}{*}{ Fibrinogen (g/l) } & 0 & $3.5(2.4-4.8)$ & $3.3(2.8-5.3)$ & 0.460 \\
\hline & 4 & $3.3(2.4-6.3)$ & $3.5(2.2-4.9)$ & 0.800 \\
\hline & 8 & $3.9(2.6-5.7)$ & $3.3(2.7-4.6)$ & 0.146 \\
\hline
\end{tabular}

${ }^{1}$ Values are mean \pm SEM or median (range); BMI, body mass index; CRP, Creactive protein; DBP, diastolic blood pressure; HDL, high density lipoprotein; $L D L$, low density lipoprotein; MOF, monomeric and oligomeric flavanols; SBP, systolic blood pressure; tChol, total cholesterol; TG, triglycerides. ${ }^{2} P$ value for between-groups differences assessed by independent Student's t-test or Mann-Whitney U-test where median (range) is indicated. 


\section{Results}

Both test groups did not differ significantly at baseline with respect to their anthropometric characteristics, smoking habits, blood pressure and serum lipid concentrations (Table 3). Blood pressure values were within the normal range and did not fluctuate significantly over the intervention period. Eleven subjects of the MOF group and 10 subjects of the placebo group exhibited elevated tChol concentrations, i.e. $>5 \mathrm{mM}$ [34]. In both groups 9 subjects revealed LDL concentrations $>3.2 \mathrm{mM}$. TG serum concentrations were within the normal range for both groups [35].

\section{Effects of the MOF supplementation on vascular function}

Macrovascular function assessed as FMD of the brachial artery did not differ between the MOF and the placebo group throughout the study period (table 5).

In addition, MOF supplementation did not affect the maximal ACh-induced blood flow response and the maximal endothelial nitric oxide synthase (eNOS)-mediated blood flow response, which was obtained from the maximal blood flow induced by ACh with and without the eNOS inhibitor L-NMMA (data not shown). Large within-subject fluctuations of the blood flow responses upon SNP application reduced the sensitivity of the assessment of these data.

After 4 weeks the $\mathrm{ED}_{50}$ of $\mathrm{ACh}$ was one dosage interval lower in the MOF group than in the placebo group $(P<0.05)$ indicating an increased sensitivity towards the endotheliumdependent vasodilator $\mathrm{ACh}$. However, at the end of the study the $\mathrm{ED}_{50}$ in both test groups were not significantly different $(P=0.26)$ (table 5$)$.

\section{Effects of the MOF supplementation on biochemical vascular parameters}

No effects of the MOF supplementation on plasma nitrite, nitrate and ET-1 concentrations as well as arginase activity in erythrocytes were detected (table 5).

\section{Effects of the MOF supplementation on serum lipid concentrations}

Serum lipid concentrations did not change significantly during the 8 weeks intervention in both test groups (table 3). However, in the subgroup of individuals with baseline tChol $>5 \mathrm{mM}(\mathrm{n}=11)$ MOF supplementation significantly lowered tChol by $9 \%$ after 4 weeks ( $P<0.05$ vs. baseline) and by $5 \%$ after 8 weeks ( $P=0.05$ vs. baseline). In contrast, in the similar placebo subgroup $(n=10)$, no significant effects on $\mathrm{tChol}$ were seen during the study (figure 1A).

LDL concentrations in the subgroup with baseline levels $>3.2 \mathrm{mM}(\mathrm{n}=9)$ decreased 
significantly by $11 \%$ after 4 weeks ( $P<0.05$ vs. baseline) and $7 \%$ after 8 weeks MOF intake $(P<0.05$ vs. baseline; figure 1B). In relation to that, in the similar placebo subgroup $(n=9)$ no significant effect on LDL was observed.

In the MOF and the placebo subgroup the tChol-HDL-ratio did not differ significantly during the intervention (figure 1C).

Five subjects of the MOF group and 4 of the placebo group had TG concentrations $>1.7 \mathrm{mM}$, which is defined by the American Heart Association as "borderline high" [35].

A

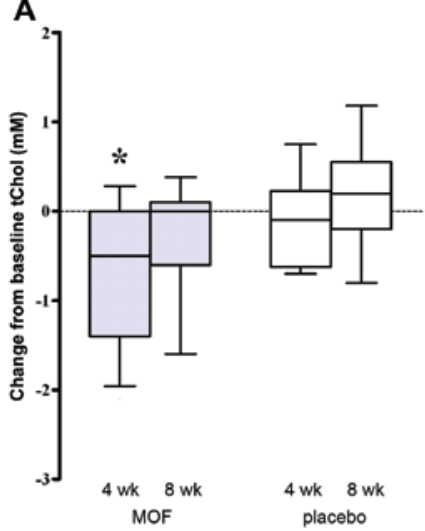

C

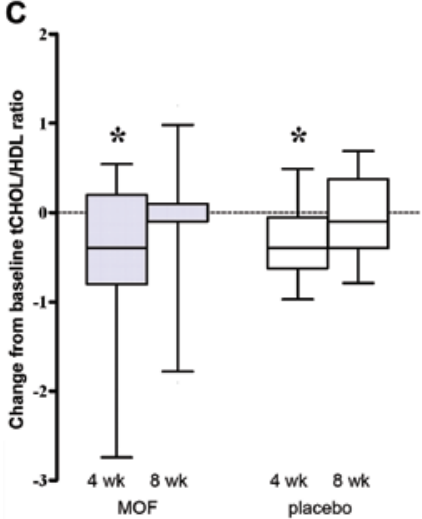

B

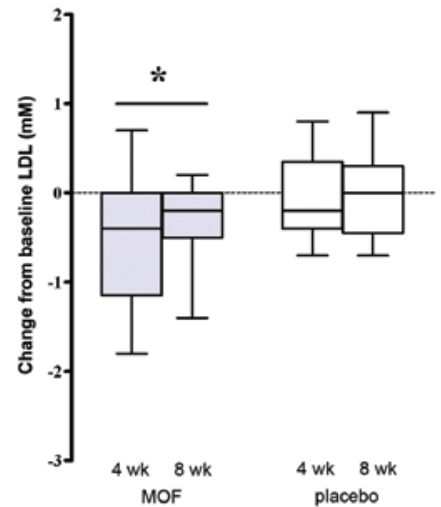

D

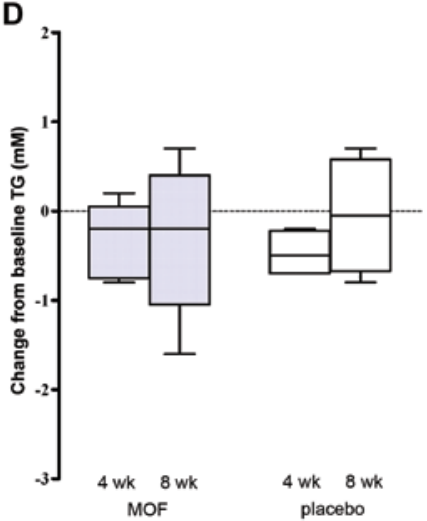

Figure 1. Changes from baseline in median ( $10^{\text {th }}$ to $90^{\text {th }}$ percentile) serum lipid concentrations after 4 and 8 wk supplementation with either $200 \mathrm{mg} / \mathrm{d}$ monomeric and oligomeric flavanols (MOF) or placebo: (A) total cholesterol (tChol) concentrations of subjects with tChol baseline concentrations $>5.0$ mM (MOF group: $n=11$, placebo group: $n=10$ ); (B) low density lipoprotein (LDL) concentrations of subjects with LDL baseline concentrations $>3.2 \mathrm{mM}$ (MOF group: $n=9$, placebo group: $n=9$ ); (C) ratio of tChol to high density lipoprotein (HDL) of subjects with tChol baseline concentrations $>5.0$ mM (MOF group: $n=11$, placebo group: $n=10$ ); (D) triglycerides (TG) concentrations of subjects with TG baseline concentrations $>1.7$ mM (MOF group: $n=5$, placebo group: $n=4$ ).

Within-group changes were appraised by Wilcoxon Signed Ranks test, between-group changes by Mann-Whitney $\mathrm{U}$ test; *Significantly different from baseline in the same group, $\mathrm{P}<0.05$. There were no significant differences between the MOF and the placebo group at the same time points. 
After 4 weeks the average TG concentrations dropped by $13 \%$ (MOF, P $=0.16$ vs. baseline) and $16 \%$ (placebo, $P=0.06$ vs. baseline). While in the placebo subgroup TG concentrations returned to baseline after 8 weeks ( $P=0.44$ vs. baseline), in the MOF subgroup TG concentrations remained on the low 4 weeks level ( $P=0.31$ vs. baseline; Fig. 1D).

\section{Effects of the MOF supplementation on platelet aggregation ex vivo and plasma fibrinogen levels}

Whereas the total percentage of collagen-and ADP-induced platelet aggregation did not change by the 8 weeks MOF supplementation (table 4), the rate of the collagen-induced aggregation was lower in the MOF group than in the placebo group after 8 weeks $(P<0.01$, Table 4). In contrast to this, the rate of the ADP-induced aggregation increased significantly from baseline in the MOF group $(P<0.05)$. Plasma fibrinogen concentrations were unaffected by the MOF supplementation (table 3 ).

\section{Effects of the MOF supplementation on systemic inflammatory parameters}

Ex vivo LPS-induced release of the proinflammatory cytokine TNF-a decreased from baseline by $14 \%(P<0.05)$ after 8 weeks MOF supplementation. This reduction was also

Table 4. Platelet aggregation parameters. ${ }^{1}$

\begin{tabular}{lllll}
\hline & $\begin{array}{l}\text { Time } \\
\text { (weeks) }\end{array}$ & $\begin{array}{l}\text { MOF } \\
(\mathbf{n = 1 5})\end{array}$ & $\begin{array}{l}\text { Placebo } \\
(\mathbf{n = 1 3 )}\end{array}$ & P value $^{2}$ \\
\hline APA (\%) & 0 & $75(65-86)$ & $77(58-96)$ & 0.872 \\
& 4 & $74(65-81)$ & $71(48-84)$ & 0.117 \\
& 8 & $74(57-85)$ & $74(62-83)$ & 0.835 \\
APAR (slope) & 0 & $102(59-135)$ & $109(74-133)$ & 0.140 \\
& 4 & $107(62-127)$ & $97(83-141)$ & 0.872 \\
& 8 & $112(77-139)$ & $101(81-138)$ & 0.278 \\
CPA (\%) & 0 & $76(70-81)$ & $77(71-96)$ & 0.151 \\
& 4 & $78(65-84)$ & $78(71-83)$ & 0.746 \\
& 8 & $78(60-81)$ & $79(71-82)$ & 0.782 \\
CPAR (slope) & 0 & $88 \pm 13$ & $94 \pm 17$ & 0.338 \\
& 4 & $92 \pm 12$ & $95 \pm 11$ & 0.486 \\
& 8 & $86 \pm 12$ & $99 \pm 8$ & 0.003 \\
\hline
\end{tabular}

\footnotetext{
${ }^{1}$ Values are mean \pm SEM or median (range); APA, ADP-induced platelet aggregation; APAR, ADPinduced platelet aggregation rate; CPA, collagen-induced platelet aggregation; CPAR, collageninduced platelet aggregation rate.

${ }^{2} P$ value for between-groups differences assessed by independent Student's t-test or MannWhitney U-test where median (range) is indicated.
} 
significant compared to the placebo group at 8 weeks $(P<0.05$; Fig. $2 A)$. The release of the anti-inflammatory IL-10 did not deviate significantly from baseline in the MOF supplemented group and was similar to the alterations observed in the placebo group. However, the significantly lower ratio of the pro- and the anti-inflammatory cytokine (TNF-a/IL-10: baseline median $=105$ vs. 8 weeks median $=62, \mathrm{P}<0.05)$ underlines the antiinflammatory effect of the MOF supplementation.

Moreover, the MOF supplementation significantly attenuated gene expression of the cytokines IL- 6 (after 4 weeks: $-18 \%, P<0.05$ vs. baseline) as well as TNF-a (after 8 weeks: $-12 \%, \mathrm{P}<0.05$ vs. baseline) and IL-10 (after 8 weeks: $-27 \%, \mathrm{P}<0.05$ vs. baseline) in whole blood (figure $3 \mathrm{~A}, \mathrm{C}, \mathrm{E}$ ). Contrary, MOF supplementation did not alter serum CRP concentrations (table 3 ) and the expression of genes coding for IL-1 $\beta$ and IL-8, NOS2, nuclear factor of kappa light polypeptide gene enhancer in B-cells inhibitor alpha, intercellular adhesion molecule 1 and vascular cell adhesion molecule 1 (figure 3B, D, F-I).

Table 5. Macro- and microvascular function and biochemical vascular parameters. ${ }^{1}$

\begin{tabular}{lllll}
\hline & $\begin{array}{l}\text { Time } \\
\text { (weeks) }\end{array}$ & $\begin{array}{l}\text { MOF } \\
(\mathbf{n}=15)\end{array}$ & $\begin{array}{l}\text { Placebo } \\
(\mathbf{n}=13)\end{array}$ & P value $^{2}$ \\
\hline FMD (\%) & 0 & $3.5(0.9-5.8)$ & $4.8(0-11.8)$ & 0.294 \\
& 4 & $3.0(20.8-11.5)$ & $4.7(1.3-10.7)$ & 0.149 \\
& 8 & $3.5(0.8-5.6)$ & $3.7(1.9-5.2)$ & 0.678 \\
ED $_{50}$ ACh & 0 & $5(2-7)$ & $5(0-7)$ & 0.384 \\
& 4 & $4(3-6)$ & $5(0-8)$ & 0.039 \\
& 8 & $4(2-6)$ & $3(0-6)$ & 0.257 \\
NOX $(\mu \mathrm{M})$ & 0 & 25.862 .1 & 24.363 .3 & 0.518 \\
& 4 & 23.861 .7 & 25.762 .9 & 0.637 \\
& 8 & 23.261 .8 & 21.962 .2 & 0.525 \\
ET-1 (pM) & 0 & $6.6(4.8-7.9)$ & $6.8(5.7-8.4)$ & 0.322 \\
& 4 & $6.2(5.0-12.0)$ & $6.3(4.9-8.4)$ & 0.790 \\
& 8 & $6.3(4.9-7.3)$ & $6.3(5.6-7.8)$ & 0.596 \\
Arg. activity, & 0 & $1.6(1.2-3.4)$ & $1.6(1.0-2.0)$ & 0.627 \\
$\left(\mu \mathrm{M}\right.$ urea $\left.\times \mathrm{mg}^{-1}\right)$ & 4 & $1.7(1.1-2.9)$ & $1.4(1.0-2.0)$ & 0.277 \\
protein $\left.{ }^{-1} \times \mathrm{h} \mathrm{h}^{-1}\right)$ & 8 & $1.7(1.2-3.0)$ & $1.5(1.1-2.0)$ & 0.391 \\
\hline
\end{tabular}

'Values are mean \pm SEM or median (range); Arg. activity, erythrocytes' arginase activity; $\mathrm{ED}_{50} \mathrm{ACh}$, ACh dose interval resulting in $50 \%$ of the maximum dermal blood flow response; ET-1, plasma endothelin-1; FMD, flow mediated dilation; MOF, monomeric and oligomeric flavanols; NOx, plasma nitrite and nitrate.

${ }^{2} P$ value for between-groups differences assessed by independent Student's t-test or MannWhitney U-test where median (range) is indicated. 


\section{Effects of the MOF supplementation on redox state parameters and oxidative stress}

The antioxidant capacity of plasma, quantified as TEAC and corrected for uric acid as major antioxidant in blood, tended to increase by the 8 weeks MOF supplementation. However, significant differences compared to the placebo group could not be found (figure 4A).

Circulating levels of the lipid peroxidation product 8-iso-PGF ${ }_{2 a}$ were not affected by the 8 weeks supplementation with MOF (figure 4B).

Subjects allocated to the MOF group revealed 22\% higher GSH/GSSG concentrations in erythrocytes after 8 weeks compared to baseline $(P<0.05$, figure $4 C)$. This increase appeared to originate from a reduction in the GSSG quantities rather than from a substantial increase in the amount of erythrocytes' GSH (data not shown).

No effect on the systemic expression of genes coding catalase (CAT), glutathione peroxidase (GPX)1 and 4, glutathione reductase (GSR), heme oxygenase 1 (HMOX1) and superoxide dismutase 2 (SOD2) were observed in both groups (figures 5A-F). In the MOF group the expression of CAT, GSR and HMOX1 tended to decline after 8 weeks regarding baseline (figures 5A, 5D, 5E).
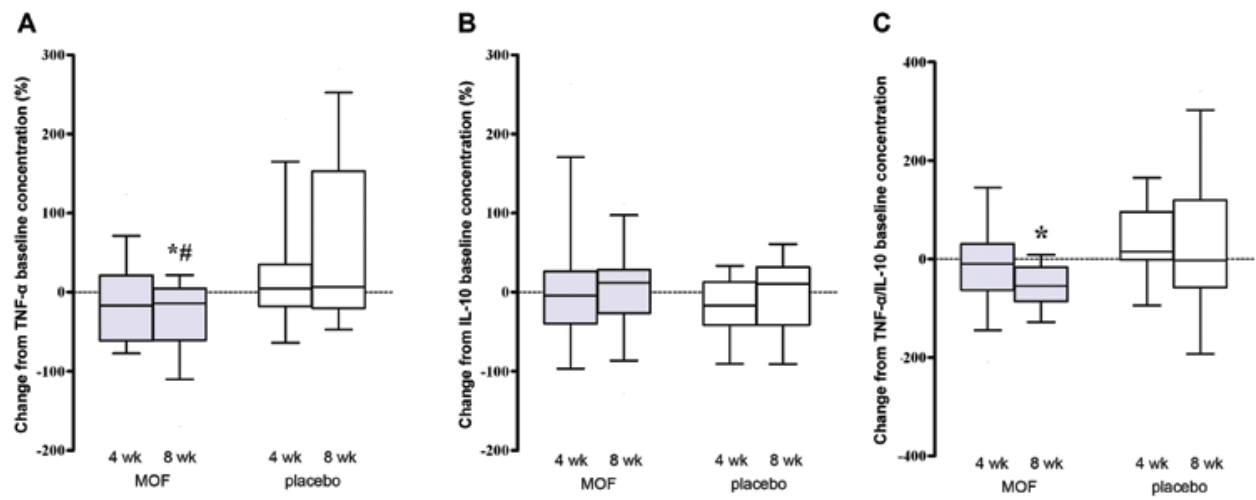

Figure 2. Changes from baseline in median $\left(10^{\text {th }}\right.$ to $90^{\text {th }}$ percentile) cytokine concentrations released upon LPS addition $(100 \mathrm{ng} / \mathrm{mL})$ to subjects' blood ex vivo after 4 and 8 wk supplementation with either $200 \mathrm{mg} / \mathrm{d}$ monomeric and oligomeric flavanols (MOF, $n=15)$ or placebo $(n=13)$ : (A) TNF-a, percentage change; (B) IL-10, percentage change; (C) ratio of TNF-a to IL-10, absolute change.

Within-group changes were appraised by Wilcoxon Signed Ranks test, between-group changes by Mann-Whitney $\mathrm{U}$ test; * Significantly different from baseline in the same group, $\mathrm{P}<0.05$. \#Significant difference between groups at the same time, $\mathrm{P}<0.05$. 


\section{Effects of the MOF supplementation on the VHI}

The VHI is used to integrate the multiple effects monitored in the present study. After 4 weeks the VHI tended to be higher in the MOF group (mean \pm SD $=62 \pm 75$ ) than in the placebo group (mean $\pm S D=-35 \pm 61$, Figure $6 A$ ). The difference increased after 8 weeks resulting in significantly higher $\mathrm{VHI}$ levels in the MOF group (mean $\pm \mathrm{SD}=123 \pm 47, \mathrm{P}<0.05$ vs. baseline) compared to the placebo group (mean $\pm S D=-66 \pm 79, P \leq 0.05$, Figure $6 B$ ).
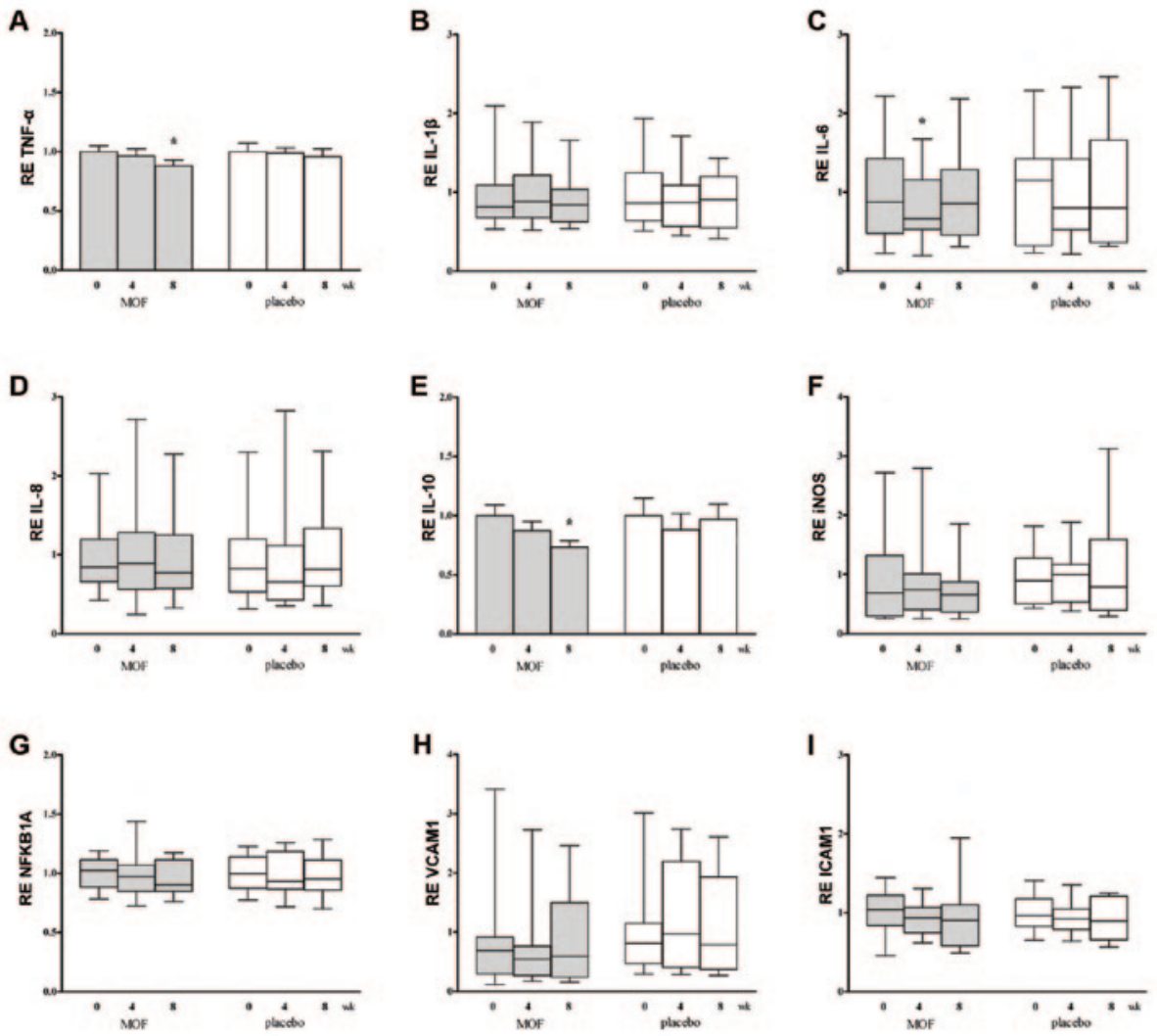

Figure 3. Mean \pm SEM (bars or median $\left(10^{\text {th }}\right.$ and $90^{\text {th }}$ percentile) (box and whiskers) relative gene expression (RE) of tumor necrosis factor alpha (TNF-a) (A), interleukin 1 beta (IL-1 $\beta$ ) (B), interleukin 6 (IL-6) (C), interleukin 8 (IL-8) (D), interleukin 10 (IL-10) (E), nitric oxide synthase 2 (NOS2) (F), nuclear factor of kappa light polypeptide gene enhancer in B-cells inhibitor alpha (NFKBIA) (G), intercellular adhesion molecule 1 (ICAM1) (H), vascular adhesion molecule 1 (VCAM1) (I) in blood of subjects at baseline ( $0 \mathrm{wk}$ ) and after 4 and $8 \mathrm{wk}$ supplementation with either $200 \mathrm{mg} / \mathrm{d}$ monomeric and oligomeric flavanols (MOF, $n=15)$ or placebo $(n=13)$. Within-group changes were appraised by either one-tailed paired-samples t-test (bar plots) or Wilcoxon Signed Ranks test (box and whiskers plots), between-group changes by either two-tailed independent samples t-test (bar plots) or Mann-Whitney $U$ test (box and whiskers plots); *Significantly different from baseline in the same group, $\mathrm{P}<0.05$. There were no significant differences between the MOF and the placebo group at the same time points. 

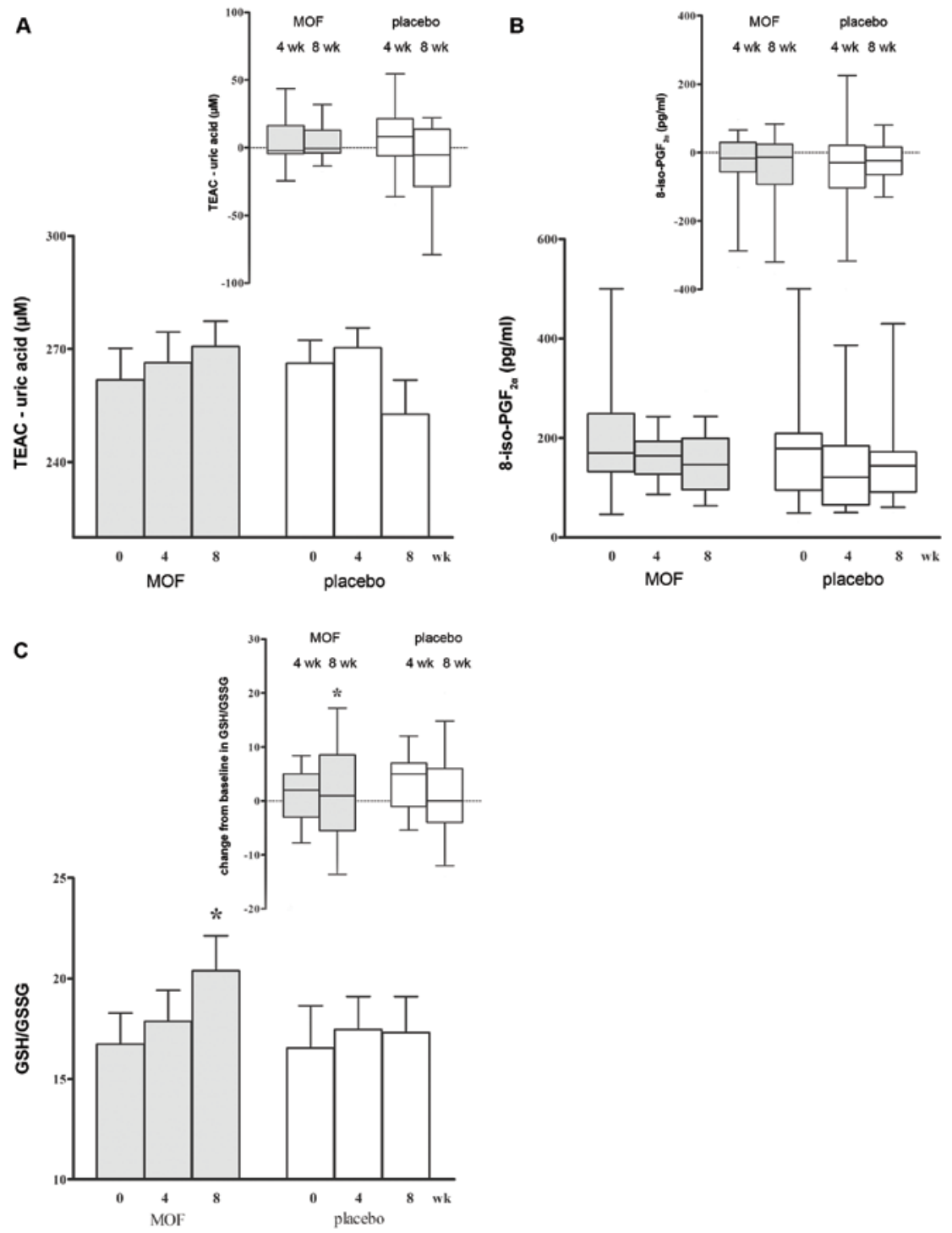

Figure 4. Mean \pm SEM (bars) or median $\left(10^{\text {th }}\right.$ and $90^{\text {th }}$ percentile) (box and whiskers) antioxidant capacity of plasma measured as trolox equivalent antioxidant capacity (TEAC) and corrected for uric acid plasma concentrations (A), 8-isoprostaglandine F2a (8-iso-PGF2a) plasma concentrations of subjects at baseline (0 wk) (B) and and ratio of glutathione (GSH) to glutathione disulphide (GSSG) in erythrocytes (C) after 4 and 8 wk supplementation with either $200 \mathrm{mg} / \mathrm{d}$ monomeric and oligomeric flavanols (MOF, $n=15)$ or placebo $(n=13)$. The insert displays for each of the parameter the changes from baseline after 4 and 8 weeks intervention. Within-group changes were appraised by either one-tailed paired-samples t-test (bar plots) or Wilcoxon Signed Ranks test (box and whiskers plots), between-group changes by either two-tailed independent samples t-test (bar plots) or Mann-Whitney $U$ test (box and whiskers plots); ${ }^{*}$ Significantly different from baseline in the same group, $\mathrm{P}<0.05$. There were no significant differences between the MOF and the placebo group at the same time points. 

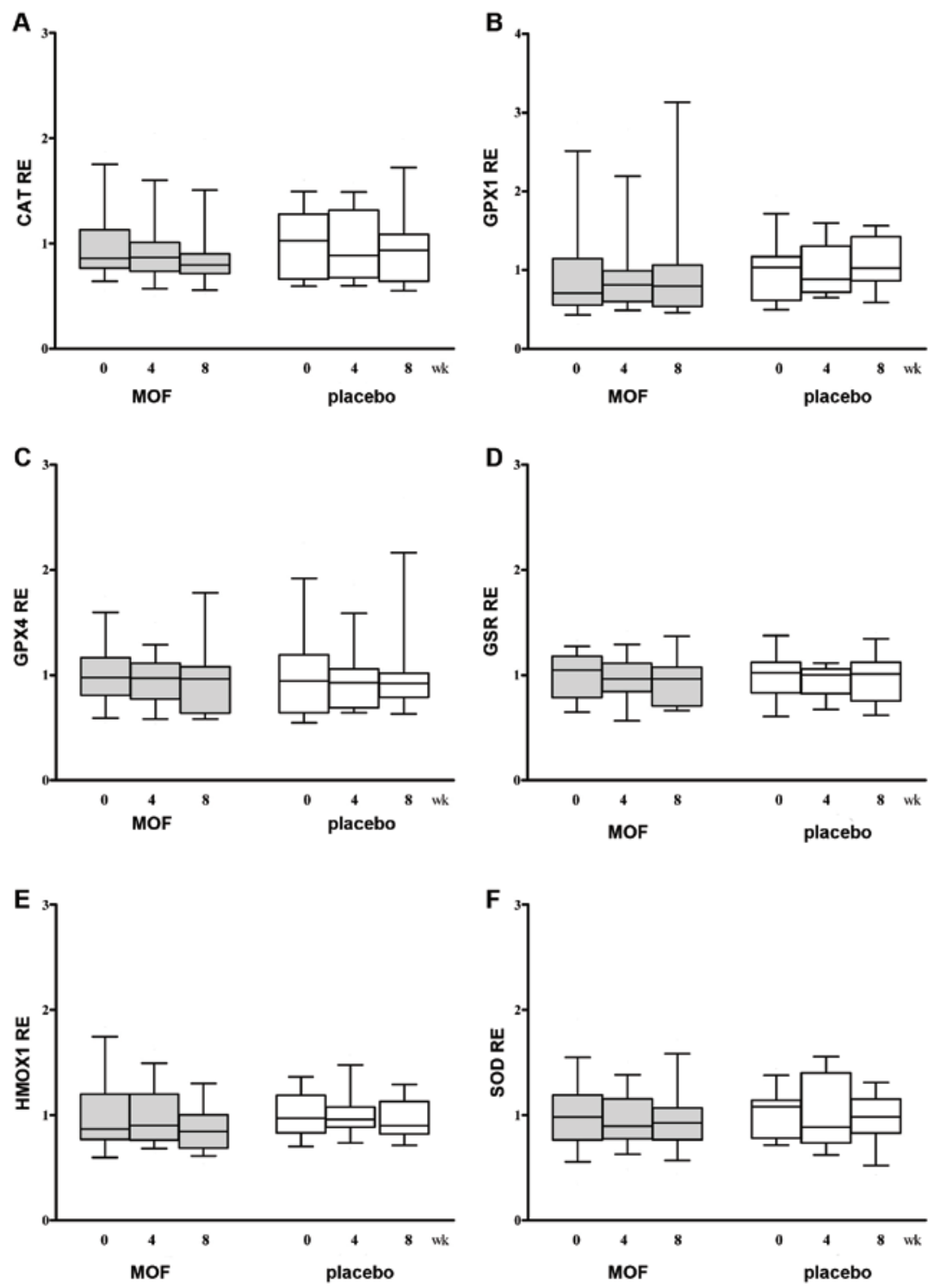

Figure 5. Mean \pm SEM (bars) or median (10th and 90th percentile) (box and whiskers) relative gene expression (RE) of catalase (CAT) (A), glutathione peroxidase 1 (GPX1) (B), glutathione peroxidase 4 $(G P X 4)(C)$, glutathione reductase (GSR) (D), heme oxygenase 1 (HMOX1) (E), superoxide dismutase 2 (SOD2) (F) in blood of subjects at baseline $(0 \mathrm{wk})$ and after 4 and 8 wk supplementation with either $200 \mathrm{mg} / \mathrm{d}$ monomeric and oligomeric flavanols (MOF, $n=15)$ or placebo $(n=13)$. Within-group changes were appraised by either one-tailed paired-samples t-test (bar plots) or Wilcoxon Signed Ranks test (box and whiskers plots), between-group changes by either two-tailed independent samples t-test (bar plots) or Mann-Whitney $\mathrm{U}$ test (box and whiskers plots). There were no significant differences from baseline in the same group and between both groups at the same time points. 

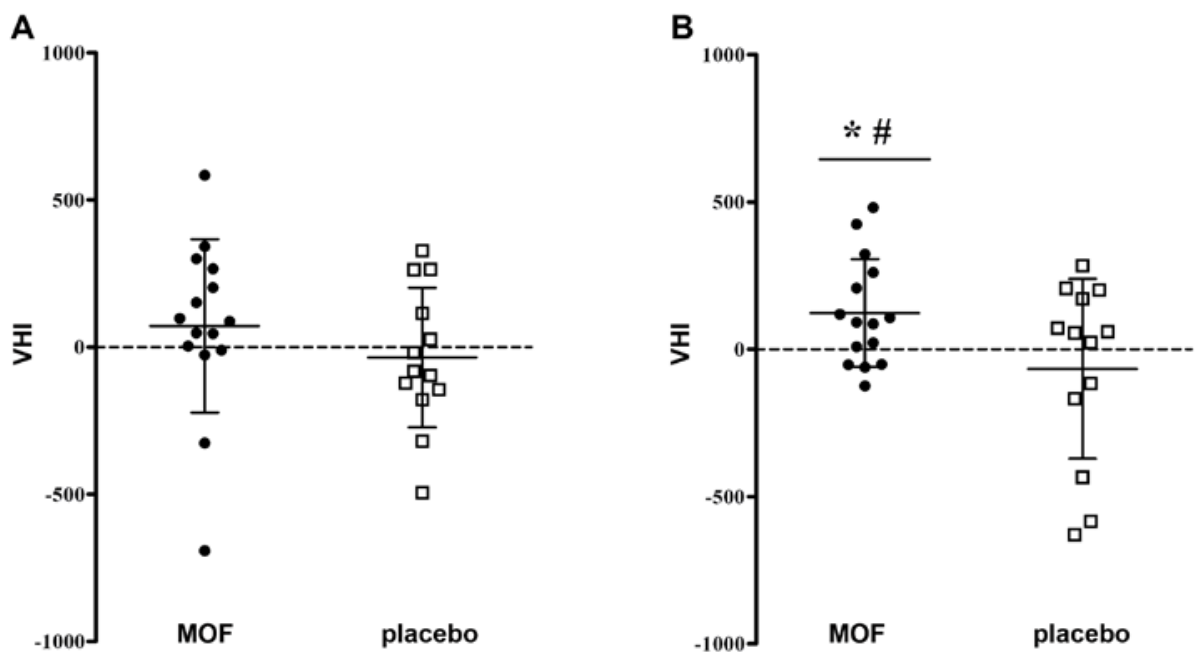

Figure 6. Mean \pm SD vascular health index $(\mathrm{VHI})$ of individual subjects after $4(\mathrm{~A})$ and $8 \mathrm{wk}(\mathrm{B})$ supplementation with either $200 \mathrm{mg} / \mathrm{d}$ monomeric and oligomeric flavanols (MOF, $n=15$ ) or placebo $(n=13)$. Within-group changes were appraised by one-tailed paired-samples t-test, between-group changes by two-tailed independent samples t-test; *Significantly different from baseline in the same group, $\mathrm{P}<0.05$. \#Significant difference between groups at the same time, $\mathrm{P}<0.05$. 


\section{Discussion}

The beneficial effects of food derived flavanols on vascular health are becoming increasingly aware. However, the clinical efficacy of these compounds in particular longterm is yet unclear and limits their purposive application in daily medical practice. The results of the present pilot study unveiled the potency of MOF from Vitis vinifera L. to improve vascular health when regularly applied for 8 weeks in relatively small amounts of $200 \mathrm{mg}$ per day in addition to the normal diet. The frequently observed positive trends on single endpoints add up to a distinctive overall vascular health benefit, as indicated by a significantly higher vascular health index compared to placebo.

In order to study health effects of dietary supplements the study population, while generally healthy, should have or produce under stress elevated levels of the relevant parameters. The disturbances should be mild so that no pharmacological intervention is required. The group of 28 smokers recruited in the present trial fulfilled these criteria adequately. The majority of the volunteers exhibited a number of established cardiovascular risk factors, e.g. elevated serum total cholesterol and LDL [34], as well as slightly increased CRP concentrations [34,36], but were neither diagnosed with a vascular disease nor on cardiovascular medication. Notably, the averaged endothelial function of smokers measured non-invasively by means of brachial artery FMD at baseline (mean $\mathrm{FMD} \pm \mathrm{SD}=4 \pm 3 \%$ ) was in good agreement with data from Celermajer and colleagues who reported impaired macrovascular function of smokers (mean FMD $\pm S D=4 \pm 4 \%$ ) compared to age- and sex-matched non-smokers (mean FMD $\pm \mathrm{SD}=10 \pm 3 \%$ ) [37]. Considering cardiovascular risk classification by the Framingham Risk Scores [38] and by an approach based on brachial artery FMD values [26], indicates that the healthy subjects in our test groups might be at a moderate cardiovascular risk.

Interestingly, it has been found that in a population at low cardiovascular risk FMD values are inversely correlated with cardiovascular risk, while in populations at intermediate or high risk this correlation diminishes and disappears, respectively [26]. This phenomenon has been explained by the observation that people with elevated cardiovascular risk possess a limited distensibility of the brachial artery [39]. As a result FMD values may not reflect any longer an exclusively endothelial NO--mediated response. Irrespective from this aspect, evidence is lacking yet that MOF may improve macrovascular function in humans upon a long-term ingestion period, i.e. more than 4 weeks [40]. Interestingly, dermal microvasculature became transiently more sensitive to the endothelium-dependent stimulus ACh upon 4 weeks MOF intake. However, we cannot rule out that this effect was due to chance, since after 8 weeks of intervention a 
similar increase in sensitivity was observed in the placebo group.

Despite a wealth of animal studies demonstrating serum cholesterol-lowering effects of various mixtures of grape seed flavanols, studies in humans are less conclusive [22, 41]. Species differences as well as variations in flavanolic composition might result in altered clinical efficacy [42]. Our trial clearly emphasized the potential of MOF to reduce hypercholesterolemia to a significant and clinically relevant extent over an 8 weeks consumption period. Although the cholesterol-lowering effects were more pronounced after 4 than after 8 weeks, the median LDL concentrations remained $0.2 \mathrm{mM}$ lower at the end of the study compared to baseline. The same efficacy was reported for green tea and soy protein isolate [41] and was estimated to reduce all-cause mortality by $3 \%$ and CHDrelated mortality and total CHD events by $6 \%$ [43].

Moreover, our study showed a significant enhancement of the smokers' resistance against inflammatory stimuli, such as bacterial endotoxin, upon the 8 weeks MOF supplementation. Remarkably, MOF alleviated the inflammatory response in blood not only by mitigating the LPS-induced secretion of the pro-inflammatory cytokine TNF- $a$, but also by enhancing the release of the anti-inflammatory cytokine IL-10. Likewise we could demonstrate that the MOF-mediated increase in systemic inflammatory resistance extends in humans to the modulation of the gene expression of inflammatory cytokines, in particular TNF-a, IL- 6 and IL-10. Although cell culture experiments suggest a direct interference of isolated MOF with NF-KB-mediated gene expression [44], the unaltered expression of the inhibitory subunit NFKBIA did not indicate an effect on the NF-KB pathway by MOF. Additionally, we could not detect significant changes in the gene expression of adhesion molecules, which are also regulated by the transcription factor NF-KB.

Smokers are known to exhibit elevated levels of oxidative stress, which has been established among others as reduced antioxidant status $[45,46]$ as well as a rise in biomarkers for lipid peroxidation such as F2 isoprostanes [11,47]. We thus determined the systemic extra- and intracellular redox state of the smokers under MOF supplementation by measuring TEAC in plasma, GSH/GSSG concentrations in erythrocytes and gene expression levels of the redox enzymes CAT, GPX1, GPX4, GSR, HMOX1 and SOD2 in blood. The trend of increasing plasma TEAC values and the considerable augmentation of the GSH/GSSG ratio in erythrocytes indicate that MOF improve extra- and intracellular redox status in the circulation. These effects, however, could not be ascribed to alterations of gene expression of the most important enzymatic antioxidant defense systems in circulatory white blood cells as discussed above. The systemic oxidative stress 
levels assessed as plasma concentrations of the lipid peroxidation marker 8-iso-PGF2a were unaffected upon the 8 weeks MOF intake. Similarly, it has been reported that a daily ingestion of $1000 \mathrm{mg}$ grape seed polyphenols for 6 weeks did not lower plasma isoprostane levels in hypertensive subjects.

Our study also revealed that chronic MOF consumption did not affect ADP- and collagen stimulated platelet aggregation ex vivo. Whereas platelet-inhibiting effects could be clearly proven in humans upon ingestion of cocoa-related products [48], the clinical evidence for MOF from Vitis vinifera $L$. is less clear and might be related to a difference in polyphenolic composition and dose [48]. Moreover, experiments with isolated human platelets suggest that grape seed extract inhibits aggregation only in quite high concentrations (100 mg/l blood) [49], which fairly exceed plasma levels achievable in vivo. A prothrombotic state has also been associated with elevated fibrinogen plasma concentrations, typically occurring in smokers [50]. This glycoprotein has been identified to promote plasma viscosity, platelet aggregation, coagulation and inflammation, thereby fueling atherogenesis. Therefore, agents that lower circulatory fibrinogen might be valuable [51]. The 8 week MOF intervention, however, remained ineffective in this respect.

In the past decade in vitro and in vivo studies unraveled several molecular mechanisms of flavanols that are essential in the beneficial mediation of their vascular effects. These mechanisms comprise a reduction in arginase activity that may contribute among others to an increased endothelial NO - level [52], as well as a decline in plasma ET-1 concentration [53]. In the setting of our clinical trial we could not find significant changes in plasma nitrate and nitrite concentration measured as surrogate for endothelial NO- production [54], as well as in arginase activity in erythrocytes and ET-1 plasma concentration.

Already during the screening of the volunteers we carefully checked by means of an investigator-guided interview and a suitable questionnaire the intake of coffee, tea and chocolate containing drinks as well as the consumption of chocolate and chocolate containing food products and alcoholic beverages, including beer, red and white wine. Also the use of any vitamins and/or food supplements, adherence to a vegetarian and vegan diet, a regular (at least 3 times a day) eating pattern as well as fluctuations in body weight were evaluated and had to comply with the in- and exclusion criteria of the study (see Methods, "Subjects and study design"). In this way we could exclude beforehand extreme and unusual behaviors and recruit a quite homogenous group of typical Dutch middle-aged men [55]. Since, however, we neither used food frequency questionnaires to determine the exact daily food intake before and during the study nor measured plasma 
levels of relevant flavanol metabolites, we could not accurately assess the total intake of these compounds in both test groups. The rational for imposing no restriction regarding diet and lifestyle was, that in this way clinical data were collected on the vascular health effects of a relatively low-dose supplementation with MOF under real-life conditions.

Food scientists are facing the challenge to proof the clinical efficacy of nutrients that modulate human physiology in a subtle and non-specific manner [25]. In drug research, where the one-target-one-hit concept is imperative, randomized clinical trials with a well-defined single endpoint are the gold standard of efficacy testing. However, a single endpoint neither sufficiently reflects the multifarious nature of nutrients' functions in humans nor the complexity of pathomechanisms underlying virtually all diseases.

Our study pioneered the implementation of a pragmatic solution for this problem: Carefully select a representative panel of markers that reflect the major relevant pathological aberrations and integrate all measured effects into a global health index. This concept is in particular elegant, since it can easily be applied to practically any other field of diseases.

In conclusion, our integrative multi-biomarker approach proved to be a sensitive and therefore powerful strategy to unveil the pleiotropic benefit of an 8 weeks supplementation with $200 \mathrm{mg} / \mathrm{d}$ MOF on vascular health in humans. 


\section{References}

1. (WHO) WHO. Cardiovascular diseases (CVDs), Fact sheet Nr. 317. 2011: http://www.who.int/mediacentre/ factsheets/fs317/en/index.html.

2. European Heart Network Cds. http://wwwehnheartorg/cvd-statisticshtml. 2008.

3. Mallika V, Goswami B, Rajappa M. Atherosclerosis pathophysiology and the role of novel risk factors: a clinicobiochemical perspective. Angiology. 2007;58:513-22.

4. Yanbaeva DG, Dentener MA, Creutzberg EC, Wesseling G, Wouters EF. Systemic effects of smoking. Chest. 2007;131:1557-66.

5. Barua RS, Ambrose JA, Srivastava S, DeVoe MC, Eales-Reynolds LJ. Reactive oxygen species are involved in smoking-induced dysfunction of nitric oxide biosynthesis and upregulation of endothelial nitric oxide synthase: an in vitro demonstration in human coronary artery endothelial cells. Circulation. 2003;107:2342-7.

6. Powell JT. Vascular damage from smoking: disease mechanisms at the arterial wall. Vascular medicine (London, England). 1998;3:21-8.

7. Pryor WA, Stone K. Oxidants in cigarette smoke. Radicals, hydrogen peroxide, peroxynitrate, and peroxynitrite. Annals of the New York Academy of Sciences. 1993;686:12-27; discussion -8.

8. Bazzano LA, He J, Muntner P, Vupputuri S, Whelton PK. Relationship between cigarette smoking and novel risk factors for cardiovascular disease in the United States. Annals of internal medicine. 2003;138:891-7.

9. Bermudez EA, Rifai N, Buring JE, Manson JE, Ridker PM. Relation between markers of systemic vascular inflammation and smoking in women. The American journal of cardiology. 2002;89:1117-9.

10. Hughes DA, Haslam PL, Townsend PJ, Turner-Warwick M. Numerical and functional alterations in circulatory lymphocytes in cigarette smokers. Clinical and experimental immunology. 1985;61:459-66.

11. Morrow JD, Frei B, Longmire AW, Gaziano JM, Lynch SM, Shyr Y, et al. Increase in circulating products of lipid peroxidation (F2-isoprostanes) in smokers. Smoking as a cause of oxidative damage. The New England journal of medicine. 1995;332:1198-203.

12. Orhan H, Evelo CT, Sahin G. Erythrocyte antioxidant defense response against cigarette smoking in humans--the glutathione S-transferase vulnerability. Journal of biochemical and molecular toxicology. 2005;19:226-33.

13. Craig WY, Palomaki GE, Haddow JE. Cigarette smoking and serum lipid and lipoprotein concentrations: an analysis of published data. BMJ (Clinical research ed). 1989;298:784-8.

14. Takajo Y, Ikeda H, Haramaki N, Murohara T, Imaizumi T. Augmented oxidative stress of platelets in chronic smokers. Mechanisms of impaired platelet-derived nitric oxide bioactivity and augmented platelet aggregability. Journal of the American College of Cardiology. 2001;38:1320-7.

15. Howard G, Wagenknecht LE, Burke GL, Diez-Roux A, Evans GW, McGovern P, et al. Cigarette smoking and progression of atherosclerosis: The Atherosclerosis Risk in Communities (ARIC) Study. JAMA : the journal of the American Medical Association. 1998;279:119-24.

16. Leone A. Relationship between cigarette smoking and other coronary risk factors in atherosclerosis: risk of cardiovascular disease and preventive measures. Current pharmaceutical design. 2003;9:2417-23.

17. Fennessy FM, Moneley DS, Wang JH, Kelly CJ, Bouchier-Hayes DJ. Taurine and vitamin C modify monocyte and endothelial dysfunction in young smokers. Circulation. 2003;107:410-5.

18. Heitzer T, Just H, Munzel T. Antioxidant vitamin C improves endothelial dysfunction in chronic smokers. Circulation. 1996;94:6-9.

19. de Lorgeril M, Salen P, Paillard F, Laporte F, Boucher F, de Leiris J. Mediterranean diet and the French paradox: two distinct biogeographic concepts for one consolidated scientific theory on the role of nutrition in coronary heart disease. Cardiovascular research. 2002;54:503-15.

20. Panagiotakos D, Sitara M, Pitsavos C, Stefanadis C. Estimating the 10-year risk of cardiovascular disease and its economic consequences, by the level of adherence to the Mediterranean diet: the ATTICA study. Journal of medicinal food. 2007;10:239-43. 
21. Oligomeric proanthocyanidins (OPCs). Monograph. Alternative medicine review : a journal of clinical therapeutic. 2003;8:442-50.

22. Blade C, Arola L, Salvado MJ. Hypolipidemic effects of proanthocyanidins and their underlying biochemical and molecular mechanisms. Mol Nutr Food Res. 2010;54:37-59.

23. Chang WC, Hsu FL. Inhibition of platelet aggregation and arachidonate metabolism in platelets by procyanidins. Prostaglandins, leukotrienes, and essential fatty acids. 1989;38:181-8.

24. Sano T, Oda E, Yamashita T, Naemura A, ljiri Y, Yamakoshi J, et al. Anti-thrombotic effect of proanthocyanidin, a purified ingredient of grape seed. Thrombosis research. 2005;115:115-21.

25. Heaney RP. Nutrients, endpoints, and the problem of proof. The Journal of nutrition. 2008;138:1591-5.

26. Witte DR, Westerink J, de Koning EJ, van der Graaf Y, Grobbee DE, Bots ML. Is the association between flow-mediated dilation and cardiovascular risk limited to low-risk populations? Journal of the American College of Cardiology. 2005;45:1987-93.

27. Corretti MC, Anderson TJ, Benjamin EJ, Celermajer D, Charbonneau F, Creager MA, et al. Guidelines for the ultrasound assessment of endothelial-dependent flow-mediated vasodilation of the brachial artery: a report of the International Brachial Artery Reactivity Task Force. Journal of the American College of Cardiology. 2002;39:257-65.

28. Giustarini D, Rossi R, Milzani A, Dalle-Donne I. Nitrite and nitrate measurement by Griess reagent in human plasma: evaluation of interferences and standardization. Methods in enzymology. 2008;440:36180.

29. Corraliza IM, Campo ML, Soler G, Modolell M. Determination of arginase activity in macrophages: a micromethod. Journal of immunological methods. 1994;174:231-5.

30. Swennen EL, Bast A, Dagnelie PC. Immunoregulatory effects of adenosine 5 '-triphosphate on cytokine release from stimulated whole blood. European journal of immunology. 2005;35:852-8.

31. Fischer MA, Gransier TJ, Beckers LM, Bekers O, Bast A, Haenen GR. Determination of the antioxidant capacity in blood. Clinical chemistry and laboratory medicine : CCLM / FESCC. 2005;43:735-40.

32. Julicher RH, Sterrenberg L, Haenen GR, Bast A, Noordhoek J. Sex differences in the cellular defence system against free radicals from oxygen or drug metabolites in rat. Archives of toxicology. 1984;56:83-6.

33. Griffith OW. Determination of glutathione and glutathione disulfide using glutathione reductase and 2-vinylpyridine. Analytical biochemistry. 1980;106:207-12.

34. Simoons ML, Casparie AF. [Therapy and prevention of coronary heart diseases through lowering of the serum cholesterol levels; third consensus 'Cholesterol'. Consensus Working Group, CBO]. Nederlands tijdschrift voor geneeskunde. 1998;142:2096-101.

35. Fletcher B, Berra K, Ades P, Braun LT, Burke LE, Durstine JL, et al. Managing abnormal blood lipids: a collaborative approach. Circulation. 2005;112:3184-209.

36. Pearson TA, Mensah GA, Alexander RW, Anderson JL, Cannon RO, 3rd, Criqui M, et al. Markers of inflammation and cardiovascular disease: application to clinical and public health practice: A statement for healthcare professionals from the Centers for Disease Control and Prevention and the American Heart Association. Circulation. 2003;107:499-511.

37. Celermajer DS, Sorensen KE, Georgakopoulos D, Bull C, Thomas O, Robinson J, et al. Cigarette smoking is associated with dose-related and potentially reversible impairment of endothelium-dependent dilation in healthy young adults. Circulation. 1993;88:2149-55.

38. Wilson PW, D'Agostino RB, Levy D, Belanger AM, Silbershatz H, Kannel WB. Prediction of coronary heart disease using risk factor categories. Circulation. 1998;97:1837-47.

39. Witte DR, van der Graaf Y, Grobbee DE, Bots ML. Measurement of flow-mediated dilatation of the brachial artery is affected by local elastic vessel wall properties in high-risk patients. Atherosclerosis. 2005;182:32330.

40. van Mierlo LA, Zock PL, van der Knaap HC, Draijer R. Grape polyphenols do not affect vascular function in healthy men. The Journal of nutrition. 2010;140:1769-73.

41. Hooper L, Kroon PA, Rimm EB, Cohn JS, Harvey I, Le Cornu KA, et al. Flavonoids, flavonoid-rich foods, and cardiovascular risk: a meta-analysis of randomized controlled trials. The American journal of clinical 
nutrition. 2008;88:38-50.

42. Ernst E. The efficacy of herbal medicine--an overview. Fundamental \& clinical pharmacology. 2005;19:4059.

43. Gould AL, Davies GM, Alemao E, Yin DD, Cook JR. Cholesterol reduction yields clinical benefits: metaanalysis including recent trials. Clinical therapeutics. 2007;29:778-94.

44. Park YC, Rimbach G, Saliou C, Valacchi G, Packer L. Activity of monomeric, dimeric, and trimeric flavonoids on NO production, TNF-alpha secretion, and NF-kappaB-dependent gene expression in RAW 264.7 macrophages. FEBS Lett. 2000;465:93-7.

45. Moriarty SE, Shah JH, Lynn M, Jiang S, Openo K, Jones DP, et al. Oxidation of glutathione and cysteine in human plasma associated with smoking. Free radical biology \& medicine. 2003;35:1582-8.

46. Petruzzelli S, Puntoni R, Mimotti P, Pulera N, Baliva F, Fornai E, et al. Plasma 3-nitrotyrosine in cigarette smokers. American journal of respiratory and critical care medicine. 1997;156:1902-7.

47. Reilly M, Delanty N, Lawson JA, FitzGerald GA. Modulation of oxidant stress in vivo in chronic cigarette smokers. Circulation. 1996;94:19-25.

48. Ostertag LM, O'Kennedy N, Kroon PA, Duthie GG, de Roos B. Impact of dietary polyphenols on human platelet function--a critical review of controlled dietary intervention studies. Molecular nutrition \& food research. 2010;54:60-81.

49. Shanmuganayagam D, Beahm MR, Osman HE, Krueger CG, Reed JD, Folts JD. Grape seed and grape skin extracts elicit a greater antiplatelet effect when used in combination than when used individually in dogs and humans. The Journal of nutrition. 2002;132:3592-8.

50. Tarallo P, Henny J, Gueguen R, Siest G. Reference limits of plasma fibrinogen. European journal of clinical chemistry and clinical biochemistry : journal of the Forum of European Clinical Chemistry Societies. 1992;30:745-51.

51. Kakafika Al, Liberopoulos EN, Mikhailidis DP. Fibrinogen: a predictor of vascular disease. Current pharmaceutical design. 2007;13:1647-59.

52. Schnorr O, Brossette T, Momma TY, Kleinbongard P, Keen CL, Schroeter H, et al. Cocoa flavanols lower vascular arginase activity in human endothelial cells in vitro and in erythrocytes in vivo. Arch Biochem Biophys. 2008;476:211-5.

53. Corder R, Warburton RC, Khan NQ, Brown RE, Wood EG, Lees DM. The procyanidin-induced pseudo laminar shear stress response: a new concept for the reversal of endothelial dysfunction. Clinical science (London, England: 1979). 2004;107:513-7.

54. Moshage H, Kok B, Huizenga JR, Jansen PL. Nitrite and nitrate determinations in plasma: a critical evaluation. Clinical chemistry. 1995;41:892-6.

55. van Kreijl CFKA, Busch MCM, Havelaar AH, Kramers PGN, Kromhout D, van Leeuwen FXR, et al. Ons eten gemeten. Gezonde voeding en veilig voedsel in Nederland. Rijksinstituut voor volksgezondheid en milieu (RIVM) Ministerie voor volksgezondheid, welzijn en sport RIVM Rapport 270555007. 2004. 



\section{Chapter 7}

General discussion 
Daily we consume many foods and drinks consisting of a vast amount of different compounds. Most of these compounds are derived from plants, which contain flavonoids, a major group of polyphenols [1]. Numerous epidemiological and clinical studies have demonstrated the health benefits of these flavonoids. High intake of flavonoid-rich foods have been indicated to prevent cardiovascular diseases, improve cognitive function, reduce the risk for developing cancer and prevent chronic inflammatory diseases like chronic obstructive pulmonary disease (COPD) and rheumatoid arthritis (RA) [2-5]. However, the mode of action and the cellular and molecular targets of flavonoids in the human body have not been fully elucidated yet.

To increase our understanding of the effects of flavonoid-rich diets have on health and the prevention of diseases, more experimental studies are needed. One of the major current debates concern the antioxidant and anti-inflammatory effects of flavonoids and their impact on health and disease prevention. Therefore, the aim of this thesis was to further investigate the antioxidant and anti-inflammatory activity of flavonoids and to elucidate how these effects can contribute to their health promoting properties.

\section{Antioxidant effect of (-)-epicatechin and several metabolites}

Oxidative stress is defined as an imbalance between oxidants and antioxidants in favor of the oxidants, potentially leading to cellular and subcellular damage [6]. In chapter 2 we determined the antioxidant effect of the flavanol (+)-catechin (Cat), (-)-epicatechin (EC) and several metabolites in human umbilical vein endothelial cells (HUVECs). Additionally, we determined the superoxide $\left(\mathrm{O}_{2}{ }^{--}\right)$radical scavenging activity in a test tube assay. This study showed that Cat and EC are effective $\mathrm{O}_{2}^{--}$scavengers, but glucuronidation, methylation and sulfation significantly reduced this scavenging activity. A catechol moiety proved to be important for the antioxidant activity $[7,8]$. The $7-\beta-D-g l u c u r o n i d e$ metabolite showed $\mathrm{O}_{2}^{--}$radical scavenging activity comparable with $E C$, which is probably due to the unmodified catechol moiety in both compounds. In line with this, O-methylation of the catechol moiety drastically reduced the radical scavenging activity. The O-methylated metabolites still significantly decreased $\mathrm{H}_{2} \mathrm{O}_{2}$-induced oxidative stress levels in HUVECs.

Although the direct scavenging plays a major role in the antioxidant effect of these flavanols, on a cellular level the protective effect of O-methylated metabolites might also involve other mechanisms that reduce intracellular oxidative stress. These potential mechanisms include inhibition of free radical-producing enzymes like the $\mathrm{O}_{2}{ }^{--}$ producing enzymes nicotinamide adenine dinucleotide phosphate-oxidase (NOX) and 
xanthine oxidase $(\mathrm{XO})$, chelation of transition metals, inhibition of lipid peroxidation, or the metabolite could show similar antioxidant effects as the parent compound in cells because it can more easily cross the cell membrane and thereby have a higher intracellular concentration [7, 9, 10]. In our experiments inducing the innate antioxidant machinery of the Nrf2 pathway does not seem to be involved. The results do indicate that EC and its metabolites provide protection against oxidative stress via a direct antioxidant mechanism.

\section{Protection of the glucocorticoid response by flavonoids and other bioactives}

An imbalance between oxidants and antioxidants has also been reported in patients with chronic inflammatory diseases, which also leads to increased systemic oxidative stress. To investigate the potential health effect of flavonoids in chronic inflammatory diseases, an in vitro cell system was developed mimicking the occurrence of oxidative stress and successive inflammation. For this purpose, human monocytes (U937 cells) were differentiated to macrophage-like cells. These cells were exposed to $\mathrm{H}_{2} \mathrm{O}_{2}$-induced oxidative stress and subsequently an inflammatory response was elicited by adding lipopolysaccharide (LPS). Under these conditions the anti-inflammatory activity of the endogenous glucocorticoid (GC) cortisol was determined. In chapter 3 we show that oxidative stress extinguishes this anti-inflammatory effect of cortisol, leading to a state of cortisol resistance. The cocoa flavanol EC reduced intracellular oxidative stress and prevented the occurrence of cortisol resistance. This finding demonstrates a synergy of EC and cortisol in coping with inflammation and exemplifies the crosstalk between oxidative stress and inflammation. Reducing oxidative stress, and in this way protecting the cortisol response, appears to be a promising strategy to strengthen the endogenous anti-inflammatory mechanism.

In chapter 4 we extended the study performed with cortisol and determined the effect of EC on the anti-inflammatory efficacy of the synthetic GC drug dexamethasone. Additionally, the cell model was further characterized by investigating the influence of cell differentiation, concentration of dexamethasone and $\mathrm{H}_{2} \mathrm{O}_{2}$, incubation times and the fate of $\mathrm{H}_{2} \mathrm{O}_{2}$ in cell medium. In this study we showed that the anti-inflammatory efficacy of dexamethasone in differentiated monocytes exposed to oxidants was partially maintained by EC. Moreover, this protective effect was time-dependent. EC prevented the $\mathrm{H}_{2} \mathrm{O}_{2}$-induced decline in anti-inflammatory $\mathrm{GC}$ activity over a period of $2 \mathrm{~h}$. However, after $4 \mathrm{~h} \mathrm{GC}$ resistance occurred and no protective effect of EC could be observed anymore. This illustrates the importance of measuring over time to accurately determine the efficacy 
of bioactives. Also, a bioactive like EC exerts relative subtle and non-pharmacological effects, therefore the partial and temporary outcome on GC resistance could have been anticipated. The advantage of the subtle and the time-dependent nature of the effect of bioactives like EC is that overt toxicity is unlikely to occur. These results show that EC may be used as adjuvant therapy to restore or preserve the efficacy of GC drugs in the treatment of inflammation.

Plant-derived food products contain a large variety of different polyphenols and other natural compounds. This prompted us in chapter 5 to investigate a broad array of food-derived compounds with respect to their ability to preserve the anti-inflammatory activity of cortisol under oxidative stress conditions. The food-derived bioactives showed antioxidant and anti-inflammatory activity by reducing intracellular stress and protecting the cortisol response in human macrophages exposed to oxidative stress. The level of protection against GC resistance did not directly correlate with their intracellular antioxidant effect. This indicates that next to the antioxidant activity of the bioactives, also other mechanisms seem to be involved in their capability to preserve the antiinflammatory activity of GC in the presence of oxidative stress.

\section{Potential mechanisms of glucocorticoid resistance}

The induction of GC resistance is still not fully understood, but several mechanisms have been proposed which could be modulated by flavonoids and other food-derived bioactives. In COPD systemically ROS production is pronounced and frequently GC resistance develops [11]. ROS suppress histone deacetylase 2 (HDAC2) activity [12] and previous studies have shown that curcumin and theophylline improve GC response, presumably by restoring HDAC2 activity $[13,14]$. Additionally, a recent study by Hakim et al. [15] showed that oxidative stress reduces protein expression responsible for the transport of the glucocorticoid receptor (GR) into the nucleus thereby impairing the intracellular action of GC.

As outlined above, we have also demonstrated that the anti-inflammatory effect of GC drugs can be protected by EC in oxidant exposed cells. Flavonoids exert their beneficial effects through direct scavenging of ROS and thereby decreasing oxidative stress. Next to their antioxidant activity, flavonoids are known to modulate various enzymes and signaling cascades involved in inflammation. For example, flavonoids have been reported to exert beneficial effects on the cardiovascular system by the inhibition of phosphodiesterase (PDE) which leads to an activation of the CAMP-dependent protein kinase A (PKA) [16, 17]. As a consequence, microvascular leakage is diminished and trafficking and release 
of cytokines and chemokines from inflammatory cells is inhibited [18]. Another possible mode of action is the activation of peroxisome proliferator activated receptor a (PPARa). Activated PPAR can inhibit the pro-inflammatory transcription factor NF-KB and it has been demonstrated that various isoflavones are potent PPARa and PPARY agonists [1921]. By activating PPARa, isoflavones can reduce NF-KB-mediated pro-inflammatory gene expression and attenuate the inflammatory response. Other mechanisms currently proposed for GC resistance include: increased expression of the transcriptionally inactive GR $\beta$ [22]; reduced binding affinity, translocation or stability of GRa by activation of PI3K signaling, preventing the transcription of anti-inflammatory proteins [23]; and increased pro-inflammatory gene expression [24]. To which extend these different mechanisms are also involved in the action of the investigated dietary compounds needs to be addressed in further studies.

\section{Strength and limitation of in vitro studies}

Although extrapolation of in vitro data into the pathophysiology of oxidative stress on inflammatory and cardiovascular diseases in humans remains difficult, our data suggest a beneficial effect of flavanols in low micromolar concentrations. An in vitro cell system is a very powerful tool to identify mechanisms involved in specific processes. In general, it is relatively easy to control the exposure conditions. During our studies, however, it became clear that also in cell systems a lot of variables can influence the outcome. The experiments in macrophage-like cells with cortisol and dexamethasone were repeated on different days. It appeared that the response to LPS and the resulting protective effect of the bioactives often was variable, even though the circumstances and exposures were very well controlled. A possible explanation could be the procedure to differentiate monocytes to macrophage-like cells using phorbol 12-myristate 13-acetate (PMA). The differentiation was required to get a pronounced inflammatory response with LPS, but PMA also induces oxidative stress which increases the complexity of the cellular model.

The cell line used can be a major confounder in experimental outcomes. In chapter 2 primary HUVECs were used, selected from 5 different batches based on their inflammatory response. The cells showed an high inflammatory response when exposed to TNFa. When comparing gene expression of these primary HUVECs with a HUVEC cell line (CRL-1730) after TNFa stimulation, the primary cells showed a 20-fold increase in the gene expression of vascular cell adhesion protein 1 (VCAM-1), while the CRL-1730 cells did not show any VCAM gene expression at all. When this pro-inflammatory gene is a major parameter, this difference could have far reaching consequences for the outcome of the experiment. 
Another mechanism by which flavonoids could exert their beneficial, protective, effect is by modulating endogenous oxidants-producing enzymes. One of these enzymes is nicotinamide adenine dinucleotide phosphate-oxidase 4 (NOX4), an important radical producing enzyme. This enzyme can be activated with angiotensin (AT) II [25], as previous shown by experiments in fibroblasts (unpublished data) and HUVECs [26]. Indeed, the presence of the NOX4 gene in HUVECs was confirmed with real-time PCR. However, using multiple incubation methods and probes for detecting $\mathrm{O}_{2}{ }^{--}$production, we were neither able to activate NOX4 in primary HUVECs nor in vascular smooth muscle cells (VSMC) from rat aorta with ATII.

\section{Clinical study}

To study the effect of dietary flavonoids in humans, a clinical intervention study was conducted. In chapter 6, 28 male smokers were supplemented with $200 \mathrm{mg} /$ day of monomeric and oligomeric flavanols (MOF) from grape seeds for 8 weeks. At baseline, after 4 and 8 weeks macro- and microvascular function and a cluster of systemic biomarkers were measured. This study showed that an 8 weeks MOF supplementation significantly enhanced the smokers' resistance against inflammatory stimuli, such as LPS. Gene expression of inflammatory cytokines, in particular TNF-a and IL-6, was attenuated in blood after MOF supplementation. A recent publication by Milencovic et al. demonstrated that an 8 week daily supplementation with MOF modulates the expression of genes associated with cardiovascular disease pathways [27].

The trend of increasing plasma TEAC values and the considerable augmentation of the GSH/GSSG ratio in erythrocytes indicate that MOF improve extra- and intracellular redox status in the circulation. These effects, however, could not be ascribed to alterations of gene expression of the most important enzymatic antioxidant defense systems in circulatory white blood cells (e.g. CAT, GPX1, HO1 and SOD2).

The multi-biomarker approach proved to be a successful strategy to unveil the pleiotropic benefit of an 8 weeks supplementation with MOF on vascular health in humans. When combining all the subtle and multifarious effects of MOF supplementation, a clear health promoting effect was seen with flavanols. The decrease in oxidative stress markers, attenuation of the inflammatory response and improvement of vascular function resulted in an improved vascular health index.

In drug research, where the one-target-one-hit concept is imperative, randomized clinical trials with a well-defined single endpoint are the gold standard of efficacy testing. However, a single endpoint neither sufficiently reflects the multifarious nature 
of nutrients' functions in humans nor the complexity of pathomechanisms underlying virtually all diseases. Our findings fit into the idea of health as being dynamic and defined as the ability to adapt to changes, rather than a static state of perfection. In this dynamic concept of health, a bioactive compound has a multitude of effects. Accumulation of these effects empower the buffering capacity of the body to maintain homeostasis and to prevent relatively mild but nevertheless insidious and persistent perturbations which may gradually progress into severe pathological conditions.

\section{Recommendations for future research}

In chapter 2 the antioxidant activity of Cat and EC was determined, and the effect of the metabolism of epicatechin on its radical scavenging activity. Although e.g. methylation of the B-ring significantly reduced the superoxide scavenging activity, methylated EC metabolites still reduce intracellular oxidative stress. The results corroborate that EC and its metabolites can protect against oxidative stress in primary endothelial cells via a direct antioxidant mechanism. Next to this direct protection other molecular mechanisms have been implied and experimental proof needs to be provided to establish the role of the direct antioxidant effect as well as the alternative mechanisms.

Next to the antioxidant effect, that seems to be involved in the GC-protective and antiinflammatory effect of flavonoids, also other mechanism might contribute, as reported in chapter 3, 4 and 5. Plant-derived compounds like flavonoids - even investigated separately - do not have one specific molecular mechanism of action, but modulate a wide variety of molecular targets and signaling pathways. Even though several modes of action and pathways have been identified in literature and described in this thesis, the effect of specific compounds on these mechanisms still needs to be elucidated. In this respect also the crosstalk between pathways needs to be incorporated. For example the process of inflammation and oxidative stress are tightly intertwined and should not be treated separately.

As discussed above, in vitro studies are mandatory to understanding of the mode of action of flavonoids on a cellular and molecular level. To fully validate the potential of flavonoids as an adjuvant in anti-inflammatory therapy, a human intervention study is indispensable. In chapter 6 we revealed the pleiotropic benefits of MOF in the vascular of healthy subjects. In order to extend these findings it would be interesting to investigate a regular flavanol supplementation in patients suffering from chronic systemic inflammatory diseases like COPD, RA or irritable bowel syndrome. In particular patients who are regularly treated with GCs and are at risk to develop GC resistance 
should be included in such a trial. Proof of the clinical efficacy of EC and other foodderived bioactives to enhance or prolong the efficacy of anti-inflammatory steroids could considerably improve the therapy of those patients. 


\section{References}

1. Cheynier V. Polyphenols in foods are more complex than often thought. Am J Clin Nutr. 2005;81:223S-9S.

2. Boeing H, Bechthold A, Bub A, Ellinger S, Haller D, Kroke A, et al. Critical review: vegetables and fruit in the prevention of chronic diseases. Eur J Nutr. 2012;51:637-63.

3. de Pascual-Teresa S, Moreno DA, Garcia-Viguera C. Flavanols and anthocyanins in cardiovascular health: a review of current evidence. Int J Mol Sci. 2010;11:1679-703.

4. Rendeiro C, Vauzour D, Rattray M, Waffo-Teguo P, Merillon JM, Butler LT, et al. Dietary levels of pure flavonoids improve spatial memory performance and increase hippocampal brain-derived neurotrophic factor. PLoS One. 2013;8:e63535.

5. Surh YJ. Cancer chemoprevention with dietary phytochemicals. Nat Rev Cancer. 2003;3:768-80.

6. Mittal M, Siddiqui MR, Tran K, Reddy SP, Malik AB. Reactive Oxygen Species in Inflammation and Tissue Injury. Antioxid Redox Signal. 2014;20:1126-67.

7. Heim KE, Tagliaferro AR, Bobilya DJ. Flavonoid antioxidants: chemistry, metabolism and structure-activity relationships. J Nutr Biochem. 2002;13:572-84.

8. Lotito SB, Zhang WJ, Yang CS, Crozier A, Frei B. Metabolic conversion of dietary flavonoids alters their antiinflammatory and antioxidant properties. Free Radic Biol Med. 2011;51:454-63.

9. Masella R, Di Benedetto R, Vari R, Filesi C, Giovannini C. Novel mechanisms of natural antioxidant compounds in biological systems: involvement of glutathione and glutathione-related enzymes. J Nutr Biochem. 2005;16:577-86.

10. Lu JM, Lin PH, Yao Q, Chen C. Chemical and molecular mechanisms of antioxidants: experimental approaches and model systems. J Cell Mol Med. 2010;14:840-60.

11. Hakim A, Adcock IM, Usmani OS. Corticosteroid resistance and novel anti-inflammatory therapies in chronic obstructive pulmonary disease: current evidence and future direction. Drugs. 2012;72:1299-312.

12. Fisher AB. Redox signaling across cell membranes. Antioxid Redox Signal. 2009;11:1349-56.

13. Cosio BG, Tsaprouni L, Ito K, Jazrawi E, Adcock IM, Barnes PJ. Theophylline restores histone deacetylase activity and steroid responses in COPD macrophages. J Exp Med. 2004;200:689-95.

14. Meja KK, Rajendrasozhan S, Adenuga D, Biswas SK, Sundar IK, Spooner G, et al. Curcumin restores corticosteroid function in monocytes exposed to oxidants by maintaining HDAC2. Am J Respir Cell Mol Biol. 2008;39:312-23.

15. Hakim A, Barnes PJ, Adcock IM, Usmani OS. Importin-7 mediates glucocorticoid receptor nuclear import and is impaired by oxidative stress, leading to glucocorticoid insensitivity. FASEB J. 2013;27:4510-9.

16. Ortiz JL, Milara J, Lluch J, De Diego A, Sanz C, Cortijo J. Phosphodiesterase-4 inhibition improves corticosteroid insensitivity in pulmonary endothelial cells under oxidative stress. Allergy. 2013;68:64-73.

17. Peluso MR. Flavonoids attenuate cardiovascular disease, inhibit phosphodiesterase, and modulate lipid homeostasis in adipose tissue and liver. Exp Biol Med (Maywood). 2006;231:1287-99.

18. Ejiofor S, Turner AM. Pharmacotherapies for COPD. Clinical medicine insights Circulatory, respiratory and pulmonary medicine. 2013;7:17-34.

19. Bougarne N, Paumelle R, Caron S, Hennuyer N, Mansouri R, Gervois P, et al. PPARalpha blocks glucocorticoid receptor alpha-mediated transactivation but cooperates with the activated glucocorticoid receptor alpha for transrepression on NF-kappaB. Proc Natl Acad Sci U S A. 2009;106:7397-402.

20. Matin A, Gavande N, Kim MS, Yang NX, Salam NK, Hanrahan JR, et al. 7-Hydroxy-benzopyran-4-one derivatives: a novel pharmacophore of peroxisome proliferator-activated receptor alpha and -gamma (PPARalpha and gamma) dual agonists. J Med Chem. 2009;52:6835-50.

21. Neher MD, Weckbach S, Huber-Lang MS, Stahel PF. New insights into the role of peroxisome proliferatoractivated receptors in regulating the inflammatory response after tissue injury. PPAR research. 2012;2012:728461.

22. Li LB, Leung DY, Martin RJ, Goleva E. Inhibition of histone deacetylase 2 expression by elevated 
glucocorticoid receptor beta in steroid-resistant asthma. Am J Respir Crit Care Med. 2010;182:877-83.

23. Rossios C, To Y, Osoata G, Ito M, Barnes PJ, Ito K. Corticosteroid insensitivity is reversed by formoterol via phosphoinositide-3-kinase inhibition. Br J Pharmacol. 2012;167:775-86.

24. Barnes PJ. Glucocorticosteroids: current and future directions. Br J Pharmacol. 2011;163:29-43.

25. Dikalov SI, Nazarewicz RR. Angiotensin II-induced production of mitochondrial reactive oxygen species: potential mechanisms and relevance for cardiovascular disease. Antioxid Redox Signal. 2013;19:1085-94.

26. Steffen Y, Gruber C, Schewe T, Sies H. Mono-O-methylated flavanols and other flavonoids as inhibitors of endothelial NADPH oxidase. Arch Biochem Biophys. 2008;469:209-19.

27. Milenkovic D, Vanden Berghe W, Boby C, Leroux C, Declerck K, Szarc vel Szic K, et al. Dietary flavanols modulate the transcription of genes associated with cardiovascular pathology without changes in their DNA methylation state. PLoS One. 2014;9:e95527 



\section{Chapter 8}

Summary

Samenvatting

Valorisatie

Dankwoord

List of publications

Curriculum vitae 


\section{Chapter 8}

\section{Summary}

Samenvatting

Valorisatie

Dankwoord

List of publications

Curriculum vitae 


\section{Summary}

Numerous epidemiological and clinical studies have demonstrated various health effects of flavonoids. Intake of flavonoid-rich foods has been indicated to prevent cardiovascular diseases, reduce the risk for developing cancer and prevent chronic inflammatory diseases like chronic obstructive pulmonary disease (COPD) and rheumatoid arthritis (RA). The research presented in this thesis focusses on de antioxidant and anti-inflammatory effect of dietary flavonoids. We aimed at further elucidating the mechanism for the potential health effects of flavonoids, with an emphasis on the flavanol (-)-epicatechine (EC).

\section{What are the antioxidant properties of (-)-epicatechin and its metabolites?}

In chapter 2 we determined the antioxidant effect of the flavanol (+)-catechin (Cat), EC and several metabolites in human umbilical vein endothelial cells (HUVECs) and in a test tube assay. This study showed that Cat and EC are effective antioxidants, and glucuronidation, methylation and sulfation reduced this antioxidant activity. The relative potency of the tested compounds to scavenge superoxide anion radicals indicated that a free catechol (1,2-dihydroxybenzene) moiety in the molecule is important for the direct antioxidant activity. The results show that EC and its metabolites protect against oxidative stress in HUVECs via a direct antioxidant effect.

\section{Can (-)-epicatechin prevent oxidative stress induced endogenous glucocorticoid resistance?}

Oxidative stress extinguishes the anti-inflammatory effect of the endogenous glucocorticoid (GC) cortisol, leading to cortisol resistance. In chapter 3 we corroborated the results of chapter 2 that EC reduces intracellular oxidative stress and further demonstrated that this prevents the oxidative stress induced GC resistance. The crosstalk between both processes further deciphers the enigmatic anti-inflammatory action of EC.

\section{Can (-)-epicatechin maintain the anti-inflammatory efficacy of therapeutic glucocorticoids?}

We show in chapter 4 that dexamethasone could efficiently suppress LPS induced inflammation and that exposure to $\mathrm{H}_{2} \mathrm{O}_{2}$ induced $\mathrm{GC}$ resistance. The anti-inflammatory effect of dexamethasone was protected by EC in the oxidant exposed cells. These results show that the natural antioxidant EC may be used as adjuvance to restore or preserve the efficacy of GC drugs which will improve the treatment of inflammation. 


\section{Which other plant-derived compounds are able to restore the anti-inflammatory action of endogenous glucocorticoids?}

In the exploratory study described in chapter 5 a broad range of food derived bioactives were screened for their antioxidant and anti-inflammatory effects in order to investigate whether their antioxidant effects are associated with the ability to preserve the antiinflammatory effects of cortisol. We found that most of the dietary bioactives protect against the inhibition of the cortisol response induced by oxidative stress. This again demonstrates the crosstalk between both processes and implies that the antioxidant activity of compounds plays an important role in the protection of the GC response. Next to the antioxidant activity of the bioactives, also other mechanisms might be involved in the anti-inflammatory effect.

\section{Can flavanols improve (cardio)vascular health in humans?}

To study the effect of dietary flavonoids in humans, a clinical intervention study was conducted. In chapter 6, 28 male smokers were supplemented with $200 \mathrm{mg} /$ day of monomeric and oligomeric flavanols (MOF) from grape seeds for 8 weeks. When combining all the subtle and multifarious effects of MOF supplementation, a clear health promoting effect was seen with flavanols. The decrease in oxidative stress markers, attenuation of the inflammatory response and improvement of vascular function resulted in an improved vascular health index.

Our findings fit into the concept that health is a dynamic process characterized by the ability to adapt to changes. In this dynamic process various pathways are tightly intertwined as shown by the extensive crosstalk between inflammation and oxidative stress. Moreover, a bioactive compound like EC has a multitude of effects. The combination of these subtle effects empowers the buffering capacity of the body to maintain homeostasis and prevents that relatively mild but nevertheless insidious and persistent perturbations gradually progress into severe pathological conditions. 


\section{Chapter 8}

Summary

Samenvatting

Valorisatie

Dankwoord

List of publications

Curriculum vitae 


\section{Samenvatting}

Epidemiologische en klinische studies laten zien dat flavonoïden op verschillende manieren onze gezondheid kunnen verbeteren. Zo vermindert de consumptie flavonoïden-rijke voeding de kans op het krijgen van hart- en vaatziekten, kanker en chronische inflammatoire ziekten zoals chronisch obstructieve longziekte (COPD) en reuma. In dit proefschrift is het onderzoek naar de anti-inflammatoire en antioxidant werking van flavonoïden beschreven. Het doel was om de gezondheidsbevorderende effecten van flavonoïden in kaart te brengen. De nadruk van het onderzoek in dit proefschrift ligt op het flavonoïde (-)-epicatechin (EC).

De werking van (-)-epicatechine en metabolieten als antioxidant. In hoofdstuk 2 is de directe antioxidant werking van (+)-catechine (Cat), (EC) en enkele metabolieten in endotheelcellen beschreven. Het onderzoek toont aan dat EC en Cat efficiënte antioxidanten zijn en dat metabolisme, via glucuronidering, methylering en sulfatering, de antioxidantactiviteit vermindert. Door de moleculaire structuur aan de antioxidantactiviteit te koppelen, kwam naar voren dat een vrije catecholgroep (een 1,2-dihydroxybenzeengroep) belangrijk is voor de antioxidantwerking. De resultaten laten ook zien dat EC en metabolieten de endotheelcellen beschermen door middel van een directe antioxidantactiviteit, dat wil zeggen het direct wegvangen van reactieve oxiderende species.

De bescherming door (-)-epicatechine tegen oxidatieve stress geïnduceerde glucocorticoïd resistentie. Oxidatieve stress vermindert de anti-inflammatoire werking van glucocorticoïden (GC), hetgeen resulteert in GC resistentie. In hoofdstuk 3 bevestigen we de resultaten die zijn gevonden in hoofdstuk 2, namelijk dat EC de intracellulaire oxidatieve stress vermindert. Daarnaast blijkt dat deze antioxidantactiviteit de ontwikkeling van GC resistentie voorkomt. Dit geeft aan dat in de anti-inflammatoire werking van EC de antioxidantwerking een rol speelt. Dit is een voorbeeld van een wisselwerking tussen twee pathofysiologische processen, namelijk oxidatieve stress en ontsteking, die tot nu toe onderbelicht is gebleven.

De bescherming van de anti-inflammatoire werking van het glucocorticoïd dexamethason door (-)-epicatechine. In hoofdstuk 4 is beschreven dat de antiinflammatoire werking van dexamethason in witte bloedcellen ook wordt verminderd door oxidatieve stress. Een dergelijke GC resistentie heeft grote klinische gevolgen. 
Het blijkt dat EC de anti-inflammatoire werking van dexamethason in cellen, die zijn blootgesteld aan oxidatieve stress, in de hand houdt. Deze resultaten geven aan dat EC de effectiviteit van GC medicatie kan bevorderen, waardoor de behandeling van chronische inflammatie verbetert.

Het herstel van de anti-inflammatoire werking van endogene glucocorticoïden door plantaardige bioactieve stoffen. In de studie beschreven in hoofdstuk 5 zijn verschillende plantaardige bioactieve stoffen gescreend op hun antioxidantwerking en hun vermogen om de GC resistentie te voorkomen. De meeste stoffen die wij hebben getest bezaten zowel een antioxidantwerking als het vermogen om de GC respons te beschermen. Dit bevestigt de wisselwerking tussen inflammatie en oxidatieve stress en geeft aan dat het antioxidanteffect een belangrijke rol speelt in de bescherming van de GC respons. Naast de antioxidantactiviteit van de bioactieve stoffen spelen waarschijnlijk ook andere eigenschappen een rol in hun anti-inflammatoire effect.

Het (cardio)vasculaire gezondheidseffect van flavanolen. Een klinische studie is uitgevoerd om de potentiële gezondheidseffecten van flavonoïden in mensen te onderzoeken. In het onderzoek beschreven in hoofdstuk 6 kregen 28 mannelijke rokers gedurende 8 weken 200 mg/dag flavanol monomeren en oligomeren (MOF) uit een druivenpitextract. Door de subtiele effecten van MOF op verschillende processen te combineren kon het gezondheidsbevorderende effect van MOF supplementatie op hart en bloedvaten worden aangetoond. De gesommeerde vermindering van oxidatieve stress markers, vermindering van ontstekingsreacties en het verbeteren van de vaatfunctie resulteerde in een verbeterde vasculaire gezondheidsindex door de MOF interventie.

Onze bevindingen passen in het concept dat gezondheid een dynamisch proces is, waarin het aanpassingsvermogen centraal staat. In dit dynamisch proces is een intensieve wisselwerking tussen meerdere processen en mechanismen. Een bioactieve stof als EC heeft verschillende, maar relatief subtiele, effecten. De combinatie van deze subtiele effecten zorgt ervoor dat de bufferende capaciteit en aanpassingsvermogen toenemen wat resulteert in het gezondheidsbevorderende effect van EC. 


\section{Chapter 8}

Summary

Samenvatting

\section{Valorisatie}

Dankwoord

List of publications

Curriculum vitae 


\section{Valorisatie}

\section{De maatschappelijke relevantie van de onderzoeksresultaten}

Ons dagelijks dieet bevat een breed scala aan voedingsstoffen. Dat voeding ook kan helpen bepaalde ziektes te voorkomen of zelfs te genezen wordt steeds meer bevestigd. In dit proefschrift hebben we de gezondheidseffecten van flavonoïden onderzocht. Flavonoïden zijn stoffen die in allerlei voedingsproducten voor komen. Wij hebben ons speciaal gericht op flavanolen, een subgroep van de flavonoïden. (-)-Epicatechine is één van deze flavanolen en thee en cacao bevatten relatief hoge concentraties van deze stof.

Wij hebben de antioxidant- en ontstekingsremmende werking van (-)-epicatechine onderzocht. Deze werking kan van groot belang zijn bij chronische inflammatoire ziektes zoals reumatoïde artritis, chronische darmontsteking, astma en COPD. Deze ziektes worden namelijk gekenmerkt door verhoogde mate van ontsteking (inflammatie) en eveneens een verhoogde mate van oxidatieve stress. Inflammatie is een belangrijk mechanisme om het fysiologisch systeem intact te houden. Het helpt bij genezing, het afweren van ziektekiemen en het verwijderen van parasieten. Als deze ontstekingsreactie echter te heftig is of te lang aanhoudt kan dit tot negatieve gezondheidseffecten leiden. Het lichaam heeft meerdere terugkoppelmechanismen en mogelijkheden om de ontsteking onder controle te houden. Eén van deze mechanismen wordt gevormd door het cortisol, een glucocorticoïd dat geproduceerd wordt door de bijnieren. Cortisol werkt ontstekingsremmend en zorgt er dus voor dat ontstekingsreacties onder controle blijven en geen schade veroorzaken. Bij chronische inflammatoire ziektes is de endogene cortisol ontoereikend en worden veelal glucocorticoïd geneesmiddelen, zoals dexamethason, gebruikt. Wanneer dit ook geen verlichting meer van de ontstekingsreactie geeft spreken we over glucocorticoïdresistentie. De inflammatie is dan moeilijk te beheersen hetgeen leidt tot allerlei klachten met soms levensbedreigende gevolgen. Resistentie maakt dat de behandeling langer duurt wat verhoging van de ziektekosten met zich meebrengt. Het verbeteren van de behandeling bij chronische ziektes en het verlichten van de symptomen door juiste voedingskeuze of voedingssupplementen zal een grote bijdrage aan de gezondheidszorg kunnen leveren. Uit ons onderzoek blijkt dat flavonoïden, en dan vooral (-)-epicatechine, een antioxidant en anti-inflammatoire werking hebben en de effectiviteit van zowel het endogene cortisol als het geneesmiddel dexamethason verbeteren.

Cellen van het immuunsysteem die aan oxidatieve stress worden blootgesteld reageren minder op de ontstekingsremmende werking van glucocorticoïden. Wanneer vervolgens flavonoïden worden toegevoegd vermindert de oxidatieve stress en wordt 
de anti-inflammatoire werking van glucocorticoïden hersteld. Vooralsnog is dit alleen in celsystemen getest. De mogelijkheden die deze waarneming biedt voor de optimalisering van de behandeling van patiënten met chronische ziektes is echter enorm.

Onze onderzoeksresultaten laten ook een positief effect zien van flavanolen op vasculaire gezondheidskenmerken. Een periode van acht weken met inname van flavanolen uit druivenpitten verbeterde de vasculaire functie in proefpersonen en verminderde markers van oxidatieve stress en inflammatie in het bloed. Deze resultaten vergroten ons begrip van het effect van flavanolen uit de voeding op het lichaam en de gezondheid.

\section{Doelgroep}

Meer kennis over de effecten van voedingsstoffen op processen in het lichaam is relevant voor iedereen. Voor mensen die een verhoogd gezondheidsrisico lopen (zoals rokers) is het mogelijk om een gebalanceerd en gepersonaliseerd dieet samen te stellen dat de gezondheid bevordert. Patiënten die lijden aan een chronische inflammatoire ziekte en behandeld worden met glucocorticoïden kunnen baat hebben bij deze onderzoeksresultaten. Met gerichte voedingsaanpassingen zouden deze patiënten beter behandeld kunnen worden met minder glucocorticoïden. Een effectievere behandeling zal een reductie in zorgkosten met zich meebrengen. De maatschappelijke relevantie van het beter in kaart brengen van de gezondheidsbevorderende effecten van voedingsstoffen is evident. Voor de patiënten heeft dit als bijkomend voordeel dat de medicatie beter tot zijn recht kan komen.

\section{Producten, diensten of processen die uit de onderzoekresultaten kunnen komen}

Met de verkregen kennis is het mogelijk om een speciaal dieet of voedingssupplementen rijk aan epicatechine en andere flavanolen te ontwikkelen om ontstekingen beter te controleren. Vooral bij chronische ontstekingen waar de werking van glucocorticoïden verminderd is, kan dit voordeel bieden. De flavanolen zouden een positief effect kunnen hebben op de werking van medicijnen die bijvoorbeeld worden ingezet bij COPDpatiënten.

Voor producenten in de voedingsindustrie laten deze onderzoeksresultaten zien dat uit planten afkomstige grondstoffen waardevolle voedingsstoffen bevatten. Bij de verwerking van grondstoffen naar het uiteindelijke product is het belangrijk om deze stoffen intact te houden zodat zij ook in het uiteindelijke product aanwezig zijn. Zo is bekend dat, afhankelijk van het productieproces, veel waardevolle stoffen, waaronder 
epicatechine, uit cacao verloren gaan voordat ze in de chocolade eindigen. Door nadruk te leggen op het belang van behoud van de gunstige voedingsstoffen kan de producent het verwerkingsproces optimaliseren om zoveel mogelijk degradatie te voorkomen. Tevens kunnen producten ontwikkeld worden die rijk zijn aan epicatechine en andere flavanolen.

\section{Innovatie}

Het nieuwe aspect van dit onderzoek is dat er onderzocht is wat het effect is van specifieke flavanolen (en enkele belangrijke metabolieten) op ontstekingscellen. Hierdoor is duidelijk in beeld gekomen wat de effecten zijn van deze belangrijke stoffen uit de voeding op de ontstekingsreactie. Uit dit onderzoek is gebleken dat epicatechine en andere flavonoïden oxidatieve stress in cellen kunnen verminderen en de inflammatoire respons kunnen remmen. Vooral de link tussen oxidatieve stress en inflammatie is een belangrijk punt. Aangezien chronische inflammatoire ziektes vaak gepaard gaan met oxidatieve stress en daardoor medicatie niet meer goed werkt is de behandeling moeilijk. In ons onderzoek kwam naar voren dat epicatechine deze oxidatieve stress vermindert en de werking van zowel het endogene cortisol als het medicijn dexamethason kan verbeteren bij cellen van het immuunsysteem. Door dieetaanpassingen of voedingssupplementen kunnen in de toekomst inflammatoire ziektes beter behandeld worden.

Tevens heeft ons onderzoek laten zien dat de vaatfunctie zelfs bij gezonde vrijwilligers kan verbeteren met behulp van flavanolen. Om dit te kunnen meten is een nieuwe methodiek voorgesteld.

\section{Planning en realisatie.}

Het onderzoek is uitgevoerd in humane cellen van het immuunsysteem en gedeeltelijk getest in een klinische studie. Tijdens de klinische studie kwamen al gezondheidsverbeterende effecten naar voren van flavanolen op het gebeid van het vaatstelsel. Het effect van flavonoïden, en dan vooral epicatechine, op glucocorticoïdresistentie is tijdens deze studie op cellen getest. Het is van belang het onderzoek uit te breiden met een klinische interventiestudie. Vooral bij patiënten met chronische inflammatie zou een klinische studie naar de effecten van een dieet rijk aan flavanolen zeer relevant zijn. Tevens moet bepaald worden wat de werkzame concentraties zijn en of dit haalbaar is met alleen een dieet of dat voedingssupplementen nodig zijn om het beoogde effect te bewerkstelligen. Om de potentie van flavanolen te onderzoeken is klinisch onderzoek nodig waarbij de verbetering van de effectiviteit 
van glucocorticoïden bij mensen met een chronische inflammatie wordt nagegaan. In dit vervolgonderzoek kan dan de progressie van de ziekte, de frequentie en de ernst van exacerbatie van de inflammatie bestudeerd worden. Deze studie zou inclusief voorbereiding en dataverwerking waarschijnlijk twee jaar in beslag nemen. Hieruit zal waardevolle informatie gegenereerd worden die de behandeling van inflammatoire ziektes zou kunnen verbeteren en kan leiden tot een significante kostenvermindering in de gezondheidszorg.

Op basis van onze bevindingen is het te verwachten dat epicatechine en andere flavonoïden de werking van anti-inflammatoire geneesmiddelen weer herstellen. Het is in de toekomst dus niet ondenkbaar dat beide tegelijkertijd worden voorgeschreven. Het is zelfs mogelijk dat enkel de toediening van flavonoïden zelf al voldoende is om een ontsteking af te remmen. 


\section{Chapter 8}

Summary

Samenvatting

Valorisatie

Dankwoord

List of publications

Curriculum vitae 


\section{Dankwoord}

Een aantal jaartjes geleden, december 2009 om precies te zijn, begon ik aan mijn promotieonderzoek bij de afdeling toxicologie, die toen nog de naam Farmacologie en Toxicologie droeg. Na 4 jaar onderzoek, gevolgd door 1 jaar schrijven te combineren met een nieuwe baan, staat de openbare verdediging dan eindelijk te gebeuren. Met het schrijven van dit dankwoord (zoals gebruikelijk laat op de avond) ben ik aan het laatste stukje van dit boekje aangekomen Een goede plek om na te denken wat er allemaal onderzocht, bezocht, berekend, gepresenteerd, gepipetteerd, gefeest, gezwoegd, gelachen, geventileerd, gezongen, gekweekt en gediscussieerd is voordat het resultaat van al dit werk naar de drukker gaat. In dit onderdeel wil ik dan ook graag alle mensen bedanken die dit mede mogelijk hebben gemaakt.

Allereerst natuurlijk een groot woord van dank en waardering voor mijn promotieteam prof dr. A. Bast, dr. G.R.M.M Haenen en dr. A.R. Weseler! Zoals meerdere dingen in het leven kun je niet zonder de hulp en begeleiding van mensen om je heen. Een promotieonderzoek is hier geen uitzondering van, je doet 4 jaar lang onderzoek in een team!

Aalt, als promotor heb ik veel van je geleerd. De deur stond altijd open voor even een korte of even een lange vraag te beantwoorden. Ook de hoeveelheid kennis en feitjes die je altijd paraat had staan bleef mij verbazen. Tijdens onze wekelijkse vergaderingen werd er altijd veel wetenschap besproken maar was er ook altijd ruimte om iets uit te wijden over andere onderwerpen wat de vergaderingen zowel nuttig als prettig maakte.

Guido, als copromotor had je altijd nieuwe ideeën voor experimenten en ook tijdens het schrijven was je altijd een goede hulp. Soms stuurde ik iets 's middags door en de volgende dag, of zelfs dezelfde avond nog had ik al je verbeteringen en suggesties binnen. Ook onze discussies over andere onderwerpen dan de wetenschap waardeer ik nog steeds!

Antje, ik kon er altijd op rekenen dat de resultaten en geschreven stukken aandachtig werden bekeken en voldoende suggesties waren om deze resultaten en teksten nog beter te maken. Tijdens de tripjes die we "moesten" maken voor het Flaviola project was je altijd een goed reisgezelschap en was er, naast het wetenschappelijke programma, altijd genoeg gespreksstof over andere leuke dingen. 
Ik wil ook graag de leden van de beoordelingscommissie, bestaande uit prof. dr. C. Neef, prof. dr. B.J. Blaauboer, prof. dr. G. Haegeman, prof. dr. P.W. de Leeuw en prof. dr. E.F.M. Wouters, bedanken voor het beoordelen van mijn proefschrift.

I would also like to thank all partners of the Flaviola consortium for making this an exciting project. The meetings we had in 6 different countries with people of different nationalities and backgrounds made this a very international and multi-disciplinary project. This allowed me to extend my knowledge beyond my own field of research. Many thanks for the great experience!

Een belangrijk onderdeel tijdens de promotie zijn je kamergenoten, ofwel je "roomies". Aangezien deze in hetzelfde schuitje zitten kun je hier veel van leren en zowel je frustraties als successen mee delen. Aangezien er enkele kamerverhuizingen zijn geweest in de afgelopen 4 jaar zijn het meerdere roomies geworden. In het eerste jaar was het Nuria, Erik en Max. Bedankt voor de hulp die vooral tijdens de eerste weken nodig waren om mijn weg te vinden.

Kristien, daarna kwam jij me op de kamer vergezellen. Bedankt voor al je steun en geduld bij het aanhoren van mijn geklaag af en toe. We hadden altijd goede gesprekken over de wetenschap en (..vul maar in..). En natuurlijk bedankt dat je mijn paranimf wil zijn en de hulp tijdens de laatste voorbereidingen! Waar ik je ook heel dankbaar voor ben is het onder controle houden van onze muzikale, spraakwaterval en boefje Matt die ons kwam vergezellen. Matt, het was zeker ook een eer om je op de kamer te hebben en bedankt voor de discussies en alle andere onzin. It goes you good in the US.

Even belangrijk als je roomies zijn de andere AiOs die het mogelijk maken de 4 jaar vol te houden. De AiO-uitjes waren altijd een succes en ook de dagelijkse lunch zorgde voor de nodige afleiding en mogelijkheid tot diepzinnige discussies. Bart, Raffaela, Jelly, Thalita, Hilde, Bregje, Danielle, Agnieszka, Jiska, Misha, Alie, Rianne, Carmen, Quan en Merel bedankt! Merel ook bedankt voor de eer om paranimf te zijn bij jouw promotie en alvast kon voelen hoe het is om daar te staan.

Wim, we kennen elkaar al een aantal jaren. Na het HBO in Heerlen, 2 jaar iets anders, dan beide op het idee komen om een master te doen, het afronden van deze master te vieren met een tripje Las Vegas, en dan ook nog beiden voor een AiO project kiezen bij 2 
afdelingen op dezelfde gang maakt het dan ook niet meer dan logisch om jou als paranimf te vragen. Samen met Kristien ben ik er helemaal gerust op dat ik, waar nodig, altijd op jullie kan rekenen! Terwijl ik dit ben aan het typen is het nog maar een paar weken totdat ik paranimf mag zijn bij jouw verdediging. Bedankt voor je hulp en alle koffie-dates.

Roger, allereerst bedankt voor het doorsturen van een vacature bij jou op de afdeling in oktober 2009. Het was een project dat iets te maken had met chocolade en het zou wel iets voor mij kunnen zijn. Nou, dat was dus inderdaad zo en 5 jaar later is dit boekje daar het resultaat van. Ook de nodige evenementen die jij, en ook wij samen, hebben georganiseerd zorgde altijd voor veel gezelligheid en goede sfeer op de afdeling. Net zoals de VMB'tjes die voor de nodige ontspanning zorgde na een drukke week.

Ook de andere analisten, Esther, Lou, Lucien, Edwin, Marie-Jose, Leonie en Danielle bedankt voor de hulp op het lab en bij de social events. Esther, bedank voor de hulp en gezelligheid op het lab, en daarbuiten, en je creativiteit bij het in elkaar zetten van allerlei cadeaus. Lou, bedankt dat voor de begeleiding tijdens de avondjes in de stad waar de rest al naar huis was en wij met een klein groepje nog even door gingen... En Lucien, wat moesten we zonder jou tijdens het jaarlijkse ambtenarenbal!

Marie-Claire natuurlijk ook een grote dankjewel voor het draaiende houden van de afdeling en vooral voor je hulp bij de hele papierwinkel die nodig is om deze promotie te laten plaatsvinden.

Ook een woord van dank aan alle stagiaires die via de een of andere weg geholpen hebben met het maken van dit boekje. Nicole, Gerben, Max, Cécile, Johanna, Marjan, Bhavana, Rik en Mathijs bedankt voor de hulp en super dat jullie het met mij als begeleider hebben uitgehouden.

Om niet verloren te raken in de wetenschap is het ook fijn om buiten de uni wat afleiding te hebben. Daarvoor heb je vrienden! Bedankt voor de broodnodige afleiding en onzin tijdens het poolen, pokeren, gamen, de whisky- en bierproeverijen, vakanties, feestjes en uitjes. 
Uiteraard ook een groot woord van dank aan mijn familie. Dave, grote broer, bedankt voor alle hulp. Pap en mam, zonder jullie was dit hele boekje natuurlijk niet mogelijk geweest. Bedankt voor alle hulp en dat jullie het nog een tijdje met mij thuis konden uithouden zodat studeren mogelijk was. Het is een fijn gevoel te weten dat de deur altijd open staat en ik kan rekenen op jullie steun. 


\section{Chapter 8}

Summary

Samenvatting

Valorisatie

Dankwoord

Curriculum vitae

List of publications 


\section{Curriculum vitae}

Erik Johannes Bernardus Ruijters was born in Maastricht on April $11^{\text {th }}$ 1984. After finishing his secondary school at the Eurocollege (Maastricht), he started the bachelor study Biochemical Research at Zuyd University of Applied Sciences in Heerlen. He did his internship at DSM Geleen at the department of Life Sciences - Advanced Synthesis, Catalysis \& Development where he investigated and

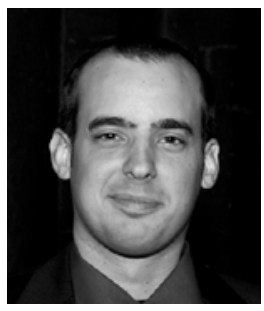
optimized enzymatic catalysis in pharmaceutical product synthesis. He obtained his Bachelor of Applied Sciences degree in 2005, after which he worked 1 year as Senior Education Assistant at Zuyd University of Applied Sciences and 1 year at MagnaMedics Diagnostics B.V. as a researcher.

In 2007 he started with the Masters study Molecular Health Sciences at Maastricht University. He did his internship at the department of Health Risk Analysis and Toxicology (GRAT), where he investigated the effect of prenatal exposure to flavonols in mice. During this internship he also worked at the National Center for Toxicological Research (Arkansas, USA), where he studied the link between epigenetic profile and cancer susceptibility in mice. During his master study he obtained the license for working with laboratory animals (according to art. 9 of the Dutch law on experimental animals) and working with radioactive material (Radiation hygiene, expert level 5b).

After his graduation in 2009 he started his PhD project at the department of Pharmacology and Toxicology, which is now the department of Toxicology. In this project he studied the antioxidant and anti-inflammatory effects of dietary flavonoids. The research performed during this period is described in the current thesis. During his PhD he attended the Postgraduate Education in Toxicology course and will become a European Registered Toxicologist (ERT). Since January 2014 he is working at MagnaMedics Diagnostics B.V. 


\section{Chapter 8}

Summary

Samenvatting

Valorisatie

Dankwoord

Curriculum vitae

List of publications 


\section{List of publication}

\section{Full papers}

Ruijters EJB, Haenen GR, Weseler AR, Bast A. The anti-inflammatory efficacy of dexamethasone is protected by (-)-epicatechin. PharmaNutrition. 2014;2:47-52.

Ruijters EJB, Haenen GR, Weseler AR, Bast A. The cocoa flavanol (-)-epicatechin protects the cortisol response. Pharmacological Research. 2014;79:28-33.

Ruijters EJB, Weseler AR, Kicken C, Haenen GR, Bast A. The flavanol (-)-epicatechin and its metabolites protect against oxidative stress in primary endothelial cells via a direct antioxidant effect. European Journal of Pharmacology. 2013;715:147-53.

Weseler AR, Ruijters EJB, Drittij-Reijnders M-J, Reesink KD, Haenen GR, Bast A. Pleiotropic benefit of monomeric and oligomeric flavanols on vascular health - a randomized controlled clinical pilot study. PloS one. 2011;6:e28460.

Vanhees K, Coort S, Ruijters EJB, Godschalk RW, van Schooten FJ, van Doorn SBvW. Epigenetics: prenatal exposure to genistein leaves a permanent signature on the hematopoietic lineage. The FASEB Journal. 2011;25:797-807.

van Waalwijk van Doorn-Khosrovani SB, Vanhees K, Van Gisbergen M, Ruijters EJB, Van Schooten F. MLL translocations as biomarker of exposure to dietary topoisomerase II inhibitors. European Journal of Cancer Supplements. 2008;6:198-9.

Van Waalwijk van Doorn-Khosrovani S, Vanhees K, Ruijters EJB, Van Schooten FJ. Etoposide-initiated MLL rearrangements: the pitfalls of inverse PCR. European Journal of Haematology. 2008;81:486-8.

\section{Abstracts}

Weseler AR, Ruijters EJB, Milenkovic D, Haenen GR, Bast A. Flavanols exert cardiovascular health benefits in humans by altering gene transcription levels in white blood cells. The FASEB Journal. 2012;26:1026.16.

Weseler AR, Milenkovic D, Vanden Berghe W, Ruijters EJB, Heyninck K, Fuks F, et al. Flavanols modulate the transcription of genes involved in cardiovascular pathology with heterogenic changes of their DNA methylation state: FLAVIOLA Associated. Free Radical Biology and Medicine. 2012;53:S89-S90.

Ruijters EJB, Haenen G, Weseler A, Bast A. (-)-Epicatechin and its glucuronidated and methylated metabolites attenuate intracellular oxidative stress: FLAVIOLA associated. Free Radical Biology and Medicine. 2012;53:S87. 
Bast A, Claude S, Haegeman G, Haenen GR, Heiss C, Heyninck K, Merx, M, Milenkovic D, Morand C, Ruijters EJB. Flavanols: what do we know about their mechanisms of action? Free Radical Biology and Medicine. 2012;53:S13.

\section{Achievements}

Awarded travel grant by the Netherlands Society of Toxicology for attendance of the 51st annual meeting of the society of Toxicology, March 2012, San Fransisco, California, USA.

Awarded travel grant by the Dutch Cancer Society for his internship at the National Center for Toxicological Research in Jefferson, Arkansas, USA. 
